\title{
Conventional Armed Forces in Europe: Technology Scenario Development
}

\section{ANL/ACTV $-90 / 3$}

DE9 1000097

by $\mathrm{G}$. Michael Houser

Energy Systems Division,

Argonne National Laboratory, 9700 South Cass Avenue, Argonne, Illinois 60439

July 1990

Work sponsored by United States Department of Energy,

Assistant Secretary for Defense Programs, Office of Arms Control 


\section{CONTENTS}

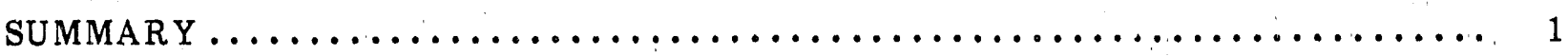

1 INTRODUCTION $\ldots \ldots \ldots \ldots \ldots \ldots \ldots \ldots \ldots \ldots \ldots \ldots \ldots \ldots \ldots \ldots \ldots \ldots \ldots \ldots$

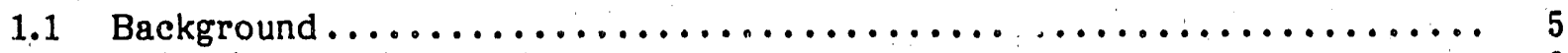

1.2 Otjective and Approach $\ldots \ldots \ldots \ldots \ldots \ldots \ldots \ldots \ldots \ldots \ldots \ldots \ldots \ldots \ldots \ldots$

2 CONVENTIONAL ARMED FORCES IN EUROPE TREATY

NEGOTIATION AREAS $\ldots \ldots \ldots \ldots \ldots \ldots \ldots \ldots \ldots \ldots \ldots \ldots \ldots \ldots \ldots \ldots \ldots$

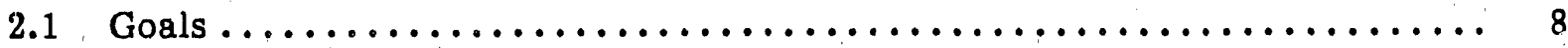

2.2 Objectives $\ldots \ldots \ldots \ldots \ldots \ldots \ldots \ldots \ldots \ldots \ldots \ldots \ldots \ldots \ldots \ldots \ldots \ldots \ldots \ldots$

2.3 Compliance Requirements $\ldots \ldots \ldots \ldots \ldots \ldots \ldots \ldots \ldots \ldots \ldots \ldots \ldots \ldots \ldots$

3 PROTOSED TREATy ARTICLES .......................... 10

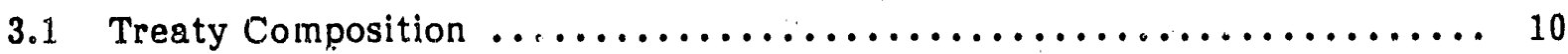

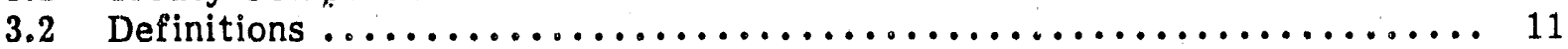

3.3 Treaty-Limited Equipment Ceilings $\ldots \ldots \ldots \ldots \ldots \ldots \ldots \ldots \ldots \ldots \ldots \ldots \ldots \ldots$

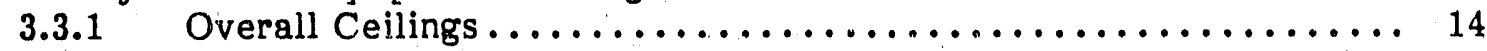

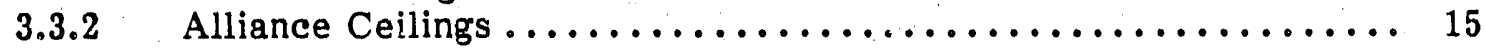

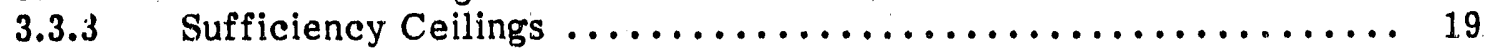

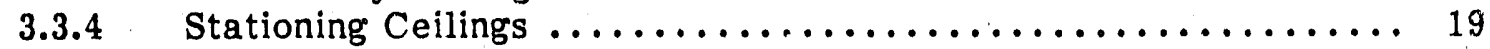

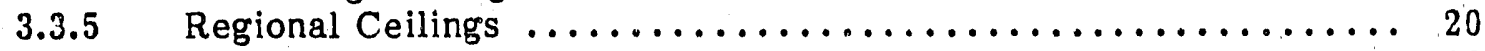

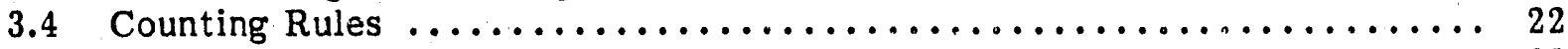

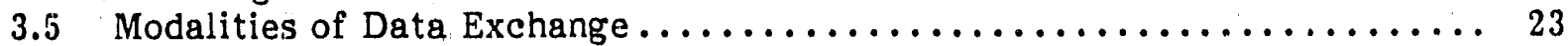

3.6 Stability Measures ................................. 29

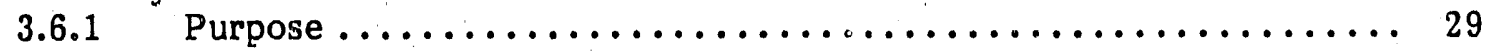

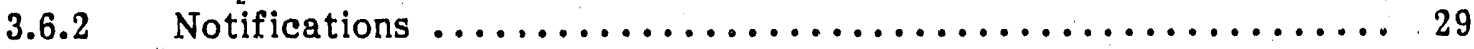

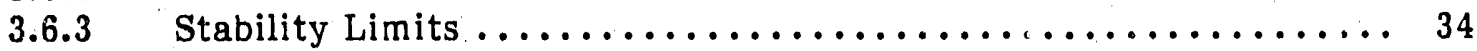

3.7 Verification Measures $\ldots \ldots \ldots \ldots \ldots \ldots \ldots \ldots \ldots \ldots \ldots \ldots \ldots \ldots \ldots \ldots \ldots \ldots \ldots 4$

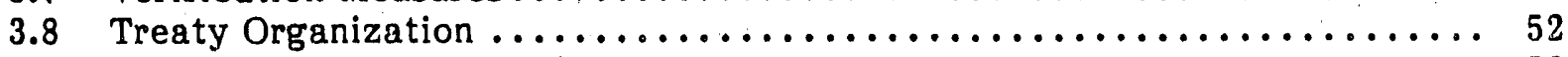

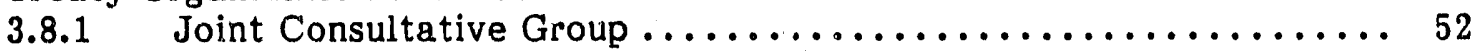

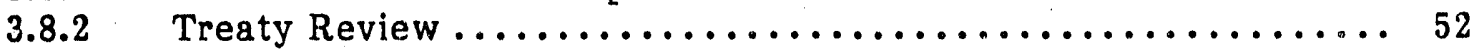

3.9 General Inspection Modalities . . . . . . . . . . . . . . . . . . 55

3.9.1 Inspection and Monitoring Responsibilities .............. 55

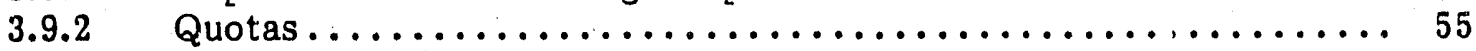

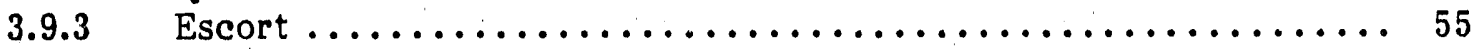

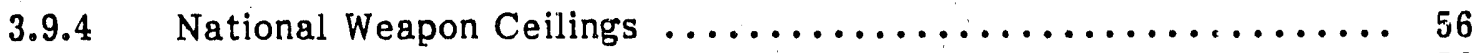

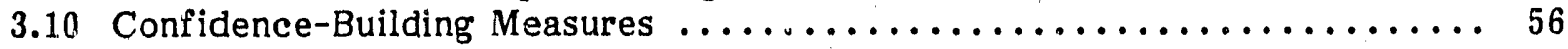

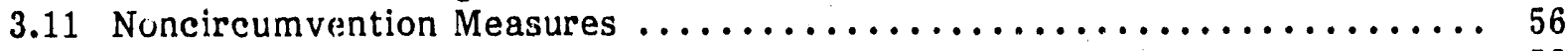

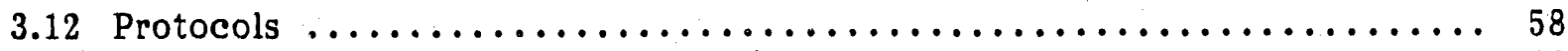

$3.12 .1 \quad$ NATO Protocol on Inspections $\ldots \ldots \ldots \ldots \ldots \ldots \ldots \ldots \ldots \ldots \ldots \ldots$

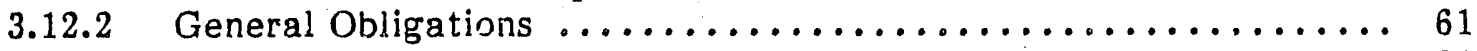

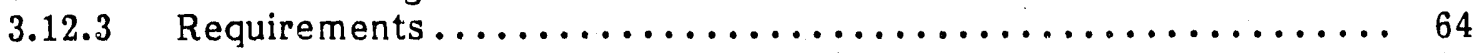

3.12 .4 Notification of Intent to Inspect................. 66

3.12.5 Procedures upon Arrival at Point of Entry $\ldots \ldots \ldots \ldots \ldots \ldots \ldots \ldots 66$

3.12.6 General Rules for Conducting Inspections ............... 67

3.12 .7 Declared Site Inspections ......................... 69

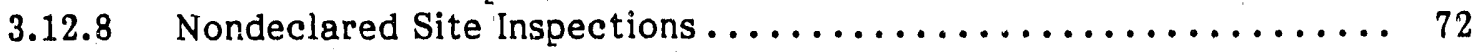

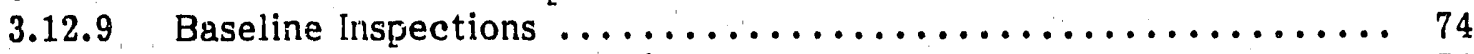

3.12.10 Inspections during Reductions Phase $\ldots \ldots \ldots \ldots \ldots \ldots \ldots \ldots \ldots$ 


\section{CONTENTS (Cont'd)}

3.12.11 Monitoring of Stability Measures $\ldots \ldots \ldots \ldots \ldots \ldots \ldots \ldots \ldots \ldots \ldots$

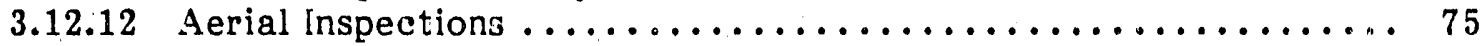

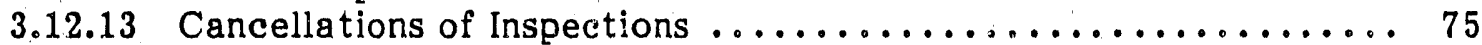

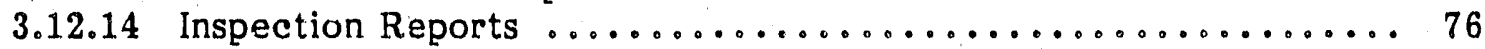

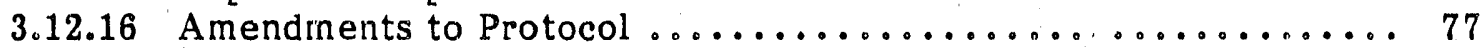

3.13 NATO Protocol on Destruction of Conventional Armaments .......... 77

3.13.1 General Requirements for Destruction of Treaty-Limited

Armaments and Equipment ............................. 78

3.13.2 Procedures for Destruction of Battle Tanks at

3.13.3 Procedures for Destruction of Armored Combat Vehicles

at Destruction Sites ......................... 80

3.13.4 Procedures for Destruction of Combat Aircraft at

Destruction Sites........................... 80

3.13.5 Procedures for Destruction of Combat Helicopters

at Destruction Sites ......................... 81

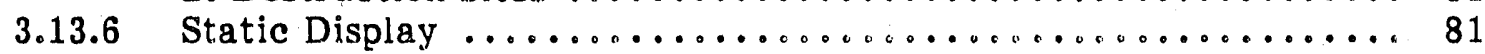

3.15.7 Procedures in the Event of Destruction by Loss or

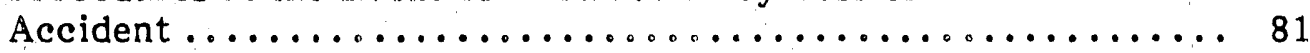

4 IDENTIFICATION OF PROBLEM AREAS AND PROPOSED SOLUTIONS . . . . . . 82

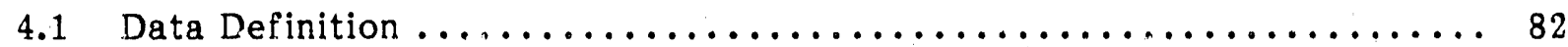

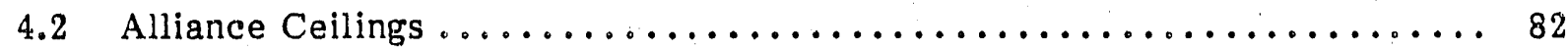

4.2.1 Treaty-Limited Equipment Tracking $\ldots \ldots \ldots \ldots \ldots \ldots \ldots \ldots \ldots . \ldots 2$

4.2.2 NATO Treaty-Limited Equipment Tracking ............. 83

4.2.3 Harmonization and Cascading of Treaty-Limited Equipment..... 83

4.2.4 Armored Infantry Fighting Vehicle and Heavy

Armanent Combat Vehicle Tracking ..........

4.2 .5 On-Site Inspection Agency and Change $\ldots \ldots \ldots \ldots \ldots \ldots \ldots \ldots . \ldots \ldots$

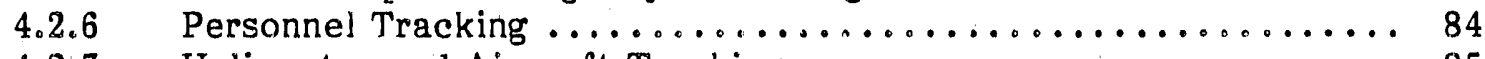

4.2 .7 Ifelicopter and Aircraft Tracking $\ldots \ldots \ldots \ldots \ldots \ldots \ldots \ldots \ldots \ldots \ldots$

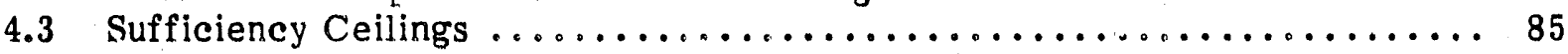

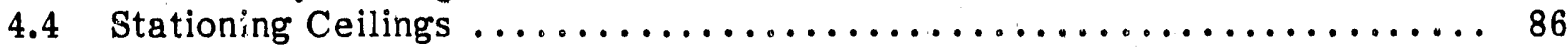

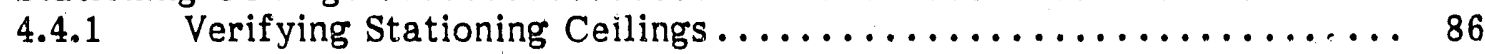

4.4.2 Verifying Storage Provisions . . . . . . . . . . . . . . . . 86

4.4.3 Tracking Low-Strength Unit Treaty-Limited Equipment ....... 86

4.4.4 Tracking Personnel Demobilization .................. 87

4.5 Regional Ceilings $\ldots \ldots \ldots \ldots \ldots \ldots \ldots \ldots \ldots \ldots \ldots \ldots \ldots \ldots \ldots \ldots \ldots \ldots . \ldots 7$

4.5.1 Tracking Treaty-Limited Equipment in Regional Subzones ...... 87

4.5.2 Determining Data-Base Requirements ............... 87

4.6 Counting Rules . ................................ 88

4.6.1 Counting Treaty-Limited Equipment $\ldots \ldots \ldots \ldots \ldots \ldots \ldots \ldots \ldots$

4.6.2 Conducting Mock Inspections $\ldots \ldots \ldots \ldots \ldots \ldots \ldots \ldots \ldots \ldots \ldots$

4.7 Data Exchange ................................... 89

4.7.1 Formulating, Consolidating, and Transferring Data ......... 89

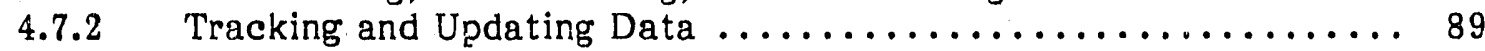

4.7.3 Performing Mock Data-Base Inspections ................ 90

4.7.4 Gathering Military Spending Data ................... 90

4.8 Stability Mersures ................................ 91

4.¿.1 Notification of Changes in Organizational Structure ......... 91 


\section{CONTENTS (Cont'd)}

4.8.2 Notification of Changes in Force Strength Level ........... 91

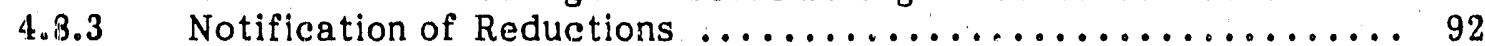

4.8.4 Notification of Changes in Maximum Levels ............... 93

4.8.5 Notification of Temporarily Exceeding Levels .............. 93

4.8.6 Notification of Reserve Mobilization ................. 93

4.8.7 Notification of Equipment Movement ................. 94

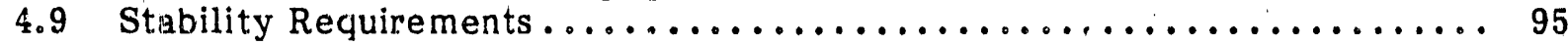

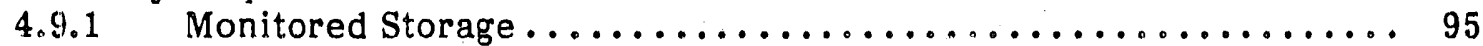

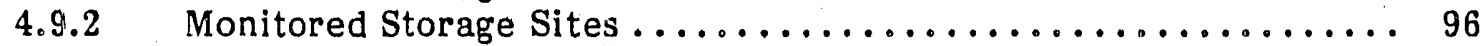

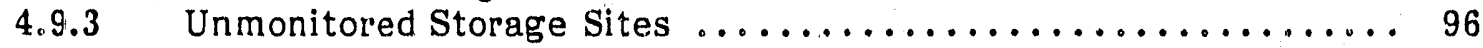

4.9.4 Removal from Monitored Storage................... 97

4.9.5 Equipment in Monitored Low-Strength Units .............. 98

4.9.6 Equipment in Unmonitored Storage .................. 98

4.9.7 Mobile Bridging-Equipment Storage $\ldots \ldots \ldots \ldots \ldots \ldots \ldots \ldots \ldots \ldots . \ldots 8$

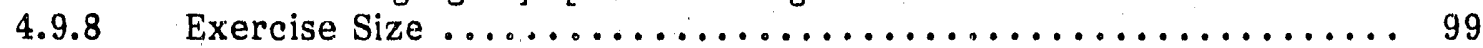

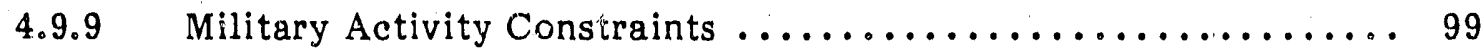

4.9.10 Transfers of Treaty-Limited Equipment ................. 100

4.9.11 Restructuring of Conventional Armed Forces .............. 101

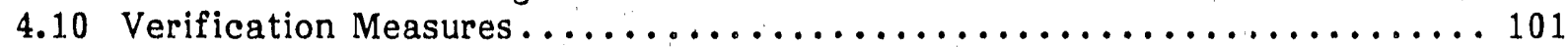

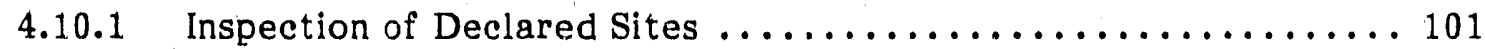

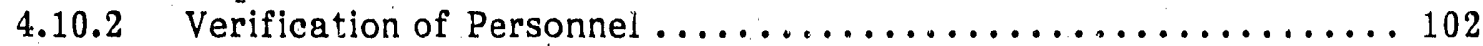

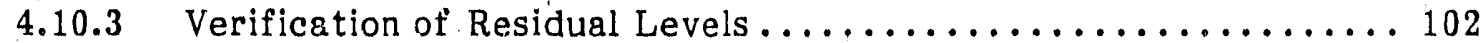

4.10.4 Verification of Compliance with Established Levels .......... 103

4.10 .5 Verification of Remaining Forces after Parity ............. 103

4.10 .6 Verification of Undeclared Sites ..................... 104

4.10 .7 Moritored Storage Sites and Low-Strength Units . . . . . . . . 104

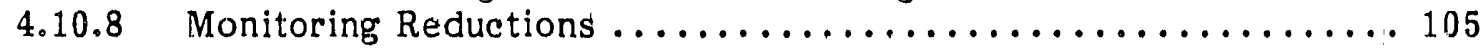

4.10.9 Replacement, Modernization, and New Technology .......... 106

4.10 .10 Monitoring Call-Up of Reserves .................... 106

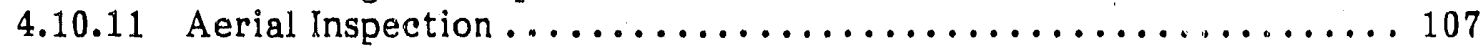

4.10 .12 Verifying Helicopter and Aircraft Limits $\ldots \ldots \ldots \ldots \ldots \ldots \ldots \ldots$

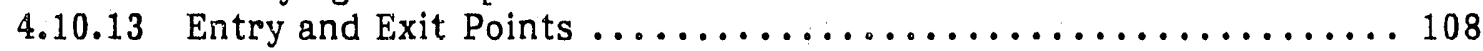

5 ELEMENTS OF CONVENTIONAL ARMED FORCES IN EUROPE PROGRAM $\ldots 110$

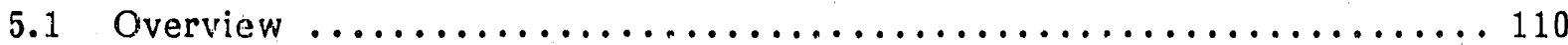

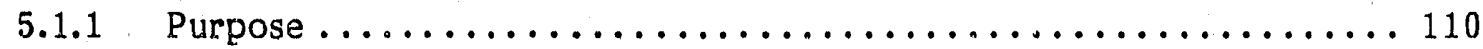

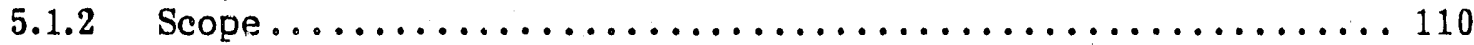

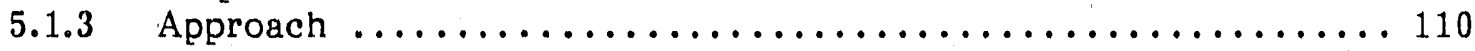

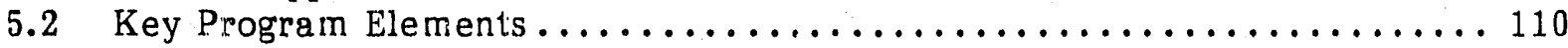

5.3 Program Tasks and Requirements .......................... 111

6 RECOMMENDATIONS $\ldots \ldots \ldots \ldots \ldots \ldots \ldots \ldots \ldots \ldots \ldots \ldots \ldots \ldots \ldots \ldots \ldots \ldots$

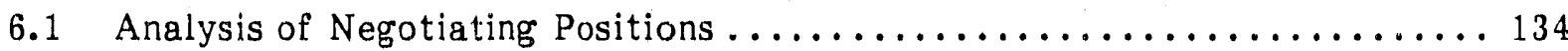

6.2 Identification of Technology Requirements $\ldots \ldots \ldots \ldots \ldots \ldots \ldots \ldots \ldots \ldots \ldots$

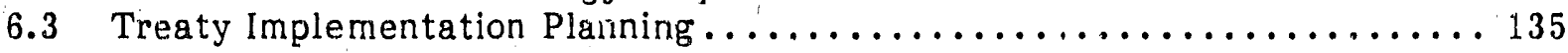

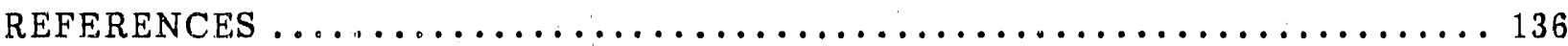




\title{
CONVENTIONAL ARMED FORCES IN EUROPE: TECHNOLOGY SCENARIO DEVELOPMENT
}

\author{
by
}

G. Michael Houser

\section{SUMMARY}

In January 1986, the Soviet Union's Mikhail Gorbachev proposed elimination of all nuclear weapons by the year 2000. In April of that year, Mr. Gorbachev proposed substantial reductions of conventional weapons in Europe, from the Atlantic Ocean to the Ural Mountains, including reductions in operational-tactical nuclear weapons. In May 1986, the North Atlantic Treaty Organization (NATO) responded with the "Brussels Declaration on Conventional Arms Control," which indicated readiness to open East/West discussions on establishing a mandate for negotiating conventional arms control throughout Europe. The "Group of 23," which met in Vienna beginning in February 1987, concluded the meeting in January 1989 with a mandate for the Conventional Armed Forced in Europe (CFE) negotiations. On 6 March 1989, CFE talks began, and these talks have continued through six rounds (as of April 1990). Although U.S. President George Bush, on 30 May 1989, called for agreement within six months to a year, and the Malta. meeting of December 1989 called for completion of a CFE agreement by the end of 1990 , much remains to be negotiated.

This report provides three types of information. First, treaty provisions brought to the table by both sides are compared. Second, on the basis of these provisions, problem areas for each of the provision elements are postulated and possible scenarios for resolving these problem areas are developed. Third, the scenarios are used as requirements for tasks assigned program elements for possible U.S. implementation of a CFE treaty, As progress is achieved during the negotiations, this report could be updated, as necessary, in each of the areas to provide a continuing systematic basis for program implementation and technology development.

\section{CFE TREATY PROPOSALS}

A final CFE treaty would probably include equal alliance ceilings on tanks, artillery, armored combat vehicles, combat helicopters, and combat aircraft. The treaty would also require reductions in Soviet and American manpower, with possible reduction in the manpower of other Alliance parties.

The final treaty would also include exchanges of information on the location, number, type, and unit affiliation of items to be limited. The treaty would define each of the equipment categories and establish Treaty-Limited Equipment (TLE) ceilings, subceilings within equipment categories, and regional ceilings for TLE. Additionally, it would set sufficiency levels for all parties and stationing levels for parties stationed outside of their national boundaries. 
The final treaty would define data-exchange modalities to ensure stability measures, which include notification requirements and stability limits on specific nonTLE equipment and activities. The treaty would define verification measures, which establish means of ensuring compliance by defining in detail regimes for on-site inspection, monitoring, and other verification methodologies (such as aerial inspection and technologies still to be established).

Proposals have been brought to the table by both sides and have been subjected to rigorous review and negotiations. This report has tracked negotiations through the working-paper process to articles and provisions brought to the table by both sides. These proposed treaty articles, although similar in substance, vary in detail, and many of the articles have provisions from one alliance with no answering provisions from the other side.

\section{SYSTEMATIC TRACKING PROGRAM}

Pending agreement on the treaty articles and establishment of firm treaty provisions, the U.S. Department of Energy (DOE) and its Office of Arms Control (OAC) needs a methodology for establishing verification technology requirements. The method used in this study was to systematically review each treaty element and subelement to define possible problems that would need to be addressed to verify the provision. The problems identified by this review revealed new concerns that needed to be addressed. These problem areas were used as starting points to propose possible solutions to the issues in the form of scenarios. These scenarios were limited by the following practical considerations:

- Both sides, especially NATO, clearly desire to institute the least intrusive verification regime possible;

- Costly solutions to verification problems would not be favorably considered;

- Long-term foreign presence as part of any verification scheme would be politically unacceptable; and

- Political changes on both sides would require flexible verification solutions.

\section{ANALYSIS RESULTS}

An analysis of scenarios developed as possible solutions to $\mathrm{CFE}$ verification problems indicates the following:

1. A strong system for compliance tracking and monitoring would be needed to maintain an overall perspective on TLE and to account for the multitude of provisions established to ensure compliance with the treaty. 


\section{$3 / 4$}

2. Although än exhaustive verification regime and use of verification technologies were not desired at the outset, both types of verification methods would be needed to verify a follow-on CFE II treaty. Whereas parity would be achieved primarily by elimination of Warsaw Treaty Organization (WTO) TLE in CFE I, CFE II would require reductions by both sides, and a more rigid verification regime would be needed to track the proportionally smaller numbers of TLE in the area of application. Technologies most needed would be in support of aerial inspection, tagging, the destruction process, and for ground sensors to facilitate TLE stationing within the area of application.

3. The evolving European political environment should play a major role in the CFE outcome. The 1992 European Economic Community structure, the desires of the Conference on Security and Cooperation in Europe (CSCE), the results of the " $2+4$ " talks, and most importantly, changes in the new Soviet state and its relationship with its Warsaw Pact neighbors will continuously shape provisions of the CFE treaty.

4. A programmatic framework for implementing a CFE treaty should contain the following:

- Major program elements;

- Tasks to be accomplished within each of the major program elements; and

- Requirements to be addressed by the program tasks. These requirements have been drawn from scenarios developed in response to problems established for the separate treaty provisions and proposals.

\section{FUTURE OUTLOOK}

The final section of this report could be expanded, if desired, to include changes in scenarios that result from the ongoing CFE negotiations. Work should continue on development of technologies for CFE II and possibly for the last stage of CFE I. Given adequate resources, national laboratories could continue developments in the fields of aerial inspection, sensors, tagging, and advanced data tracking and data management. 


\section{INTRODUCTION}

\subsection{BACKGROUND}

In January 1986, Soviet leader Mikhail Gorbachev proposed that all nuclear weapons be eliminated by the year 2000. Later in 1986, he proposed reductions of conventional weapons in Europe, from the Atlantic Ocean to the Ural Mountains, and reductions in operational-tactical nuclear weapons. In December 1986, the North Atlantic Treaty Organization (NATO) agreed to open East/West discussions to establish a mandate for negotiating conventional arms reductions in the Atlantic to the Urals (ATTU) region. In February 1987, the Group of 23 attached a mandate for these negotiations to the concluding document of the Conference on Security and Cooperation in Europe (CSCE) meeting (IDS Jan. 1990).

Round one of the Conventional Armed Eorces in Europe (CFE) talks began in March 1989; these talks were stimulated by U.S. President George Bush's challenge that he wanted an agreement within six months to a year, and President Bush agreed with the initial positions of each side. The Warsaw Traaty Organization (WTO) proposed a three-stage cut in armaments, the first cut. to be 159 below the lowest current level of armaments. NATO brought to the table its set of five rules and called for specific parity levels on tanks, artillery pieces, and armored troop carriers (IDS Jan. 1990).

Round two took place between May and July 1989. During the second round, the Warsaw Treaty Organization brought to the table ceilings for numbers of Treaty-Limited Items (TLI) and included the categories of strike aircraft, helicopters, and personinel. NATO agreed on adding specific numbers of stationed U.S. and Soviet personnel and combat aircraft and brought to the table specific new proposals for ceilings on TreatyLimited Equipment (TLE) in each of the treaty categories (IDS Jan. 1990).

Round three, which ended in October 1989, supplied definitions for TLE, measures for information exchange, stabilization, verification, and noncircumvention. Additionally, NATO provided desired limits on bridging systems and brought to the table its paper on ceilings for aircraft and helicopters (IDS Jan. 1990).

Just prior to round four, the superpowers met at Malta and agreed to seek completion of a CFE agreement by the end of 1990, which was to be capped by a summit of NATO and WTO leaders. In round four, which ended in December 1989, NATO brougnt to the table a proposal to break out tanks and armored combat vehicles (ACV) into subcategories, with sublimits for each subcategory of equipment. At the conclusion of round four, both alliances had brought to the table complete treaty drafts (IDS Jan. 1990).

Round five began in January 1990 and concluded at the end of February 1990. Round five made headway on definitions for armored vehicles and aircraft equipment in storage. As a result of the meeting of foreign ministers in Ottawa on 23 February 1990, a tentative accord on CFE manpower limits was reached. 
Round s1x, which lasted from 15 March 1990 to 26 April 1990, resulted in little progress, although NATO brought to the table new text and protocols on information, verification, and destruction. Progress was made, however, on resolving aircraft categories and numbers and inspection methodology issues. The West attributed the decreased impetus of the talks to the lack of a CFE treaty and to the fact that the USSR is not ready for such a treaty until a reduction of the future joint German army has been agreed upon at the "2+4" talks.

Round seven is scheduled to begin in mid-May 1990 (IDS March 1990).

\subsection{OBJECTIVE AND APPROACH}

The purpose of this study is to provide scenarios for addressing the various treaty compliance issues. This report contains cocumentation on the results of each round of talks through round six. Additionally, these scenarios need to be incorporated into an implementation program for CFE program management. However, the main objective of the study is to establish a systematic process for determining which technology can best assist in theting $C F E$ treaty compliance and verification problems.

To provide a systematic approach to scenario development, this study

1. Identifies the individual treaty compliance and verification elemerits;

2. Provides a set of problems for each of the identified treaty elements;

3. Suggests possible scenarios, based on the problem set for each treaty element, to resolve each problem; and

4. References each of the scenarios as requirements to be addressed in each task.

The results of this approach will be as follows:

1. The initial study could be updated, if desired, as changes occur in the treaty negotiation process. These changes, if desired, could in turn be processed through each analytical stage to scenarios and could ultimately be integrated into the implementation program as requirements.

2. Technologies that could be developed to assist in assuring compliance and verification of treaty provisions will be identified.

3. All treaty issues will have been addressed and plausible solutions identified. 
In establishing scenarios for the treaty issues, it was necessary to define a set of assumptions that guide and limit the scenario. The scenarios were limited by the following practical considerations:

- Both alliances are constrained by budgetary and political considerations to accept the least intrusive verification regime possible.

- Costly solutions to verification problems would not be favorably considered.

- Long-term foreign presence as part of any verification scheme would not be accepted.

- Political changes on both sides would require flexible verification solutions.

The remainder of the report is organized into five sections. Section 2 states the basic goals and objectives of the CFE treaty and the guidelines under which the treaty is being negotiated.

Section 3 contains the proposed treaty articles, proposals, and annexes under consideration in Vienna. These articles are identified by functional titles and contain the specifics of the negotiating positions for each group of parties. In addition to providing the text of the negotiating position, Sec. 3 also allows for rapid comparison of NATO and WTO positions on each issue and shows areas where no proposals have been brought to the table.

Section 4 identifies problems associater with eech of the functional areas identified in Sec. 3. This analysis provides insight into possible areas of concern that need to be addressed before CFE treaty implementation. These questions have been updated on the basis of current political developments in the area of application and new language contained in the proposed treaty text. Following the problem assessments, possible scenarios are suggested for resolving these prohleul areas. These scenarios, which include recommendations on programmatis responsibility for implementation, should be of value in identifying technologies that would assist in resolving each issue and provide a starting point for addressing requirements to be included in the CFE program schedule.

Section 5 proposes a CFE schedule that outlines possible major program areas for CFE implementation. The major program elements have been provided key tasks, and each of the scenarios listed in Sec. 4 has been integrated into these tasks as a requirement that should be addressed. By using Sec. $5 \mathrm{si}$ a program outline, the program manager could track program progress, assign key responsibilities, and ensure that treaty requirements are met.

Section 6 , the concluding section, provides recommendations for future actions. 


\section{CONVENTIONAL ARMED FORCES IN EUROPE TREATY NEGOTIATION AREAS}

\subsection{GOALS}

The NATO and Warsaw Pact nations agreed to the following goals for reducing conventional armed forces in Europe during the ministerial meeting of the CSCE in Vienna on 10 January 1989 (Houser 1989):

1. Establish a secure and stable balance of conventional forces at lower levels.

2. Eliminate disparities prejudicial to stability and security.

3. Eliminate capabilities for launching surprise attacks and for initiating large-scale of fensive operations.

\subsection{OBJECTIVES}

NATO has provided the following objectives, which have been agreed upon by the Warsaw Pact, that define the overall direction to be taken to reduce armaments in the ATTU region (Houser 1989):

- Focus on level of arms,

- Focus on level of readiness,

- Focus on the above two objectives in those areas having the greatest force concentrations,

- Preclude single-country domination of Europe,

- Limit stationing of arms outside national borders, and

- Prevent covert redeployment of forces.

\subsection{COMPLIANCE REQUIREMENTS}

On the basis of current proposals and the political climate in Europe, a future agreement probably will include the following (Houser 1989):

- Limits on equipment and personnel to establish a secure and stable balance at lower levels,

- Gengraphic sublimits to prevent covert redeployment of forces, 
- Information exchange to accurately define levels of arms and readiness,

- Limits on statioring of arms outside of national boundaries and measures to limit single-country domination of Europe,

- Stability measures to eliminate capabilities for launching surprise attacks and initiating large-scale offensive operations,

- Verification measures to ensure adherence to limits and stability measures, and

- Measures to ensure noncircumvention of the limits and measures. 


\section{PROPOSED TREATY ARTICLES}

This section lists treaty articles proposed by each alliance and identifies these articles by subject; these subjects are use $;$ as functional subheadings, displayed in the left column, for each article. The articles are arranged so that comparisons can be made between the positions of the two alliances, NATO and the Warsaw Pact (WP) nations. If either alliance has not brought position to the table, then a position is not included.

\subsection{TREATY COMPOSITION}

Treaty-

Limited

Categories

Annexes
NATO (ARTICLE I): The parties shall carry out the obligations set forth in this treaty in accordance with its provisions. This treaty includes an annex on existing types of conventional armaments, an annex with maps of the area of application, a protocol establishing and maintaining a data base, a protocol on inspection with an annex on privileges and immunities, and a protocol on destruction, all of which form an integral part of the treaty (BASIC Jan. 1990).

WARSAW PACT (ARTICLE I.1): The state parties shall reduce to ceilings and shall not exceed the ceilings established in Articles VI-X of this treaty for the following treaty-limited categories of conventional armed forces (BASIC Jan. 1990):

- Personnel,

- Combat aircraft of front/tactical aviation,

- Combat helicopters,

- Battle tanks,

- Armored combat vehicles, and

- Artillery.

WARSAW PACT (ARTICLE I.3) This treaty includes (1) an Annex on the Types of Treaty-Limited Categories of Conventional Armaments, (2) an Agreed Upon Format of Data Provided in Relation to the Treaty on Conventional Armed Forces in Europe, and (3) a protocol on Reduction of the Treaty-Limited Categories of Conventional Armed Forces. These documents constitute an integral part of the treaty (BASIC Jan. 1990). 
Other

Measures

\subsection{DEFINITIONS}

\author{
Main Battle \\ Tanks
}

Artillery
WARSAW PACT (ARTICLE I.2): The state parties shall also take other meas ires designed to ensure security both during the period of reduction of the treaty-limited categories of conventional armed forces and after its completion as provided for in Article XIII of this treaty (BASIC Jan. 1990).

NATO (CHAPTER II.1.F): The term "main battle tank" means a self-propelled armored combat vehicle crpable of heavy fire power, primarily of a high muzzle velocity direct fire main gun necessary to engage armored and other targets and high crosscountry mobility, and such vehicles also have a high level of self-protection. Such armored vehicles serve as the principal weapon systems of ground-force tank and other armored formations (BASIC Feb. 1990).

Battle tanks currently in the armed forces of the participants include armored all-tracked combat vehicles weighing a least 13 metric tons, all of which are armed with a rotatable turretmounted gun of at least $75 \mathrm{~mm}$ calibre. In the future, armored wheeled combat vehicles weighing at least 20 metric tons and armored tracked combat vehicles weighing at least 13 metric tons will be considered battle tanks, provided they meet the above criteria (BASIC Feb. 1990).

WARSAW PACT (ARTICLE II.5): The term "battle tank" means a self-propelled armored combat vehicle capable of high firepower and cross-country mobility. Battle tanks provide protection and are armed to engage armored and other targets mainly by using a main gun. Such armored vehicles serve as an asset to tank and other land force formations (BASIC Jan. 1990).

NATO (ARTICLE II.1.g): The term artillery comprises largecalibre systems capable of engaging ground targets by delivering primarily indirect fire, namely guns and howitzers, artillery pieces combining the characteristics of guns and howitzers, mortars, and multiple launch rocket systems. Such artillery systems provide the essential indirect fire support to combine arms formations. In addition, any future large-calibre direct-fire system that has a secondary effective indirect fire 
Armored Combat Vehicles

Helicopters capability will be counted against the artillery ceilings. Largecalibre artillery systems are considered to be artillery systems with a salibre of $100 \mathrm{~mm}$ and above* (BASIC Jan. 1990).

NATO (ARTICLE II.1.H): The term "armored combat vehicle" includes armored personnel carriers, armored infantry fighting vehicles, and heavy armament combat vehicles. An armored personnel carrier (APC) is a self-propelled vehicle with light aimor and cross-country capabilicy, designed for the transportation of combat troops. It is normally armed with an integral/organic sannon or machine gun and sometimes an antitank missile launcher. An armored infantry fighting vehicle (AIFV) is a self-propelled armored vehicle that, in addition to the characteristics of an APC, has an integral organic cannon of at least $20 \mathrm{~mm}$ (and sometimes an antitank missile launcher) and provides the capability for troops to deliver fire from inside the vehicle under armored protection. AIFVs serve as the principal weapon system of armored infantry or mechanized/motorized formations. A heavy armament combat vehicle (HACV) is a self-propelled armored combat vehicle that weighs more than seven metric tons and has an integral/organic direct fire gun of at least $75 \mathrm{~mm}$ and that does not fall within the definitions of APC, AIFV or battle tank (BASIC Jan. 1990).

WARSAW PACT (ARTICLE II.6): The term "armored combat vehicle" means a self-propelled vehicle with light armor, high cross-country mobility, and organic mounted armament. It is normally armed with a cannon and/or a machine gun and sometimes an antitank missile launcher. Armored combat vehicles are designed to enable crew/troops to deliver fire from under armored protection. These vehicles also provide transportation for personnel and perform other combat missions (BASIC Jan. 1990).

NATO (ARTICLE II.1.j): Combat helicopters include attack helicopters and combat support helicopters. Attack helicopters are permanently land-based rotary wing aircraft initially constructed or later converted to employ anti-armor or air-to-air guided weapons through an integrated fire-control and aiming system. Combat helicopters also include any permanently land-based version or variant of these helicopters that have been modified to perform another military function, provided that an attack helicopter variant exists within the

*This definition has been agreed upon. 
armed forces of a state belonging to the same group of parties. Combat support helicopters are permanently landbased rotary wing aircraft that do not fulfill the requirement to qualify as an attack helicopter and that may be armed with a variety of self-defense and area suppression weapons (BASIC Jan. 1990).

WARSAW PACT (ARTICLE II.4): The term "combat helicopter" means a rotary-wing aircraft, constructed, armed, and equipped to engage ground and air targets by employing missiles and rockets, bombs, guns/cannons and other weapons of destruction (BASIC Jan. 1990).

Aireraft

Personnel
NATO (ARTICLE II.1.i): The term "combat aircraft" means a fixed-wing or swing-wing aircraft, permanently land-based, of a type initially constructed or later converted to drop bombs, deliver air-to-air or air-to-surface missiles, fire guns, cannors, or employ any other weapons of destruction. Any uermanently land-based version/variant of these aircraft that has been modified to perform another military function is also included. An aircraft type should not, however, be included unless a combat variant of the type concerned exists within the ATrU area in the armed forces of a member state of the same tweaty of alliance to which the participating state owning the aircraft belongs (BASIC Jan. 1990).

WARSAW PAC'T (ARTICLE II.3): The term "combat aircraft of front/tactical aviation" means a fixed-wing or swing-wing aircraft, constructed, armed and equipped to engage ground targets or ground and air targets by employing missiles and rockets, bombs, guns/cannons or other weapons of destruction. Combat aircraft of front/tactical aviation currently in the armed forces of the state parties are front bombers, fighter-bombers, ground attack aircraft, front/tactical fighters, reconnaissance aircraft, and electronic warfare aircraft (BASIC Jan. 1990).

WARSAW PACT (ARTICLE II.2): The term "personnel" means all active duty military personnel wearing uniforms who are listed in agreed upon armed services and arms, units and other formations subordinated to the Ministries of Defence and/or to the joint commands of the army forces of the state parties to Warsaw Treaty or the North Atlantic flliance. The term includes the personnel of combat, combat command, and control elements of the land forces and of front/tactical aviation (BASIC Jan. 1990). 


\subsection{TREATY-LIMITED EQUIPMENT CEILINGS}

In this subsection, the numbers of TLE (as upper limits after reductions have been achieved) proposed by NATO and the Warsaw Pact are presented.

\subsubsection{Overall Ceilings*}

WARSAW PACT (ARTICLE VI): Within the area of application, the aggregate ceilings for the treaty-limited categories of conventional armed forces of the state parties to this treaty shall not exceed the following numbers (BASIC Jan. 1990):

$\begin{array}{lcr} & \text { NATO } & \text { WP } \\ \text { Main battle tanks } & 40,000 & 40,000 \\ \text { Artillery } & 33,000 & 48,000 \\ \begin{array}{l}\text { Armored troop } \\ \text { carriers }\end{array} & 56,000 & 56,000 \\ \text { Combat aircraft } & 9,400^{\ddagger} & - \\ \text { Combat helicopters } & 3,800 & 3,800 \\ \text { Manpower } & 195,000^{\$} & 700,000\end{array}$

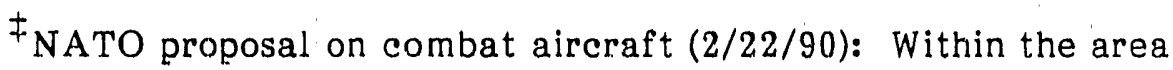
of application, the total of combat aircraft, except air defense inter-ceptors, shall not exceed 9,400 . No one country may retain more than 30 \% of this total (i.e., 2,820 ), and each group of parties belonging to the same treaty of alliance shall be limited to 4,700 such aircraft. In addition, within the area of application, each group of parties belonging to the same treaty of alliance shall be entitled to a further 500 aircraft designated as "defense interceptors." It shall be up to each group of parties to decide which aircraft it chooses to include within this separate interceptor ceiling on the basis of air defense capability. Any party would have to declare an entire type or subtype of aircraft to be in the interceptor or the combat aircraft category. Interceptors in excess of the interceptor ceiling shall be accountable under the combat aircraft ceiling of 4,700 . Within the area of application, all

*Aggregate of NATO plus Warsaw Pact conventional forces. 
categories of combat aircraft belonging to each group of parties shall be included either in the 4,700 ceiling or in the separate ceiling for air-defense interceptors. All medium bombers and permanently land-based naval aircraft must be counted under the combat aircraft ceiling. The question of heavy bombers shall be resolved in a manner compatible with the CFE mandate. Primary trainers shall not be included in the base for reduction and shall not be subject to numerical limitations. No new armament shall be added to existing primary trainers. Future primary trainers shall be unarmed for combat. Parties will agree on a list of existing primary trainers (BASIC Feb. 1990).

\$On 13 February 1990 , member states reached accord on CFE manpower limits. The newly agreed-upon position includes the Bush proposal for 195,000 troops in central Europe. The Soviet Union will have to keep its overall European force of foreign-stationed personnel below this level. For the U.S., the ceiling will be 225,000 throughout the continent. On 22 February 1990, the chief Soviet CFE negotiator brought to the table a proposal for a limit in central Europe of 700,000750,000 personnel per alliance (BASIC Feb. 1990).

Helicopter

Rules
NATO proposed rules for combat helicopters -- rule A: Overall Limit. The overall limit of attack helicopters shall at no time exceed 3,800 (BASIC Feb. 1990).

\subsubsection{Alliance Ceilings*}

NATO (ARTICLE V1.1): Each party shall limit and, as necessary, reduce its main battle tanks, artillery pieces, armored troop carriers, combat aircraft, and combat helicopters so that [information to be supplied] years after entry into force of this treaty and thereafter, for the group of parties to which it belongs the aggregate numbers within the area of application do not exceed (BASIC Jan. 1990):

WARSAW PACT (ARTICLE VII): In the area of application, the collective ceilings for the treaty-limited categories of conventional armed forces for each of the two groups of state parties shall not exceed (BASIC April 1990):

\footnotetext{
*Equal NATO and WP limits in Europe from the Atlantic Ocean to the Ural Mountains.
} 


\begin{tabular}{|c|c|c|}
\hline & NATO & WP \\
\hline Main battle tanks & 20,000 & 20,000 \\
\hline Artillery & 16,500 & 24,000 \\
\hline $\begin{array}{l}\text { Armored combat } \\
\text { vehicles }\end{array}$ & 30,000 & 28,000 \\
\hline $\begin{array}{l}\text { Armored infantry } \\
\text { fighting vehicles } \\
\text { or heavy armored } \\
\text { combat vehicle }\end{array}$ & 3,000 & - \\
\hline Combat aircraft & 5,700 & 4,700 \\
\hline Combat helicopters & 1,900 & 1,900 \\
\hline Manpower & * & 700,000 \\
\hline
\end{tabular}

\subsubsection{Discussion of Ceilings and Subceilings}

During the first round of talks, NATO proposed that each alliance be limited to 16,500 artillery pieces. The Warsaw Pact suggested a figure of 24,000. These proposals counted only equipment deployed with active units, rather than in storage. A ceiling for these systems based on the newly established definition would be between 18,500 and 19,000 ; if stored weapons were included, the figure would be somewhat higher (BASIC Sept. 1990).

\subsubsection{Discusșion of Armored Combat Vehicles}

The East has insisted that any tracked or wheeled combat vehicle weighing at least 13 tons be counted under the agreed-upon tank ceiling of 20,000 for each alliance. NATO now accepts this weight threshold for tractred vehicles, but it has stuck to a 20-ton figure for wheeled ones. The higher threshold for wheeled vehicles reflects a western desire to allow France and Italy to build equipment of this type without forcing the destruction of main battle tanks to compensate. Vehicles weighing less than these thresholds and more than seven tons fall into a subcategory of armored combat vehicles (ACVs) called "heavy armored combat vehicles" (HACV). The ACV category includes and replaces the old armored personnel category. The East objected to the West's structure of sublimits, arguing that NATO would be able to build large numbers of such

*The NATO proposal addresses U.S. and Soviet manpower only, with U.S. and Soviet ground- and air-stationed manpower levels in Europe to be limited to 195,000 each (BASIC Jan. 1990). 
equipment. NATO has now offered a subcelling of 3,000 on HACVs, of which li currently has 2,000. The other point of contention in the armored vehicle definitions is whetrer to place a sublimit on armored infantry fighting vehicles (AIFVs). NATO has proposed a combined sublimit of 14,000 for AIFVs and HACVs. The USSR strongly resists such constraints on its AIFV force of 19,000 (BASIC Feb. 1990).

\section{Armored \\ Combat \\ Vehicles}

Helicopters

Aircraft
NATO proposed that each group of parties shall not, within the area of application, hold more than 30,000 armored combat. vehicles, of which no more than 14,000 shall be armored infantry fighting vehicles or heavy armament combat vehicles. Of AIFVs and HACVs, no more than 3,000 shall be HACVs (BASIC Feb. 1990).

NATO proposed rules for combat helicopters -- rule C: Sublimits. Within the area of application delineated under the rule $4(1)$, the holdings of each group of parties shall not exceed 1,00 atrack helicopters (BA.SIC Feb. 1990).

The Warsaw Pact "working paper" on limitations of combat aircraft (paragraph 3) states that in the area of application, combat aircraft of front/tactical aviation and combat helicopters shall be counted in accordance with the following rules (BASIC April 1990):

1. Counting shall be conducted in cornbat aircraft and combat helicopter units, and

2. All combat aircraft of front/tactical aviuition and combat helicopters in combat units, combat employment centers, and storage bases (facilities) shall be subject to counting.

(Paragraph 4) In the area of application, for each group of states belonging to the same alliance, the collective celling shall not exceed the following:
- Combat aircraft
4,700
- Combat helicopters
1,900 .

For each participant the ceiling shall not exceed the following:
- Combat aircraft
3,400
- Combat helicopters
1,500 
Collective cellings outside national territories for each group of states belonging to the same alliance shall not exceed the following:

- Combat aircraft

- Combat helicopters
1,200

600.

(Paragraph 5) Participants shall exchange data concerning combat aircraft and combat helicopters. Specific proposals on such data exchange will be submitted (BASIC Nov. 1989).

(Paragraph 8a) Air defense (AD) fighter-interceptors designed to protect the territory of country (political, economic, and military installations) agiinst strategic and carrier based aircraft and against air and sea-launched cruise missiles shall not be subject to counting in the levels specified in paragraph 4 of this proposal. Appropriate procedures of verification for such aircraft and for exchange of information on them might be developed and agreed upon (BASIC Nov. 1989).

Paragraph $8 \mathrm{~b}$ states that a certain level for air defense fighter-interceptors can be established in the area of application provided that the means against which they are designed are not increased (BASIC Nov. 1989).

NATO has proposed restrictions on a broad range of aircraft, while the Warsaw Pact has argued that only planes with offensive missions should be constrained. The Pact position continues to exempt training aircraft, air-defense interceptors and land-based naval planes from limits. Soviet officials have stressed that Eastern air-defense forces are necessary to protect Soviet strategic missile silos against attack by Western strategic bombers, cruise missiles, and carrier based alrcraft. The Pact has signalled a willingness to freeze its air-defense interceptors at current levels $(1,800)$, if NATO will agree to reciprocal limits on the forces seen as threatening to Soviet missiles (BASIC Nov. 1989).

Personnel

The Soviet Union insists that limiss on troop numbers iriclude not just U.S. forces, as currently proposed, but also Belgian, British, Canadian, Dutch, and French personnel in West Germany (BASIC April 1990). 


\subsubsection{Sufficiency Ceilings}

The Warsaw Pact and NATO have proposed the following numbers of TLI as cellings that cannot be exceeded by national holdings of any one country:

NATO (ARTICLE IV): Each party shall limit and as necessary reduce its main battle tanks, artillery pieces, armored troop carriers, combat aircraft, and combat helicopters so that [information to be supplied] years after entry into force of this treaty and thereafter, the numbers within the area of application for each party do not exceed (BASIC Jan. 1990):

WARSAW PACT (ARTICLE VIII): In the area of application the cellings for the treaty-limited categories of conventional armed forces of any state party shall not exceed (BASIC Jar. 1.990):

$\begin{array}{lcr} & \text { NATO } & \text { WP } \\ \text { Main battle tanks } & 12,000 & 14,000 \\ \text { Artillery } & 10,000 & 17,000 \\ \text { Armored combat vehicles } & 6,800 & 18,000 \\ \text { Combat aircraft } & 3,400 & 3,400 \\ \text { Combat helicopters } & 1,140 & 1,500 \\ \text { Personnel strength } & & 700,000\end{array}$

NATO proposal addresses U.S, and Soviet ground- and air-stationed manpower levels in Europe to be limited to 195,000 each.

NATO proposed rules for combat helicporters-- rule B: Sufficiency. No one country may retain more than $30 \%$ of the overall limit, i.e., 1,140 (BASIC Feb. 1990).

\subsubsection{Stationing Ceilings}

An allance may not station forces outside its national territory in excess of specified limits. The proposed limits are indicated below. 
Foreign

Stationing

Personnel

NATO (ARTICLE V): Each party shall limit, and, as necessary, reduce its main battle tanks, artillery pieces, and armored troop carriers so that [information to be supplled] years after entry into force of this treaty and thereafter, for the group of parties to which it belongs, the aggregate numbers in active units stationed outside of the respective national territories of those units and stationed within the area of application do not exceed (BASIC Jan. 1990):

WARSAW PACT (ARTICLE IX): In the area of application, the collective ceilings for the treaty-limited categories of conventional forces stationed outside of the national territories for each of the two groups of state parties shall not exceed:

$\begin{array}{lrr} & \text { NATO } & \text { WP } \\ \text { Main battle tanks } & 3,200 & 4,500 \\ \text { Artillery } & 1,700 & 4,000 \\ \text { Armored combat vehicles } & 6,000 & 7,500 \\ \text { Combat aircraft } & \text { N/A } & 1,200 \\ \text { Combat helicopters } & \text { N/A } & 600\end{array}$

NATO (ARTICLE VII.1): The United States of America and the Union of Soviet Socialist Republics shall limit their ground and air force personnel stationed outside of their national territory and within the area of application so that [to be supplied] years after entry into force of the treaty and thereafter, the aggregate number of such personnel for each of them does not exceed 275,000. (BASIC Jan. 1990).

NATO (ARTICLE VII.2): The reductions provided for in paragraph 1 of article VII shall be implemented by demobilizing personnel (BASIC Jan. 1990).

\subsubsection{Regional Ceilings}

Establish definite areas within which sublimit armament ceilings are not to be exceeded.

Alliance

Ceiling, Subzone A
NATO (ARTICLE VI.2): Each party shall limit and, as necessary, reduce its main battle tanks, artillery pieces, and armored troop carriers so that [information to be supplied] 
years after entry into force of this treaty and thereafter, for the group of parties to which it belongs, the aggregate numbers in active units in the area consisting of the Kingdom of Belglum, the Czechoslovak Soclallst Republic, the Kingdom of Denmark (including the Faroe Islands), France, the German Democratic Republic, the Federal Republic of Germany, the Republic of Hungary, the Italian Republic, the Grand Duchy of Luxembourg, the Kingdom of the Netherlands, the Polish People Republic, the Portuguese Republic (including the islands of the Azores and Madeira), the Kingdom of Spain (including the Canary Islands), the United Kingdom of Great Britain and Northern Ireland, and that part of the territory of the Union of Soviet Socialist Republics west of the Ural Mountains comprising the Baltic, Byelorussian, Carpathian, Moscow, and Volga-Ui'al military districts to not exceed (BASIC Jan. 1990):

WARSAW PACT (ARTICLE X): In the area of application, the collective cellings for the treaty-limited categories of conventional armed forces located in the following regions for each of the two groups of state parties shall not exceed (BASIC Jan. 1990):

\section{NATO}

Main battle tanks

Artillery pieces

Armored coinbat vehicles
11,300

9,000

20,000
Alliance

Ceiling, Subzone B
NATO (ARTICLE VI.3): Each party shall limit and, as necessary, reduce its main battle tanks, artillery pleces, and armored troop carriers so that [information to be supplied] years after entry into force of this treaty and thereafter, for the group of parties to which it belongs the aggregate numbers in active units in the area consisting of the Kingdom of Belgium, the Czechoslovak Socialist Republic, the Kingdom of Denmark including the Faroe Islands, France, the German Democratic Republic, the Federal. Republic of Germany, the Republic of Hungary, the Italian Republic, the Grand Duchy of Luxembourg, the Kingdom of the Netherlands, the Polish People's Republics, the United Kingdom of Great Britain and Northern Ireland, and that part of the territory of the Union of Soviet Socialist Republics comprising the Baltic, Byelorussian, and Carpathian military districts do not exceed (BASIC Jan. 1990): 
NATO

Main battle tanks

Artillery pieces

Armored combat vehicles
10,300

7,600

18,000
Alliance

Ceiling,

Subzone C
NATO (ARTICLE VI.4): Each party shall limit and, as necessary, reduce its main battle tanks, artillery pleces, and armored troop carriers, so that [information to be supplied] years after entry into force of this treaty and thereafter, for the group of parties to which it belongs, the aggregate numbers in active units in the area consisting of the Kingdom of Belgium, the Czechoslovak Sccialist Republic, the German Democratic Repujlic, the Federal Republic of Germany, the Grand Duchy of Luxembourg, the Kingdom of the Netherlands, and Polish People's Republic do not exceed (BASIC Jan. 1990):

\section{NATO}

Main battle tanks

8,000

Artillery pieces

4,500

Armored combat vehicles

\subsection{COUNTING RULES}

NATO (ARTICLE III) is to be developed.

WARSAW PACT (ARTICLE III): Personnel of land forces and front/tactical aviation, combat aircraft of front/tactical avistion combat helicopters, battle tanks, armored combat vehicles, and artillery shall be counted in accordance with the following rules (BASIC Jan. 1990):

1. Personnel (to be submitted)

2. Combat aircraft of front/tactical aviation:

- In formations and units; and

- In permanent storage in all storage sites and storage bases. 
3. Combat helicopters, battle tanks, armored combat vehicles and artillery:

- In formations and units;

- In permanent storage in all depots and storage bases; and

- In military educational establishments of the land forces.

4. Combat aircraft of front/tactical aviation, combat helicopters, battle tanks, armored combat vehicles, and artillery considered incapable of combat in accordance with the provisions of the protocol on the reduction of treaty-limited categories on the conventional armed forces and p'aced in temporary storage of the period until their final elimination under permanent monitoring by inspectors of the state parties belonging to the other group of state parties, in accordance with Article XV of this treaty, shall not be counted against the levels established by Articles VI-X of this treaty.

\subsection{MODALITIES OF DATA EXCHANGE}

The NATO proposal (paragraph 5 and 6) states that information required to be exchanged will be communicated in writing through diplomatic channels in accordance with an agreed upon format. Each participant will provide the stipulated information on its military structure, forces, and equipment in the area of application (BASIC Sept. 1989):

- On signature of the agreement, with information effective as of that date.

- On coming into force of the agreement, with information effective as of that date.

- On 15th December of that year and the 15 th December of every year thereafter (with information effective as of the first day of January the following year).

- Immediately after completion of reductions. 


\section{At Treaty Signature- National Holdings Data Exchange}

Com municatiun

Protocol

Initial Data Exchange

Entry into Force Data Exchange
NATO (ARTICLE IX.3): Upon signature of the treaty, each party shall notify to all other parties the maximum levels that shall apply to its holdings of main battle tanks, armored troop carriers, artillery pieces, combat aircraft and combat helicopters. In respect of each such items, the aggregate maximum levels of holdings of each group resulting from the individual notifications of all the parties belonging to that group shall not exceed the limits set out in Articles V and VI. A notification under this paragraph shall be binding on the notifying party until a new notification is made under paragraph 4 of Article IX (BASIC Jan. 1990).

WARSAW PACT (ARTICLE XI): National level of holdings -The state parties at the time of signature of the treaty shall declare their national levels of holdings of the treaty-limited categories of conventional armed forces, related to the implementation of the provisions of Articles VI-X of this treaty (BASIC Jan. 1990)。

NATO (ARTICLE XVII): The parties shall use [information to be supplied] to: (a) exchange data and provide notifications a.s required by paragraphs [information to be supplied] of Articles [information to be supplied] of this treaty (BASIC Jan. 1990).

WARSAW PACT (ARTICLE XVI.1): The state parties shall provide data and notifications in accordance with the provisions of this article and of the protocol on information and verification. A state party shall be responsible for its own data. Receipt of this data and subsequent notifications shall not imply validation or acceptance of the data provided (BASIC Jan. 1990).

WARSAW PACT (ARTICLE XVI.2): The state parties shall provide data on the treaty-limited categories of their conventional armed forces in the area of application by the types of data contained in the agreed upon format of data, effective as of the date of signature of this treaty (BASIC Jan. 1990).

WARSAW PACT (ARTICLE XVI.3): The state parties shali provide data on the treaty-limited categories of their conventional armed forces in the area of application by the types of data contained in the agreed upon format of data, effective as of [information to be supplied] day after entry into force of this treaty (BASIC Jan. 1990). 


\section{Achieving Ceilings, Data Exchange}

\section{Annual Data Exchange}

\section{Arrangements}

Unit

Structure
Land Forces
WARSAW PACT (ARTICLE XVI.4): The state parties shall provide data on the treaty-limited categories of their conventional armed forces in the area of application by the types of data contained in the agreed upon format of data, effective as of the date of achieving of the ceilings established in Articles VI-X of this treaty (BASIC Jan. 1990).

WARSAW PACT (ARTICLE XVI.5): The state parties after entry into force of this treaty on the 15 th day of December annually shall provide data on the treaty-limited categories of their conventional armed forces in the ares of application by the types of data contained in the agreed upon format of data, effective as of the first day of January of the following year (BASIC Jan. 1990).

WARSAW PACT (ARTICLE XIX): (submitted additionally)

NATO proposed that within the area of application, each participant will provide information about its land forces command organization, showing the designation and subordination of all combat, combat support, and combat service support formations and units at each level of command down to the level of battalion or equivalent (this is to include "low-strength units"), indicating whether the unit is active or not (BASIC Sept. 1989).

The Warsaw Pact working paper states that each participant shall provide the following information about the structure of its land forces and front/tactical aviation in the area of application (BASIC Nov. 1989):

- Overall personnel strength, numbers and types of armaments in each category;

- Its land forces command organization, specifying the designation and subordination of all combat formations, combat support and combat service support units at each level of command down to the regiment or equivalent formation level.

NATO proposed that for those units that hold treaty-limited items -- tanks, artillery, armored troop carriers, helicopters, and combat aircraft - both sides would exchange data on their peacetime locations, authorized personnel levels, and holdings of TLI. Information on mobile assault bridging units would also be exchanged as well as the number of any other TLI including those held by paramilitary units and those in production (BASIC Sept. 1989). 
Air Forces

Ground and

Air Force

Personnel

Closed-Out Sites

TLI Held by Paramilitary Tnits

\section{Peacetime Locations of Declared Forces and TLE}

NATO proposed that within the area of application, each participant will provide information about its air and air defense forces command organization (to include naval aviation permanently based on land) showing the designation and subordination of formations and units at each level of command down to squadron or equivalent (BASIC Sept. 1989).

The Warsaw Pact working paper states that each participant will provide information about the structure of its front/tactical aviation command organization specifying the designation and subordination of formations at each level of command down to the air regiment or equivalent formation level (BASIC Sept. 1989).

The NATO proposal for measures of information exchange stated that the U.S. and Soviet Union shall provide information on the number and location of their ground and air force personnel stationed on the territory of other participants in the area of application (BASIC Sept. 1989).

The NATO proposal for measures of information exchange stated that each participant shall also indicate the location of any sites which held equipment of the types subject to limitation under Chapter I after 1 January 1989, and from which such equipment has been withdrawn; each of these sites will have to be declared for [information to be supplied] years following the withdrawal (BASIC Sept. 1989).

NATO proposed that each participant shall also provide information on the numbers, type and location of any main battle tanks, artillery pieces, armored personnel carriers, combat aircraft and combat helicopters present on the territory of participating states on the area of application, not subject to treaty limitation but with a potential for circumvention, e.g., equipment held by paramilitary forces and equipment which has been produced within the area of application but which is not in service with the armed forces of any participating state (BASIC Sept. 1989).

The NATO proposal for measures on information exchange (paragraph $I I, 4, b)$ states that for each of the formations and units having TLI, each participant shall provide the following information (BASIC Sept. 1989):

a. The Normal Peacetime Location (NPL) of its headquarters (HQ) component and of formations and unit at which TLI are 
stationed or held, with exact geographical terms or coordinates and peace time planned/authorized personnel strength.

b. The holdings at such locations of the following categories of TLI specifying numbers and types of main battle tanks, artillery pieces, armored troop carriers, combat aircraft, and combat helicopters.

c. The location and holdings of Armored Vehicle Launched Assault Bridges (AVLAB), in active units.

The Warsaw Pact working paper on information exchange and verification measures (paragraph $1,1,2$ ) states that each participant will provide the following information (BASIC Nov. 1989):

- Permanent locations of formations specifying exact geographical terms and/or coordinated and peacetime personnel strengths.

- The holdings at such locations of the following categories of treaty-limited armaments, specifying numbers and type:

-- combat aircraft of front/tactical aviation,

-- combat helicopters,

- tanks,

- armored combat vehicles, and

-- artillery.

Locations of Other Activities and Personnel
The NATO proposal for measures of information exchange (paragraph II, $4, c$ ) states that each participant will provide the following information about the area of application (BASIC Sept. 1989):

a. The location, including exact geographical terms or coordinates of storage depots monitored under the stabilizing and verification arrangements of this agreement, and the numbers and type of TLI held at such depots. 
b. The numbers, types, and permanent locations of TLIs not belonging to the formations and units declared under declared forces and not in monitored storage.

c. The location, including exact geographical terms or coordinates, and the number of personnel assigned to low strength units (a definition of low strength units shall be agreed upon among participants).

d. The location, including exact geographical terms or coordinates, of other sites where TLIs may be present on a regular or periodic basis, such as repair and maintenance depots, training establishments, storage depots, other than those subject to monitoring under verification measures of this agreement, and alternative operating airfields and the numbers of any TLI permanently located at such sites.

e. The numbers and location, including geographical terms or coordinates of AVLABs in monitored storage and in any other sites not covered by $A V L A B$ in active units.

The Warsaw Pact working paper stated that each participant shall also provide information on the following in the area of application (BASIC Nov. 1989):

- Permanent location of formations and units, including exact geographical terms and/or coordinates and stationed personnel strengths in Europe;

- The locations and numbers of armored vehicle launched assault bridges in units and storage;

- The locations of storage depots (storage sites) specifying exact geographical terms and/or coordinates, numbers and types of treatylimited armaments held at such sites; and

- The locations, including exact geographical terms and/or coordinates, of repairs and maintenance depots and military training establishments as well as numbers and types of treaty-limited armaments there. 


\subsection{STABILITY MEASURES}

NATO (ARTICLE X): Stability Measures -- to be developed (BASIC Jan. 1990).

\subsubsection{Purpose}

WARSAW PACT (ARTICLE XIII): The Warsaw Pact working paper on stability measures states that stability measures shall be implemented in addition to measures for achieving residual agreed upon levels of treaty-limited conventional armed forces in the area of application and shall be covered by information exchange measures and measures of verification of compliance with the treaty. The following measures shall be designed (BASIC Jan. 1990):

- To contribute to the achievement of a more stable and secure balance of forces, increased openness and predictability of military activities; and

- To limit the possibility of such activities of the armed forces of the participants that would contradict the objectives of the treaty.

\subsubsection{Notifications}

General

Notification

Requirements
NATO (ARTICLE XI.1): The parties shall provide the notifications required by this article according to the categories of data contained in the protocol establishing and maintaining a data base (BASIC Jan. 1990).

NATO (ARTICLE XI.2): The parties shall provide the notifications required by this article in accordance with the procedures set forth in Article XVII of this treaty (BASIC Jan. 1990).

NATO (ARTICLE XI.3): Upon entry into force of this treaty and thereafter, each party shall provide the following notifications to the other parties [to be determined] (BASIC Jan. 1990):

NATO (ARTICLE XV) Notification and data exchange

a. For the purpose of ensuring verification of compliance with the provision of this treaty, each state party shall provide notifications of 
data pertaining to its armed forces in accordance with the protocol establishing and maintaining a data base.

b. These notifications will be related (sic) to information about (BASIC April 1990):

- The structure of each state party's land, air, and air defense forces in the area of application;

- The location and numbers of those categories of equipment subject to limitation under the treaty;

- The location and numbers of U.S. and Soviet ground and air force personnel stationed on the territory of other state parties in the area of application;

- The location of sites that, af ter 1 January 1989 , held equipment of the types subject to limitation and from which such equipment has been withdrawn; and

- The location and numbers of any battle tanks, artillery pleces, armored combat vehicles, combat aircraft, and combat heli-copters present on the territory of the state parties in the area of application, but not subject to treaty limitation, e.g., equipment held by paramilitary forces and equipment that has been produced within the area of application but is not in service with the armed forces of any state party.

- Changes in organizational structures or force levels;

- The entry into service with the armed forces of a state party of equipment in the categories subject to limitation under the treaty; 
- The entry into and exit out of the area of application of equipment in the service of the armed forces of a state party of the types subject to limitation under the treaty.

c. The notifications, as stipulated in the protocol establishing and maintaining a data base, shall be provided in accordance with the procedures set out in Article XVIY of the treaty.

WARSAW PACT (ARTICLE XVI.9): The state partles shall provide the following (BASIC Jan. 1990).

a. Notifications of reduction of the treatylimited conventional arined forces in the area of application, including their relocation from the area of application;

b. Notffications of national levels of holdings defined in accordance with Article XI and related to the implementation of the provisions of Articles VI-X of this treaty;

c. Notifications of temporarily exceeding the cellings specifled in Articles VI-X which is envisaged in Article XII of this treaty;

d. Notifications related to the implementation of measures to verify compliance with the provisions of this treaty, envisaged by the provisions of Article XVII of this treaty and the protocol on information and verification; and

e. Notifications envisaged by Article XIII of this treaty and related to the implementation of stabilizing measures. (Time frames for providing data and notifications envisaged by this article as well as the volume of information included in such data and notifications shall be governed by the provisions of the protocol on information and verification). 
Structure Change

Notifi-

cation

Strength

Change

Notifi-

cations
Reduction

Timetables
The NATO working paper states that each particlpant shall notify all other partiolpants 42 days in advance of any permanent change in the organlagtional struoture of its existing units in the area of application or the permanent addition of any new unit of at least battalion/squadron or equivalent size to its forces in the area of application (BASIC Sept. 1989).

WARSAW PACT (ARTICLE XVI.6): After achleving the cellings established in Articles VI-X of this treaty, a state party, in case of a planned change in the organizational structure of its formation in the area of application, including addition or withdrawal of regiments and units equivalent to them as well as larger formations, shall notify thereof 42 days in advanoe (BASIC Jan. 1990).

According to the NATO working paper, each participant shall notify all other participants of changes of $10 \%$ or more in the peacetime planned/authorized strength of personnel and of treaty-limited items in any of its TLI holding combat, combat support, or combat service support units down to the battalion/squadron or equlvalent level in the area of application since the last annual report. All such changes shall be reported in the preceding annual information exchange or as they occur (BASIC Sept. 1989).

WARSAW PACT (ARTICLE XVI.7): Beside the regular provision of data envisioned in paragraph 5 of this article, the state parties shall provide notifications of changes of percent and more of the authorized peacetime strength of personriel, of combat aircruft of front/tactical aviation, combat helicopters, battle tanks, armored combat veticles, and artillery in combat, combat support and combat service support units down to the level of regiment or equivalent unit in the area of application occurred since the last annual exchange of data. Such notifications shall be provided not later than five days after such changes occur (BASIC Jan. 1990).

WARSAW PACT (ARTICLE XVI.8): The state parties shall provide timetables of reduction of the treaty-limited conventional armed forces (BASIC Jan. 1990).

NATO (ARTICLE IX.4): Any party may notify a change in the maximum levels that apply to its holting of any or all of the types of conventional armament limited by this treaty. But, if such a chang'e would, on the basis of the maximum levels of holdings notifled under this paragraph or paragraph 3 of this 
Temporarily Exceeding Limits

article by other partles belonging to the same group, result in the limits for each group of partles belonging to the same group, result in the limits for each group of partles in Articles $V$ and VI being exceeded, then It must be accompanied by the notification of a change in the maximum levels of holdings applying to one or more other parties belonging to the same group so as to ensure continued respeot for the limits set out in Artioles V and VI (BASIC Jan. 1990).

WARSAW PACT (ARTICLE XII): Temporarlly exceeding the cellings -- submitted separately (BASIC Jan. 1990).

NATO Stabillty Measure 1: Any partlcipant intending to call up 40,000 or more reservists in the area of application shall notlfy all other particlpants at least 42 days in advance. Such notification shall be in writing in an agreed upon format and shall include the number of reservists involved, the designation and location of the unit affected, and the purpose and intended duration of the call-up (BASIC Sept. 1989).

WARSAW PACT (ARTICLE XII.2.C): A state party shall notify of the call-up of reservists within the framework of exercises whenever the totrl number of the called-up reservists exceeds one-thousand me.l (BA.SIC Nov. 1989).

NATO Stability Measure 2: Any participant intending to move ground treaty-limited equipment from one location to another within the area of application shall notify all other particlpants at least 42 days in advance if such movements will exceed within 14 days the following levels (BASIC Sept. 1989):

Main battle tanks

Artillery

Armored troop carrier
600

1,200

Notification made in compliance with this measure shall be in writing, in an agreed upon format, and shall specify the number of TLIs to be moved, their normal peacetime locations, the route of their movement to and from the new locations, and the purpose and intended cluration of their presence in the new locations.

The NATO proposal for measures of verification, paragraph IV, measure 4(b), states that all destruction of weapons above agreed ceilings shall be notified in advance and be subject to on-site monitoring without quotas or right of refusal. 
Treaty-Limited Items shall be considered destroyed when agreed prior notification procedures have been followed the destruction has been carried out in accordance with agreed upon procedures, and notification has been recelved that such destruction has been completed. Particlpants will agree on the notifleation, destruction, and monitoring procedures to be followed (BASIC sept. 1989).

\subsubsection{Stability Limits}

Call-Up of

Reservists

Temporary

Storage

Monitored

Storage
WARSAW PACT (ARTICLE XII): In gddition to the measures of reduction of the treaty-1imited categories of conventional armed forces, in order to contribute to the achlevernent of a more stable and secure balance of forces in Europe, to Increase openness and predictability of military activities, the state parties shall implement the stabilizing measures listed below (BASIC Jan. 1990).

WARSAW PACT (ARTICLE XII.2): They shall limit the call-up of reservists (BASIC Jan. 1990).

a. A state party within the framework of military exercises may call up simultaneously more than [to be supplied] thousand reservists not more than once in two calendar years with prior notification thereof;

b. The state parties belonging to the same group of state parties within the framework of military exercises shall not call-up more than [to be supplied] thousand reservists simultaneously.

WARSAW PACT (ARTICLE XV): to be submitted (BASIC Jan. 1990)

NATO Stabllity Measure 3: Monitored Storage Requirements -For each group of states belonging to the same treaty of alliance, equipment in active units shall not exceed the following levels in the area of application (BASIC Sept. 1989):
Main battle tanks
16,000
Artillery
14,500
Armored troop carrier
25,500 
Treaty-Limited Equipment that is within the total authorized ceilings, but in excess of the cellings for aotive unlts stated above, shall be placed elther in monitored storage sites or in low strength units within the area 4.2. Equipment located in area 4.3 shall, however, be placed in monitored storage sites.

Monitored Storage Sites

Unmonitored

Storage

Sites

Removal from
Monitored
Storage

NATO Stability Measure 3(b) Monitored Storage Sites: Only equipment placed in declared monitored storage as specified in this section shall be regarded as equipment in storage for compliance with the requirements of monitored storage (BASIC Sept. 1989).

- The location of monitored storage sites for Treaty-Limited Equipment shall be declared and communicated to all CFE participants along with information specifying the qualities of Treaty-Limited Equipment stored at them.

- Monitored storage sites declared in ascordance with this measure shall be configured to ensure:

- An effective separation of stored equipment from active equipment.,

-- Ease of monitoring, and

-- Clearly defined boundaries with limited entrance and exit points.

NATO Stability Measure 3(b)(4): Participants may maintain as many TLI in unmonitored storage sites as they desire, but equipment kept at such sites shall be courited solely for the purposes of this agreement as being in active units (BASIC Sept. 1989).

NATO Stability Measure 3(c): Except as permitted for small amounts, equipment may be removed from monitored storage only when the state intending to remove that equipment has notifled all CFE particlpants at least 42 days prior to removal. Such equipment shall not remain out of storage for more than 42 days.

* Equipment removed from monitored storage by states belonging to the same treaty of alliance shall at no time exceed the following levels (BASIC Sept. 1989): 
Main battile tanks

Artillery

Armored troop carrier
600

400

120

- Notification of the intended removal of equipment from monitored storage shall specify the location(s) of the site(s) from which the equipment is to be removed and shall provide detalls on the intended use of the equipment during the period of its removal from storage.

- Small numbers of equipment (up to $10 \%$ of the figures approved for removal) may be removed for maintenance or other purposes without being subject to the time limit (42 days) and without prior notification except to any observer at the storage site.

- Replacement of equipment in monitored storage shall be notified by the state making the replacement at the time it takes place and shall include the disposition of any removed equipment.

Equipment in Monitored Low-Strength Units

Equipment in Unmonitored Low-Strength Units

Mobile Bridging Equipment Storage
NATO Stabllity Measure 3(d): For the purpose of the agreement, a definition of low strength units shall be agreed among the participants. The location of such units shall be declared and communicated to all CFE participants, along with information specifying the quantities. The TLIs in such units shall be subject to observation and monitoring to the same level of confidence as that for TLI stored in monitored storage sites (BASIC Sept. 1989).

NATO Stability Measure 3(d)(4): Participants may hold as many additional unmonitored low strength units as they desire, but equipment kept at such units shall be counted, solely for the purpose of this agreement, as being in active units (BASIC Sept. 1989).

NATO Stability Measure 4: Limitation and Monitored Storage of Bridging Equipment: For each group of states belonging to the same alliance, there shall be in active units in the area of application no more than 700 armored vehicle launched assault bridges. All armored vehicle launched assault bridges above 
the 700 AVLAB shall be placed in monitored storage. A maximum of 50 items of such equipment may only be removed from monltored storage in accord with the provisions for removal from monitored storage (BASIC Sept. 1989).

WARSAW PACT (ARTICLE XIII.5): They shall limit the armored vehicle launched bridges (BASIC Jan. 1990). Thus:

a. The state parties belonging to the same group of state parties shall hold no more than 700 armored vehicle launched bridged in active units in the area of application. Armored vehicle launched bridges exceeding this level shall be placed at permanent scorage sites;

b. A state party shall not remove from permanent storage sites simultaneously more than [to be supplied] armored vehicle launched bridges;

c. A state party shall not remove from permanent storage sites simultaneously more than [to be supplied] armored vehicle launched bridges if the stute party did not notify thereof at least 42 days in advance.

Exercise Size
WARSAW PACT (ARTICLE XII.1): They shall limit the scope and the number of military exercises (BASIC Jan. 199(1). Thus,

a. A state party or several state parties belonging to the same group of state parties shall not conduct military exercises exceeding at least one of the following levels: personnel, 40,000 ; combat aircraft, 400 ; combat helicopters, 150; battle tanks, 800; armored combat vehicles, 1,500; and artillery, 800;

b. A state party or several state parties belonging to the same group of state parties may conduct, as an exception, a military exercise involving no more than 75,000 troops no more than once in three calendar years, provided that notification of such an exercise is given no later than two calendar years before the exercise begins; 
c. A state party may conduct no more than two military exercises in a calendar year exceeding at least one of the following levels: personnel, 25,000 ; combat aircraft, 200; combat helicopters, 100; battle tanks, 400; armored combat vehicles, 750; and artillery, 400;

d. The state parties belonging to the same group of state parties shall not conduct simultaneously more than three exercises specified in paragraph c) in a calendar year; and

e. The state parties belonging to the same group of state parties may conduct not more than six military exercises specified in paragraph c) in a calendar year.

Military

Activity Constraints
The NATO Stabilizing measure, Stability Measure 5: Constraint on the Size of Military Activity, states that no participant shall conduct in the area of application any military activity involving more than 40,000 troops or 800 main battle tanks, if organized into a divisional structure or into at least two brigades/regiments, not necessarily subordinate to the same division, except as permitted in the following incidence (BASIC Sept. 1989):

- A participant may conduct one military activity exceeding the limits stated above within two years. Such an activity shall require prior notification to other participants at least 12 months before the activity is to be conducted. The notification shall include the information under paragraph 56 of the Stockholm Document supplemented by:

1. The planned area of the military activity, indicated by geographic coordinates and geographic features if appropriate.

2. The planned duration of the activity, indicated by projected start and end times.

3. The envisaged total number (rounded to the nearest hundred) of troops taking part in the military activity. For activities 
involving more than one participant, the host state will provide such information for each participant involved.

4. The planned level and designation of direct operational command under which the activity will take place.

5. For each participant, the number, type and designation of each ground formation unit down to the battalion or equivalent level whose participation is envisaged.

WARSAW PACT (ARTICLE XIII.8): Military activities covered by the provisions of the article shall be subject to notification and verification in accordance with the protocol on information and verification (BASIC Jan. 1990).

Transfers of TLI
NATO has not provided a proposal on provisions for transferring TLIs into and out of the area. NATO has stated that measures will be required for notification and monitoring, under appropriate circumstances to be worked out, of arrivals of main battle tanks, artillery pieces, armored troop carriers, land-based combat aircraft and land-based combat helicopters in the area of application. Exits will be taken into account to provide necessary assurance that the agreed ceilings under Chapter 1 will not be exceeded or circumvented (BASIC Jan. 1990).

WARSAW PACT (ARTICLE XII.4): They shall establish limits on transfers of the treaty-limited categories of conventional armed forces into the area of application or through it (BASIC Jan. 1990. Thus,

a. A state party or several state parties belonging to the same group of state parties shall not transfer into the area of application or through it personnel, combat aircraft of front tactical aviation, combat helicopters, battle tanks, armored combat vehicles and artillery, the number of which exceeds at least one of the following levels for [to be supplied] days (BASIC Jan. 1990):

- Personnel

- Combat aircraft

- Helicopters 
- Battle tanks

- Armored combat vehicles

- Artillery

b. A state party or several state parties belonging to the same group of state parties, in accordance with the protocol on Information and Verification, shall notify no later than 42 days in advance of planned transfers of personnel, combat aircraft of front/tactical aviation, combat helicopters, battle tanks, armored combat vehicles, and artillery into the area of application or through it, if their number exceeds at least "one of the following levels (BASIC Jan. 1990):

- Personnel

- Combat aircraft

- Helicopters

- Battle tanks

- Armored combat vehicles

- Artillery

Entry and Exit Points

Restructuring of Conventional Armed Forces c. Transfers of the treaty-limited categories of conventional armed forces into the area of application or through it shall be conducted via permanent or temporary entry/exit points specified in [to be supplied] or in subsequent data and notifications (BASIC Jan. 1990).

WARSAW PACT (ARTICLE XIII.7): They shall restructure of the treaty-limited conventional armed forces. Thus:

The state parties shall implement measures to restructure their treaty-limited conventional armed forces and to reduce their offensive capabilities.

As priority measures in this direction the participants shall:

a. Limit military activities and the number of highly mobile attack formations and units 
(aviation, tank, airborne, air assault, and air. mobile) in forward groupings;

b. Withdraw bridging equipment from forward groupings;

c. Change accordingly the permanent location of land force units equipped with attack weapons (combat helicopters, tanks, artillery with a caliber of $100 \mathrm{~mm}$ and above, including Multiple Launch Rocket System [MLRS]).

Limit

New Bases

Limits on

Production

Coinbat

Aircraft and Helicopters

Information on Military Spending
The state parties shall refrain from establishing new and expanding the existing military bases (large military installations) outside of their national territories in the area of application (BASIC Jan. 1990).

NATO has stated that measures will be required to provide necessary assurance that the agreed ceilings under Chapter 1 are not exceeded or circumvented through the disposition in the zone of newly produced main battle tanks, artillery pieces, armored troop carriers, land-based combat aircraft and landbased combat helicopters (BASIC Sept. 1989).

The Warsaw Pact working paper on limitations of combat aircraft states that appropriate stabilizing measures shall apply to combat aircraft and combat helicopters (BASIC Nov. 1989).

WARSAW PACT (ARTICLE XIII.6): They shall provide information on the volume and structure of military spending (BASIC Jan. 1990). Thus:

a. The state parties shall annually provide information on the volume and structure of military spending, taking into account the scheme worked out under the auspices of the United Nations;

b. The state parties shall provide information on the relevant changes in military spending caused by reductions of the treaty-limited conventional armed forces in the area of application.

\subsection{VERIFICATION MEASURES}

NATO (ARTICLE XIII): General Verification (BASIC April 1990). 
General

1. For the purpose of ensuring verification of compliance with the provisions of this treaty, each state party shall have the right to conduct and the obligation to accept, within the area of application, an agreed upon number of on-site inspections at declared and nondeclared sites in accordance with the protocol on Inspections and of aerial inspections.

2. Each state party shall also have the right to conduct and the obligation to accept inspections:

a. To verify the holdings of equipment and personnel limited by this treaty.

b. To monitor the process of destruction of battle tanks, armored combat vehicles, artillery, combat aircraft, and combat helicopters carried out at destruction facilities in accordance with Article [to be supplied] of this treaty and the protocol on destruation.

c. To monitor the re-categorization of helicopters, where appropriate.

d. To monitor the reduction of U.S. and Soviet stationed personnel pursuant to Article VII of this treaty.

e. To monitor designated permanent storage sites.

f. To monitor stability measures and movements of TLE into the area of application.

3. Each state party shall also have the right to conduct, and the obligation to accept within the area of application, an agreed upon number of overflights.

a. The number of such overflights that each state party shall be obliged to accept is specified in the protocol on inspections. 
b. The obligation to accept such overflights shall be additional to the obligation that the state parties have accepted under the provisions of the Open Skies Treaty of which they are signatories.

c. To the greatest extent possible, the modalities for the conduct of these overflights shall be the same as those set out in paragraphs [to be supplied] of the Open Skies Treaty, a copy of which is annexed to this treaty.

4. Placeholder for the right to apply and the obligation to accept other measures of verification, including the placement and use of mechanical devices for verification purposes.

5. No state party shall exercise the rights stated in paragraphs 2,3 , and 4 of this article in respect of state parties who belong to the group of state parties of which it is a member in order to elude the objertives of the verification regime and especially of the dispositions set forth in paragraph 8 of this article.

6. In the case of an inspection conducted jointly by several state parties, one of them shall be responsible for the execution of the provisions of this treaty.

7. Within the area of application, each state party shall have the right to concluct each year up to a specified number of team days of onsite inspection and up to a specified number of aerial inspections on the territory of other state parties. These active quotas are to be determined among the members of the same group. Unused quotas may be transferred to other members of the same group, but no state party will be obliged to accept more than $50 \%$ of its passive quota of inspections in each calendar year from the same state party. 
8. Each state party shall accept each year up to ar agreed upor number of team days of inspections and up to an agreed upon number of aerial inspections of its territory within the area of application. These numbers will be determined in accordance with the dispositions set forth in paragraphs [to be supplied] of the protocol on inspections.

The Warsaw Pact working paper (paragraph II.1) states that implementation of verification measures shall be the responsibility of each sovereign state party to the treaty. Verification may be implemented both on a national basis, i.e., independently by each state party to the treaty, and on a collective basis, i.e., with participation of several states belonging to the same alliance (BA.SIC Nov. 1989).

- The major verification tasks will be:

-- Validation of data relating to the treatylimited categories of conventional armed forces;

-- Verification of reductions; and

-- Verification of compliance with agreed upon levels of remaining treaty-limited categories of conventional armed forces and other provisions for the life of the treaty.

- The principal verification methods can be:

- Ground and aerial on-site inspection with no right of refusal;

- Continuous or regular inspections at agreed upon sites, including at temporary and permanent entry/exit points to and from a region, to and from the area of application; and

-- Use of national (multinational) technical means of verification, including those developed on the basis of international cooperation. Use of concealment measures that would impede verification by technical 
means shall be prohibited. The obligation not to use concealment measures would not cover armaments and personnel concealment practices associated with normal training and operations of equipment. Inspection regime, composition of inspection teams, their rights and duties, technical equipment, material support and financing, quota inspection procedure are to be agreed upon at the negotiations.

\section{Inspections and Monitoring \\ Inspection \\ of \\ Declared \\ Sites}

\section{Baseline Inspection}

\footnotetext{
Inspection

Length
}

WARSAW PACT (ARTICLE XVII): Text to be submitted.

NATO Verification Measure 1: All sites declared under the terms $4(\mathrm{~b}), 4(\mathrm{c})$ and $4(\mathrm{e})$ of the provisions for exchange of information shall be subject to inspection at short notice with no right of refusal and in accordance with the provisions of the general considerations for inspection listed below (BASIC Sept. 1989).

The Warsaw Pact working paper (paragraph II.4) states that to verify residual levels, the participants shall have the right to conduct inspection at any site specified in the information provided in an agreed format to verify the number of armaments and personnel held there (BASIC Nov. 1989).

The NATO working paper states that the intensity of inspections shall be greater during the initial $(x)$ month period after the entry into force of the treaty in order to facilitate the initial validation of the baseline data. The armed forces of participants will not be required tio suspend out-of-garrison training (stand-down) for the entire period of the baseline inspection (BASIC Sept. 1989).

The Warsaw Pact working paper (paragraph II.2) states that verification of data provided on signature and on coming into force of the treaty shall be implemented on a random basis by conducting on-site inspections within agreed upon inspection quotas and by other agreed upon methods, ith verification of these data to be completed before the beginning of the reduction process (BASIC Nov. 1989).

NATO Verification Measure 1(d) states that within the quota established, the participant sending the inspection teams will be free to decide for how long each team will stay on the territory of the inspected state and which declared sites it will 
Personnel

Strength

\section{Residual}

Levels

\section{Compliance}

with the

Established

Levels

\section{Activities \\ of Forces \\ Remaining \\ After the \\ Agreed upon \\ Levels are \\ Met}

visit during this period, but no team may stay more than (y) days at any one site. While it is understood that the full inspection quota must be capable of being fulfllled, there will be a limit to the number of inspection teams that a participant must receive at any one time (BASIC Sept. 1989).

NATO Verification Measure 1(e) states that provisions will be required for the application of the inspection regime to the information provided for U.S. and Soviet personnel based on the territory of other participants in the area of applleation (BASIC Sept. 1989).

The Warsaw Pact working paper (paragraph II.4) states that the partiolpants belonging to one alliance may within [to be supplied] days conduct on-site inspections to verify residual levels of the armed forces and armaments of the participants belonging to the other alliance according to the agreed upon quota. For the conduct of such inspection there shall be a quota for each group of states belonging to the same alliance. One inspection team may visit [to be supplied] sites in succession, the visiting time at each site shall be $11 \mathrm{mited}$ to [to be supplied] days (BASIC Nov. 1989).

The Warsaw pact working paper (paragraph II.5) states that to verify compliance with established levels, the following measures shall be implemented (BASIC Nov. 1989):

a. Inspections with no right of refusal in accordance with agreed upon quotas at sites specified in information provided in the agreed upon format.

b. Inspection to confirm the cessation of use of a site for deployment of treaty-limited tems of conventional armed forces upon notification thereof.

The Warsaw Pact working paper (paragraph II.7) states that the participants shall have the right to verify implementation of provisions concerning constraints on military activities in the area of application and its individual regions as provided for stabilization measures, on transfers of troops and conventional armaments into the area of application, in the area of application or transit transfers, including by establishment of entry/exit points (BASIC Nov. 1989). 
Undeclared Sites

\section{Monitored \\ Storagg \\ Sites and \\ Monitored \\ Low-Strength \\ Units}

\section{MONITORING REDUCTIONS}

Destruction
The Warsaw Paot working paper (paragraph II.7) states that verifloation of activities of conventional armed forces will be implemented by on-site inspeotlons pursuant to an agreod upon quota as well as by national (multinational) technical means of verifleation (BASIC Nov. 1989).

Warsaw Pact working paper (paragraph II.7) states that the particlpants shall also rave the right to verlfy temporary excesses of cellings for troops and armaments ralated to routine replacement of troops or other agreed upon reasons for excess (BASIC Nov. 1989).

NATO Verification Measure 2: Particlpants shall also have the right to request inspection of other sites on the territory of another participant in the area of application. While there would be a right of delay and ultimate refusal, these should be kept to a minimum. In any case, an obligation to attempt, in good falth, to satisfy the concerns of the party requesting an inspection at an undeclared site will lemain. Quotas for such inspections could be based on the same cilterla as those for declared sites, but differently weighted.

Particlpants will agree on deralled modalltes to govern such inspections, taking into account the provisions of general considerations (BASIC Sept. 1989).

NATO Veriflcation Measure 3 states that in addition to the provisions of Measure 1, these sites and units will be subject to appropriate monitoring measures to be agreed upon (BASIC Sept. 1989).

The Warsaw Pact working paper (paragraph II.8) states that measures to verify armaments in permanent storage will be agreed upon (BASIC Nov. 1989).

NATO (ARTICLE XII.1): The reduction to achleve the numerical limitations set forth in Articles IV, $V$, and VI of this treaty shall be accomplished by means of destruction. The conventional armaments subject to destruction in accordance with the obligations of this treaty are main battle tanks, artillery pleces, armored troop carriers, combat alrcraft, and combat helicopters (BASIC Jan. 1990). 


\section{Destruction}

Notifications

Military

Equilibrium

Time Limit

Persoinnel

Reduction

Elimination

Methods

Locations

for Personnel

Reductions
NATO (ARTICLE XII.2): All destruction of equipment above g.greed upon limits shall be notlfled and be subject to on-site monitoring without quotas or right of refusal and to other measures to be speclfled (BASIC Jan. 1990).

WARSAW PACT (ARTICLE XIV.1): The state partles acting within their respective groups of state parties shall reduce the treaty-1lmited categories of conventional armed forces in such a manner that in all stages of the reductions, the overall milltary equilibrium between the groups of state parties shall not be upset and the security of any state party shall not be undermined (BASIC Jan. 1990).

WARSAW PACT (ARTICLE XIV.2): The state parties shall reduce the treaty-limited categories of conventional armed forces to the cellings specifled in Articles VI-X of this treaty In accordance with the protocol on reduction within three years from the time of entry into force of this treaty (BASIC Jan. 1990)。

WARSAW PACT (ARTICLE XIV.3): The reductlon of personnel shall be implemented through (BA.SIC Jan. 1990):

a. Demobllization and

b. Relocation from the area of application.

NATO proposed that reduction of U.S. and Soviet stationed personnel shall be completed according to an agreed upon timetable within a period of $(x)$ months and the reductions shall be subject to monitoring by any of the participants.

WARSAW PAC'T (ARTICLE XIV.4): The ellmination of the treaty-limited categorles of conventional armaments shall be Implemented through (BASIC Jan. 1990);

a. Elimination and

b. Conversion.

WARSAW PACT (ARTICLE XIV.5): The reduction of personnel shall be implemented at the following (BASIC Jarı, 1990):

a. At permanent locations of formations and units;

b. At temporary disbandment points; and

c. At points of exit from the area of application. 
Reduction

Sites

\section{Reduction \\ Site \\ Listings \\ Reduction Completion \\ TLE Replacement, Modernization, New Techno- logles}

Monitoring Call-Up of Reserves
WARSAW PACT (ARTICLE XIV.6): The leduction of the treaty-limited categories of conventional armaments shall be Implemented (BASIC Jan. 1990):
a. At [to be supplied] sites of ellinination;
b. At [to be supplled] sites of conversion; and
c. At points of exit from the area of application.

WARSAW PACT (ARTICLE XIV.7): Sites of reduction of the treaty.limlted categorles of conventional armed forces shall be listed when providing data and/or in subsequent notiflations (BASIC Jan, 1990).

WARSAW PACT (ARTICLE XIV.8): Personnel and conventional armaments listed in Article I of this treaty shall be deemed reduced after the implementation of the procedures envisaged be the protocol on reduction (BASIC Jan. 1990).

NATO (ARTICLE XV.1): Subject to the provisions of th!s treaty, main battle tanks, artillery pleces, armored troop carriers, combat alrcraft and combat hellcopters may be replaced within the area of application (BASIC Jan. 1990).

NATO (ARTICLE XV.2): Subject to the provisions of this treaty, such equipment may be modernized within the area of application (BASIC Jan. 1990).

WARSAW PACT (ARTICLE IV): New types of combat aircraft of front/tactical aviation, combat hellcopters, battle tanks, armored combat vehicles, and artillery and modifications of such equipment capable of carrying out the missions performed by the types of the treaty-limited categorles of conventional armaments, listed in the Annex on the Types of the TreatyIimited Categories of Conventional Armaments, adopted for service by the state parties and located in the area of application, shall be subjected to limitations provided for in Articles VI through $\mathrm{X}$ of this treaty (BASIC Jan. 1990).

NATO VERIFICATION MEASURE 5: Participants shall also have the right to monitor, under appropriate conditions, the call-up of reservists (Stabllity Measure 1), the movements of reserves from one location to another (Stabillty Measure 2), and the size of military activities (Stabillty Measure 5) (BASIC Sept. 1989). 
Aerial Inspection

Verifying Helicopter and Airoraft Limits
NATO Verifloation Measure 6: A CFE regime will include provisions for aerlal inspection. Modallties and quotas require Purther study. The partles shall consider cooperative measures to enhance aerial inspection (BASIC Sept. 1989).

NATO Verlfication Measure 7: The possibllity of additional measures to deal specifically with the verification of combat airoraft and combat hellcopters, such as identification by number or perhaps tagging of aircraft and helicopters permanently land based in the ATTU area, requires further study (BASIC Sept. 1989).

Paragraph 6 of the Warsaw Paot working paper on limitations of combat alroraft states that for the purpose of assuring compliance with the provisions of the treaty concerning alroraft and combat hellcopters the particlpants shall take appropriate verification measures. Specific pioposals on such verification measures will be submitted additionally (BASIC Nov. 1989).

The Warsaw Pact working paper (paragraph II.6) states that national (multinational) technical means of verification, onsite land and aerial inspections with no right of refusal, and inspection teams placed by agreement at air bases or airflelds may be used to verify treaty-limited aviation (BASIC Nov. 1989).

- For the purpose of creating favorable conditions for the use of national (multinational) technical means of verification for the duration of their operation, aircraft at airflelds can be placed in the open (rolled out of hangars and shelters) at a prior request and pursuant to agreed quotas. The request shall be sent [to be supplled] In advance.

- Inspection teams shall have the right of free access to aircraft located at the inspected airfleld, and the right to examine aircraft, including weapons systems. To verify compliance with the established levels, inspectors may use various methods of aircraft identification. Inspection can cover simultaneously [to be supplied] airfield by agreement. Periodically, aerial general survey inspection on a quota basis may be conducted. 
Entry and Exit Points

National or Multinational Technical Means
- Inspection teams placed by agreement at alr bases or alrflelds shall be provided with an opportunity to use, in their work and in an agreed upon manner, optical and electronic means of observation.

The Warsaw Pact working paper states that to verify the reductions, the achievment of agreed upon levels, and consequent complianoe with them as well as movements (transfers) of troops, there shall be established entry/exit points both along and inside the regions and, in general, in the area of application, at rallway junctions, ports, air force bases and air flelds (BASIC Nov. 1989).

NATO (ARTICLE XIV.1): For the purpose of ensuring verification of compliance with the provisions of this treaty, each party shall have the right to use, in addition to the procedures included in Article XIII, national technical means at its disposal in a manner consistent with generally recognized principles of international law (BASIC Jan. 1990).

NATO (ARTICLE XIV.2): A party shall not interfere with the carrying out of any inspection or monitoring activity provided for in Article XIII of this treaty, with the national technical means of verlfication of another party operating in accordance with paragraph 1 of this article, or with any other agreed upon measure of verification (BASIC Jan. 1990).

NATO (ARTICLE XIV.3): A party shall not use concealment measures that impede verification of compliance with the provisions of this treaty by any inspection or monitoring activity provided for in Article XIII of this treaty or by national technical means of verification. The obligation not to use concealment measures does not apply to cover or concealment practices associated with normal training, maintenance, or operations (BASIC Jan. 1.990).

NATO (ARTICLE XIV.4): For the purpose of enhancing observation by national technical means of verification, each party shall implement cooperative measures. Such measures shall include (BASIC Jan. 1990): 


\subsection{TREATY ORGANIZATION}

\subsubsection{Joint Consultative Group}

NATO (ARTICLE XVI): To promote the objectives and implementation of the provisions of this treaty, the parties will establish a Joint Consultative Group in the framework of which they will resolve ambiguities, address questions of compliance, and promote the treaty's viability (BASIC Jan. 1990).

WARSAW PACT (ARTICLE XVIII.1): The state parties shall settle all disputes or ambiguous situations arising in the course of implementation of this treaty by conducting consultations between the state parties concerned in accordance with the provisions on the protocol on consultations (BASIC Jan. 1990).

WARSAW PACT (ARTICLE XVIII.2): To ensure the viability of this treaty and to promote its implementation, the state parties shall establish a joint consultative body. Regulations of the joint consultative body shall be contained in annex [to be supplied] to this treaty. The state parties agree that meetings of the joint consultative body shall be convened at the request of any one of the state parties for the purposes of the following (BASIC Jan. 1990):

a. Settling disputes that have not been resolved in accordance with the procedure envisaged in paragraph 1 of this article as well as solving other questions relating to compliance with the obligations assumed under this treaty, and

b. Agreeing upon measures as may be necessary to improve the viability and effectiveness of this treaty.

\subsubsection{Treaty Review}

\section{Review of Implemen- tation}

Review Conference
WARSAW PACT (ARTICLE XVIII.3): The depositary(ies) of this treaty shall convene a conference of duly authorized representatives of the state parties to review the operation of this treaty (BASIC Jan. 1990).

WARSAW PACT (ARTICLE XVIII.4): In case a situation arises that substantially affects the stability and security in Europe and influences the compliance with the provisions of this 


\section{Amendments}

Five-Year

Review

Ratification treaty, the depositary(ies) shall, at the request of any state party, convene no later than [to be supplied] days after the receipt of such a request, a conference of state parties in order to review the operation of this treaty and, if necessary, to revise it (BASIC Jan. 1990).

WARSAW PACT (ARTICLE XVIII.5): Any state party may propose amendments to this treaty. The text of each amendment shall be submitted to the depositary(ies), which shall circulate it to all state parties and, if necessary, convene a conierence for discussion and approval. Amendments approved by all state parties shall enter into force in accordance with the procedures governing the entry into force of this treaty (BASIC Jan. 1990).

NATO (ARTICLE XIX.1): Any party may propose ainendments to this treaty or to its annexes of protocols. The text of proposed amendments shall be submitted to the depositary(ies), which shall circulate them to all parties. Thereupon, if requested to do so by five or more of the parties, the depositary(ies) shall convene a conference to consider such amendments (BASIC Jan. 1990).

NATO (ARTICLE XIX.2): An amendment to this treaty must be approved by all parties to the treaty. An amendment so approved shall enter into force in accordance with the procedures set forth in Article XX governing entry into force of this treaty (BASIC Jan. 1990).

NATO (ARTICLE XIX.3): As provided for in Article XVI, the Joint Consultative Group may agree upon such implementing and other measures as may be necessary to improve the viability and effectiveness of this treaty. Such measures shall not be deemed amendments to this treaty (BASIC Jan. 1990).

NATO (ARTICLE XIX.4): Five years after entry into force of this treaty, and at five-year intervals thereafter, the parties shall together conduct a review of the operation of this treaty, unless requested to do so sooner by five or more of the parties (BASIC Jan. 1990).

NATO (ARTICLE XX.1): This treaty, including the annexes and protocols referred to in Article I, all of which forin an integral part hereof, shall be subject to ratification in accordance with the constitutional procedures of each party. Instruments of ratification shall be deposited with [to be supplied] hereby designated the depositaries (BASIC Jan. 1990). 
Depository

Depository Duties

Entry into Force

Registered
WARSAW PACT (ARTICLE XXIII.1): This treaty shall be subject to ratification. Instruments of ratification shall be deposited with the governments of [to be supplied] which is/are hereby designated the depository government(s) (BASIC Jan. 1990).

WARSAW PACT (ARTICLE XXIII.2): The depositary governments shall promptly inform all states parties of the date of deposit of each instrument of ratification and of receipt of other notices (EASIC Jan. 1990).

NATO (ARTICLE XX.2): This treaty shall enter into force [to be supplied] days after instruments of ratification have been deposited by the Kingdom of Belgium, the Peoples Republic of Bulgaria, Canada, the Czechoslovak socialist Republic, the Kingdom of Denmark, France, the German Democratic Republic, the Federal Republic of Germany, the Hellenic Republic, the Republic of Hungary, the Republic of Iceland, the Italian Republic, the Grand Duchy of Luxembourg, the Kingdom of the Netherlands, the Kingdom of Norway, the Polish People's Republic, the Portuguese Republic, the Socialist Republic of Romania, the Kingdom of Spain, the Republic of Turkey, the Union of Soviet Socialist Republies, the United Kingdom of Great Britain and Northern Ireland, and the United States of America, hereafter referred to as the parties (BASIC Jan. 1990).

1. This treaty, of which the English, French, German, Italian, Russian, and Spanish texts are each equally authentic, shall be deposited in the archives of the depositary(ies).

2. This treaty shall be registered by the depositary(ies) pursuant to Article 102 of the Charter of the United Nations.

WARSAW PACT (ARTICLE XXIII.3): This treaty shall enter into force [to be supplied] after the deposit of the last instrument of ratification (BASIC Jan. 1990).

WARSAW PACT (ARTICLE XXIII.5): This treaty shall be registered pursuant to Article 102 of the Charter of the United Nations (BASIC Jan. 1990). 


\subsection{GENERAL INSPECTION MODALITIES}

Implementation of CFE verification provisions and judgment about treaty compliance will be the responsibility of each sovereign state party to the treaty, but treaty provisions should not impede whatever cooperative arrangements allies may choose to make in the exercise of those responsibilities. The three major verification tasks will be: (1) validation of baseline data, relating to the forces to be reduced, (2) monitoring of reductions, and (3) confirmation of compliance with agreed upon residual force limits and other provisions for the life of the treaty (BASIC April 1990).

\subsubsection{Inspection and Monitoring Responsibilities}

NATO proposed that no state shall exercise inspection rights on the territory of other parties who belong to the same treaty of alliance. Each inspection or monitoring team shall be the responsibility of one state. That state may include representatives of other members of the alliance to which it belongs on its inspection or monitoring team if it chooses. In conducting on-site inspections, the inspecting party should be permitted access, entry, and unobstructed survey within the site that is being inspected, except at sensitive areas or points (BASIC Sept. 1989).

\subsubsection{Quotas}

NATO proposed that each participant shali be entitled to conduct an agreed upon number of inspections on the territory of other participants in the area of application. These active quotas are to be determined among the members of the same alliance. Unused quotas may be transferred to other members of the same alliance; however, no participant will be obliged to accept more than $50 \%$ of its passive quotas of inspections in each calendar year from the same participant. The number of inspections available for the participants in each alliance should be sufficient for effective verification (BASIC Sept. 1989).

\subsubsection{Escort}

NATO Verification Measure 1(b) states that each state shall be liable to receive on its territory an agreed upon quota of inspections. The quota will reflect relevant parameters. The quotas will be expressed in terms of the number of days that the inspection teams spend at the receiving state* (BASIC Sept. 1989).

\footnotetext{
See Intra-Alliance understanding.
} 


\subsubsection{National Weapon Ceilings}

The Warsaw Pact has proposed that all weapon reductions, including aircraft cuts, should be made on a country-by-country basis. (The Soviet proposal would cap, by weapon type, the number of arms each nation may keep in its arsenal).

- NATO officials admit this is the easiest approach both politically and legally. The CFE treaty is not being negotiated as a pact-topact treaty, but rather as an accord among 23 separate nations (BASIC Nov. 1989).

- France agrees with the Eastern proposal.

- NATO proposes that apportioning reductions is an internal matter for each alliance.

\subsection{CONFIDENCE-BUILDING MEASURES}

The third round of Confidence and Security-Building Measure (CSBM) talks, which were held in September 1989, focused on preparations for new military doctrine "SEMINARS" slated to begin in 1990. NATO has resisted demands by the WTO that naval and air forces be included in the CSBM talks. The neutral and nonaligned participants have brought: to the table a more modest request for exchange of data on naval forces. The U.S. said that these requests would open the door to further demands concerning naval forces (BASIC Nov. 1989).

\subsection{NONCIRCUMVENTION MEASURES}

Treaty Duration

Right of Withdrawal
NATO (ARTICLE XVIII.1): This treaty shall be of unlimited duration (BASIC Jan. 1990).

WARSAW PACT (ARTICLE XXIII.4): This treaty shall be of unlimited duration (BASIC Jan. 1990).

NATO (ARTICLE XVIII.2): Each party shall, in exercising its national sovereignty, have the right to withdraw from this treaty if it decides that extraordinary events related to the subject matter of this treaty have jeopardized its supreme interests. A party intending to withdraw shall give notice of its decision to withdraw to the depositary(ies), as well as to all othor parties, three months in advance of its withdrawal. Such notice shall include a statement of the extraordinary events the party regards as having jeopardized its supreme interests (BASIC Jan. 1990). 
WARSAW PACT (ARTICLE XXIII.6): Each state party shall, in exercising its national sovereignty, have the right to withdraw from this treaty if it decides that extraordinary events related to the subject matter of this treaty have jeopardized its supreme interests. It shall give notice to the depositary(ies) of its decision [to be supplied] days prior to the withdrawal from this treaty. Such notice must include a statement of the extraordinary events the state party regards as having jeopardized its supreme interests. In the event that a state party gives notice of its decision to withdraw from this treaty, the depositary(ies) no later than [to be supplied] days af ter the receipt of such a notice shall convene a conference of state parties in order to consider the effect of the withdrawal on this treaty (BASIC Jan. 1990).

NATO (ARTICLE XVIII.3): Each party shall, in particular, in exercising its national sovereignty have the right to withdraw from this treaty if another party were to increase its holdings in main battle tanks, artillery pieces, armored troop carriers, combat aircraft, or combat helicopters, as defined in Article II of this treaty, which are outside the scope of the limitations of this treaty, in such proportions as to pose an obvious threat to the balance of forces within the zone of application (BASIC Jan. 1990).

NATO (ARTICLE XVIII.4): In the event that a party gives notice of its decision to withdraw from this treaty, a conference of all of the other parties shall be convened not more than [to be supplied] days after receipt of such notice by the depositary(ies) in order to consider the effect of the withdrawal of this treaty (BASIC Jan. 1990).

Stable Environment

International Obligations
WARSAW PACT (ARTICLE XX.1): For the purposes of ensuring the viability and effectiveness of this treaty, the state parties shall not perform any actions leading to a disruption of the stable and secure balance of conventional armed forces between the two groups of state parties in the area of application, which constitute circumvention of the treaty (BASIC Jan. 1990).

WARSAW PACT (ARTICLE XX.2): The state parties shall not adopt any international obligations and shall not resort to any actions that would be contrary to the provisions of this treaty (BASIC Jan. 1990). 
Non-Parties

Further

Steps
WARSAW PACT (ARTICLE XXI): Nothing in this treaty affects any states that are not parties to it and their security interests or shall be interpreted as prejudicial to other international treaties previously concluded by the state parties (BASIC Jan. 1990).

WARSAW PACT (ARTICLE XXII): The state parties after the entry into force of this treaty shall promptly continue the negotiations with the purpose of an early achievement of agreement on further measures strengthening stability in Europe [further provisions to be submitted] (BASIC Jan. 1990).

\subsection{PROTOCOLS}

\subsubsection{NATO Protocol on Inspections (BASIC April 1990)}

Pursuant to and in implementation of the treaty between the parties on Conventional Armed Forces in Europe of (date), hereinafter referred to as the treaty, the parties hereby agree upon procedures governing the conduct of inspections provided for in Article XIII of the treaty.

Definitions

Inspected

Party
For the purposes of this protocol, the treaty, the protocol establishing and maintaining a data base and the protocol on destruction:

a. The term "inspected party" means the party to the treaty on whose territory an inspection is carried out in compliance with Article XIII of the treaty.

In the case of sites at which only a stationing party's TLE is present, this stationing party exercises, in compliance with the pertinent provisions of this protocol, the right and obligations of the inspected party as set forth in this protocol for the duration of the inspection within that site where its TLE is located.

In the case of sites containing TLE of more that one party, each such party exercises, each in respect of its own TLE, the rights and obligations of the inspected party as set forth in this protocol for the duration of that site where such TLE is located. 
Stationing

Party

Host

Party

Stationed

Forces

Inspecting

Party

Inspector

Inspection

Team

Escort

Team

Inspection

Site b. The term "stationing party" means the party to the treaty stationing TLE outside of its own national territory in the area of application.

c. The term "host party" means the party to the treaty receiving on its territory and in the area of application TLE stationed by another party belonging to the same group of parties.

d. The term "stationed forces" means conventional armed forces, or treaty-limited equipment, belonging to a party, stationed within the area of application on the territory of another party belonging to the same group of parties.

e. The term "inspecting party" means the party to the treaty who is responsible for the conduct of an inspection.

f. The term "inspector" means an individual designated by one of the parties to carry out an inspection and included on that party's arcepted list of inspectors in accordance with the provisions of Section III of this protocol.

g. The term "inspection team" means the group of inspectors designated by the inspecting party to conduct a particular inspection; this may include members from other parties belonging to the same group of parties, the inspection team may be split into sub-teams.

h. The term "escort team" means the group of individuals assigned in respect of a particular site by the inspected party to accompany and to assist, as required, the inspectors as well as to assume other responsibilities, as set forth in Section VI of this protocol. In the case of inspection of a stationing party's TLE, this group shall also include individuals assigned by the stationing party.

i. The term "inspection site" means an area, location, or facility at which an inspection is carried out. 
Declared

Site

Nondeclared

Site

Specially

Designated

Storage Site

Sensitive

Point:

Point

of Entry j. The term "declared site" means a site at which TLEs and AVLABs, as defined in Article [to be supplied] of the treaty, are declared to be located, are regularly or periodically declared present, or were present after [to be supplied]. A declared site consists of all territory forming an integral part of an installation, such as an airfield and other facilities, including TLE-related firing ranges, unit training areas, rail loading facilities, and maintenance and storage area. Declared sites shall be appropriately identified in the data exchange annex.

k. The term "nondeclared site" means any location other than both declared sites and locations of activities notified under stabilizing measures that might be used to violate or circumvent the obligations of the treaty, and which can be inspected under the provisions of Section VIII of this protocol.

1. The term "specially designated storag'e site" means [to be supplied].

$m$. The term "sensitive point" means any structure or location that has been designated to be sensitive by the escort team and to which access or overflight could be delayed, limited, or refused.

n. The term "point of entry" (POE) means the ground border crossing point, airport, or other area designated by the inspected party through which duly nutified personnel of an inspecting party gain authorized access to the territory on which an inspection is to be carried out.

Team

Days

Passive Quotas o. The term "team day(s)" means the 24 hours following the arrival of an inspection team at the point of entry and every following 24 hours or fraction thereof.

p. The term "passive quota" means the total number of team days of inspection each party is liable to receive on its territory on the aren of application within a specified period. 
Active

Quotas

Baseline

Validation

Period

Aircrew
Member

Airbase

\subsubsection{General Obligations (BASIC April 1990)}

a. For the purpose of ensuring verification of compliance with the provisions of the treaty, each party, as appropriate, shall facllitate inspection by the inspecting party pursuant to this protocol.

b. In the case of TLE stationed in the area of application but outside the national territory, the host party and the stationing party shall jointly ensure the respect of the rights and obligations of this protocol. The stationing party shall be fully responsible for the treaty obligations with respect to its TLE stationed on the territory of the host party.

c. The escort team shall be placed under the responsibility of the inspected party. In the case of sites at which only a stationing party's TLE is present and are under this party's command, the escort team shall be placed under the responsibllity of a representative of the stationing party for the duration of the inspection within that site where the 
Inspection

Team

Quota

Acceptances

Inspection stationing party's TLE Is located. In the oase of sites containing TLE of both the host party and the stationing party, the escort team shall Include representatives from both parties when TLE belonging to the stationing party is actually inspected. During the Inspection within the site, the host party shall exercise the rights and obligations of the inspected party with the exception of those rights and obligations related to the inspection of the TLE belonging to the stationing party, which will be exercised by this stationing party.

d. Inspection teams and sub-teams shall be under the control and responslbility of a representative of the inspecting party.

e. No party shall be obllged to accept mol'e than $50 \%$ of its passive quota of inspections in a calendar year.

f. Each inspection team shall spend no more than two days at any one inspection site, and no more than 10 days continuously on the territory of the inspected party. Within the restrictions above, parties sending teams of inspectors shall be free to decide for how long each team will stay on the territory of the inspected party and which sites each team will visit during this period.

g. Travel expenses between the home state and the point(s) of entry shall be borne by the inspecting party. The cost of receiving an inspection shall be incurred by the inspected party and, where appilcable, the stationing party, as agreed upon botween the parties.

h. Each party shall have the right to conduct Inspections within the area of application on the territory of other partles belonging to the other group of parties. It shall be the responsibility solely of each group of parties to determine the allocations of such inspections for each party within its group. Each party shall notify all other parties of its active quota of inspection for the following year on 
15 December each year. Subjeot to the limitation In paragraph [to be supplied] of this section, each party shall have the right to transfier part or all of its Inspentions to any other party or partles within lts group of partles.

Quota

Type

Quota Formula
1. Each party with terrltory within the area of applloation shall be obliged to acoept Inspections within its territory, in a number taking acoount of the number of TLE notifled as present on it and its geographleal size. These Inspections may be of declared and of nondeclared sites. No more than lto be supplied] percent of them may be of nondeolared sites.

j. The formula for calculating the number of inspection days that each party with territory within the area of appllcation must accept shall be as follows:

- Each party shall accept a standard minimum obligation of three Inspection days per year;

- Each party shall accept one inspection day for every 100 combat alreraft and combat hellcopters, as defined in Article [to be supplied] of the treaty, which it, or any other party, has notifled in the data exchange of the previous 15 December as based on its territory;

- Each party shall accept one inspection day on its territory for every 300 tanks, ACVs and artillery pieces, as defined in Artlole [to be supplled] of the treaty, which 1t, or any other party, has notifled in the data exchange of the previous 15 December as based on its territory; and

- Each party shall accept one Inspection day for each $50,000 \mathrm{~km}$ of 1 ts territory within the area of application. 
k. Each party shall be llable to accept the total number of inspection days calculated by the above formula during the baseline validation perlod, as defined in Article IX of the protocol. Each party shall thereafter be liable to accapt the total number of inspection days caloulated by the above formula during the year following completion of the baseline validation period and during each subsequent year. No party may be obliged to accept on its territory simultaneously a number of inspection teams greater than $2 \%$ of the number of inspection days calculated for it under paragraph $(x)$ above for that year. No party shall be requlred to acoept more than six simultaneous Inspections of its stationed forces within the area of application during the baseline validation period, and four such Inspections during the post-baseline perlod.

\subsubsection{Requirements (BASIC April 1990)}

Inspector

Designation

Inspector

Citizenship

Inspector

Notification

List

Inspector

List:

Approval a. Inspections conducted under this treaty shall be carried out by inspectors designated in accordance with paragraphs (c) and (d) of this section.

b. Inspectors shall be cltizens of the inspecting party or of other parties belonging to the inspectirig party's group of parties.

c. At entry into force of the tragty, each party shall provide to the other parties lists of proposed inspectors who will carry out inspections pursuant to paragraphs [to be supplied] of Article [to be supplied] of the treaty. This list shall contain at any time no more than 250 individuals.

d. Each party shall review these lists proposed by parties not belonging to its group of parties. A party may request, without right of refusal, deletion from lists of any names on them. Reasons for the deletion shall be provided. If an Individual has been declared "persona non 
gratal by a party, or has been convicted of a oriminal offense according to the law of a party, these shall be adequate reasons for requesting deletion of his name from the list.

Inspector

List

Amendment

Inspector

Documents

Inspector

Privileges

ar.d

Immunities

\section{Aircraft}

Clearance e. Each party shall have the right to amend its 1ists. New inspectors shall be designated in the same manner as set forth in paragraphs (c) and (d) of this section.

f. Parties shall ensure the timely provision of such visas and other documents to each individual as required to ensure that such personnel may enter and remain in the territory of the party in which an inspection site is located throughout the individual's presence in that territory for the purpose of carrying out inspection activities in accordance with the provisions of this protocol.

g. To exeroise their functions effectively, inspectors and aircrew shall be accorded, throughout their presence, privileges and immunities in accordance with the Vlenna Convention of Diplomatic Relations,

h. Within [to be supplied] days after entry into force of the treaty, each party shall inform the other parties of the standing diplomatic clearance number for the aircraft of the party transporting inspectors and equipmerit necessary for inspection into and out of the territory of the party in which such an inspection is located. Aircraft routings to and from the designated point(s) of entry shall be along established international airways or other routes that are agreed upon by the parties as the basis for such diplomatic clearance. Inspectors may use scheduled commercial flights for travel to those points of entry that are served by airlines. The provisions of this paragraph relating to diplomatic clearance numbers shall not apply to such flights. 


\subsubsection{Notification of Intent to Inspect (BASIC April 1990)}

Inspection

Notification

Acknowledg-

ment

a. Parties shall notify intention to carry out inspections to the inspected party through diplomatic channels in an agreed upon format in accordance with Article XVII of the treaty. In the case of inspections of stationed forces, the notification, with the specification of the forces to be inspected, is to be sent simultaneously both to the inspected party and to the stationing party.

b. The notification shall contain full details of the inspection team and aircrew. It will indicate the desired POE, desired time and means of arrival at the POE, the state/military district/area to be inspected, language, the likely number of sequential inspections, and any other data required to process the entry of the personnel and means of transportation into the POE.

c. The parties notified under (a) above must acknowledge receipt within two hours. The inspection team shall be permitted to enter the territory of the inspected party within 36 hours after the issuance of a notification of an inspection.

d. Flight plan(s) must be rendered [to be supplied] hours before the planned time of entry into the inspected state.

\subsubsection{Procedures upon Arrival at Point of Entry (BASIC April 1990)}

Times a. When the inspection team arrives at the point of entry, it will be met by the escort team. At the time indicated in the notification, but no later than 16 hours after the arrival, the inspection team chief will declare the first site to be inspected. Inspection of any subsequent site requires notification of the inspected party at the end of the preceding inspection. The time between the declaration of the site to be inspected and the arrival at 
the site to be inspected must not exceed six hours. The time between the declaration of the next site to be inspected and the arrival at this site must also not exceed six hours. If necessary, the inspected party will provide appropriate quarters and meals at the point of entry.

b. Proredures will be outlined for the clearance of team and equipment.

c. Procedures will be outlined for the provision of food, accommodations, and medical care for inspertors and aircrew.

d. Procedures will be outlined for the provision of fuel, servicing and security for aircraft.

e. Procedures will be outlined for onward flight planning.

\subsubsection{General Rules for Conducting Inspections (BASIC April 1990)}

\section{Team}

Composition

Communications

Transportation a. An inspection team shall include a maximum of [information to be supplied] inspectors and may divide itself into up to [information to be supplied] subgroups. The inspecting party shall ensure the necessary linguistic ability for the team to be able to perform its task.

b. The inspection team shall have access to appropriate telecommunications equipment for the purpose of communicating with its embassy or other official mission or consular point located on the territory of the receiving State and for communication between subteams.

c. The inspected party shall transport the inspection team to the site to be inspected. The route and type of transport to and between sites shall be selected by the inspected party. The inspecting party may request a variation in the selected route. The inspected party will, if possible, grant such a request. 
Inspection

Start Time

Authorized

Equipment

Conduct of Inspection d. Each inspection shall start as soon as possible after the arrival of the inspection team at the point of entry and, in any case, within six hours of the designation of the site to be inspected, unless an extension is agreed between the inspection team and the head of the escort team. Arrival and ceparture times at the POE will be recorded and agreed by both the inspectors and the representatives of the inspected party.

e. Inspectors may use night-vision devices, binoculars, video, lap-top computers, still cameras (including telephoto lenses), dictaphones, global positioning sets, generic navigation equipment, and other equipment as agreed upon. Inspectors may bring their own maps and charts and are to have access to any unclussified maps and charts of the inspected party at scales of $1: 50,000$ or $1: 100,000$. The inspectors may use their own vehicles and communication systems and equipment subject to the approval of the inspected party.

f. The inspecting party shall specify whether the inspection shall be conducted on foot, by cross-country vehicle, by helicopter or by any combination of these methods. The inspected party shall provide and operate the appropriate cross-country vehicles and helicopters. The inspected party has the option of providing a helicopter either at an inspection team's POE or at the indicated inspection locarion. Such aircraft should be large enough to carry at least two members of the inspection team, and team members will be allowed to take with them and use all devices ordinarily permissible. An inspection flight by helicopter must permit an unobstructed view of the ground, and due to the inspected party's ownership of the aircraft, circling and loitering would be permitted, as would the land, terrain permitting. The duration of such helicopter flights shall not exceed [to be supplied] hours. 


\section{Noninterference Rule}

Team

Safety

Team

Identifi-

cation

Violation of

Privileges and

of the Party

Immunity

Inspection

Report g. In discharging their functions, inspectors shall not interfere directly with ongoing activities at the inspection site and shall avoid unnecessarily hampering or delaying the operation of a facility or taking actions affecting its safe operation.

h. The inspected party shall be responsible for ensuring the safety of the inspection team and aircrew.

i. Inspectors shall wear some clear identification of their role.

j. Without prejudice to their privileges and immunities, inspectors and aircrew shall be obliged to respect the laws and regulations of the party on whose territory an inspection is carried out and shall be obliged not to interfere with the internal affairs of that party. In the event that the inspected party determines that an inspector or aircrew has violated the conditions governing the inspection activities set forth in this protocol, it shall so notify the inspecting party, which shall immediately strike the individual from the list of inspectors or inspection support groups. If at that time the individual is on the territory of the inspected party, the inspecting party shall be obliged to remove that individual from the country.

k. Upon completion of inspections, the inspecting party shall complete a report on the inspection in accordance with the provisions of section XIV of this protocol.

\subsubsection{Declared Site Inspections (BASIC April 1990)}

\section{Refusal or Delay}

a. Notifications of intent to inspect a declared site cannot be refused by the inspected party. Delays to the notified inspection may only be permitted for reasons of force majeure. 
Points of

Entry

Pre--Inspection

Briefing

Conduct of

Inspection b. Each party shall specify in the notifications of data it makes under Article XI of the treaty which point or points of entry should be recommended for the purpose of conducting an inspection, in respect of each of the declared sites on its territory. The point(s) of entry shall be such as to allow access to the declared site within six hours of declaration of the site to be inspected.

c. Immediately upon arrival at the site to be inspected, the inspection team shall be escorted to a briefing facility and given a preinspection briefing. This briefing shall last no more than one hour and shall include the following elements:

- Safety procedures at the inspection site;

- Presentation of a site diagram that will provide an accurate depiction of the perimeter, major buildings and roads, positions of TLE (and if appropriate, AVLABs and U.S. or Soviet stationed personnel), geographic coordinates and entrances, location of an administrative area for the inspection team (a small work area for storage of equipment, report writing, rest breaks and meals), and communications facilities; and

- Transportation on site.

The briefing will also include any changes to the numbers of equipment at the site and temporary locations of equipment, including training activities, down to battalion squadron levels. The inspection team shall not directly interfere with operations at the inspection site.

d. In conducting on-site inspections, the inspecting party shall be permitted access, entry, and unobstructed inspection within the site that is being inspected except at sensitive points to which access or helicopter overflight is normaily denied or restricted. The number and extent of theses points should be as 
TLE

Accountability

Declaration of Sequential Inspection

Country

Departure

Procedures limited as possible. When sensitive points are declared, a declaration must also be made whether TLE is contained therein and, if so, the number and type of TLE. If TLE is declared, the inspected party shall provide for the display of the TLE to the inspecting party. Shrouding of sensitive items shall be permitted. If the sensitive point is declared not to contain TLE, the inspected party shall take steps to satisfy the inspecting party that none is indeed present.

e. The party owning the inspected TLEs shall be responsible for the accuracy of the equipment numbers stated for a location. In the event that TLE present do not correspond with what was indicated in the previous data exchange associated with that site, the party owning that TLE must provide specific information on the origin, departure times from origin and transit routes taken to the inspected site, and time of arrival and projected stay at the inspected site.

f. Immediately upon completion of the inspection and the signing of the inspection report, or earlier if there is a nearby site that the inspection team wishes to inspect, the inspection team chief may declare a sequential inspection. From this point, the inspected party shall have six hours to transport the inspection team to the next site to be inspected. If no sequential inspection is declared, the inspection shall be deemed to have been completed once the inspection report has been signed and countersigned. The inspection team shall then be transported back as soon as possible to the POE and shall leave the territory of the inspected party no later than [to be supplied] hours after return to the POE.

g. The inspection team must depart the country in which it has been conducting inspections from the same point of eritry at which it entered. If an inspection team chooses to proceed to a point of entry in another country for the purpose of conducting further 
inspections, it may do so providing that the inspecting party has provided the necessary notifications in accordance with Article [to be supplied] of the treaty (BASIC April 1990).

\subsubsection{Nondeclared Site Inspections (BASIC April 1990)}

Notification

Site

Specifi-

cation

Point of

Entry

Designation

Inspection

Brief

Rejecting or

Accepting

Site Designa-

tion a. Each party may address a request to inspect a nondeclared site to a party of the other group of parties, in accordance with procedures contained in Section IV of this protocol.

b. The inspecting party shall specify in its request the area in which the site it wishes to inspect lies, but need not designate the precise location. The area will be defined by geographical coordinates with a maximum size of state/military district.

c. If no designated point of entry lies within six hours travel time of the specified area, the inspected party shall designate an additional point of entry as close as possible to the specified area or inside of it.

d. If the inspected party so wishes, the inspection team may be briefed on arrival at the point of entry on uny TLE, AVLABs or U.S./Soviet stations personnel temporarily located within the area specified, down to battalion and squadron levels. This briefing is to last no more than one hour. Safety procedures and administrative arrangements may also be covered in this briefing.

e. The inspection team shall designate the first site to be inspected within two hours of its arrival. The inspected party must accept or reject the designation being made. If it is accepted, access to the site must be allowed within six hours. Once access is granted, the rules for inspection of declared sites as regards sensitive points shall apply (Section VII paragraph iv). 
Site

Rejection

Reasonable

Assurance

Site Access

Non-inspection, Inspection

Day Calculations f. An inspected party may reject the designation of as site to be inspected on the following grounds:

- The site in question is sensitive, and access or helicopter overflight would jeopardize important national security interests, or

- The site in question is one in which it can be shown that the TLE cannot be stored.

g. Should access to a site be denied, the inspected party must provide all reasonable assurance that the location in question does not contain equipment limited by the treaty.

h. In conducting inspections at nondeclared sites, the inspection team shall be permitted access, helicopter overflight, entry, and unobstructed inspection, except as follows:

- Access or helicopter overflight need not be allowed to buildings or enclosures in which it can be shown that TLE cannot be stored;

- Shrouding of sensitive items shall be permitted. Access shall not be refused or delayed to any site where equipment of a treaty-limited type has, upon the arrival of the inspection team at the point of entry, been declared temporarily present.

If access is denied to a designated site, or if after the inspection team arrives at the site, part of it is declared a sensitive point or access to it is delayed for more than one hour, the inspection team must either designate for inspection another site within the area notified or declare the inspection concluded. In such case, time inspection days used will be calculated as follows:

- If access is refused or delayed for more than one hour to the first site or any part of it designated by the inspection team and the inspection is then cancelled, no inspection days will be counted; 
- If access to any part of a subsequent site is refused or delayed for more than one hour and the inspection is then cancelled, the inspection shall be deemed to have terminated at the end of the 24-hour period during which the destination of that site was made.

Subsequent

Site

Designation

Completion

Activities

Duration
1. During or within two hours of completion of the inspection of a signated site, the inspection team must elther designate a further site that it wishes to inspect within the area originally notified or declare its inspection concluded. In the former case, the inspected party must transport the inspection team to the next location within six hours.

j. If no further site is designated for inspection, the arrangements for completion of the report, transport of the inspection team to point of entry, and departure of inspection team shall apply as in Sections VI and VII.

k. Inspection of a nondeclared site shall not last more than 12 hours.

\subsubsection{Baseline Inspections}

Program For purposes of validating baseline data, there shall be a baseline inspection phase, coming into effect upon entry into force of the treaty and for 120 days thereafter, during which there shall be intensive on-site inspection of declared sites. These inspections shall not interfere with out-of-garrison training (BASIC April 1990).

\subsubsection{Inspections during Reductions Phase}

Destruction

Destruction of TLE may be witnessed by inspectors, without quotas or restrictions of any sort. Measures for witnessing destruction are to be developed (BASIC April 1990). 


\subsubsection{Monitoring of Stability Measures (BASIC April 1990)}

Call-up of

Reservists

Times of

Notification

Inspection a. The prenotified call-up of reservists, the prenotifled movements from one location to another within the area of applleation, and the prenotifled milltary activities in aocordance with the Articles [to be supplied] of the treaty may be subject to on-site inspection without right of refusal.

b. The request to inspect the prenotifled oall-up of reservists, the prenotifled movements within the area of appllcation, or the prenotifled milltary activities has to be made [to be supplled] hours in advance (this time limit should be the same as that of Inspections at declared sites). In the case of stationed forces, the request has to be addressed simultaneously to the host and to the stationing party.

c. A party that prenotifles the call-up of reservists, movements within the area of application, or military activities in accordance with the Articles [to be supplied] of the treaty is liable to receive one inspection team each time.

\subsubsection{Aerial Inspections}

Right to

Conduct
Within the area of application, each party concerned shall be obliged to receive, and have the right to conduct, a specified number of aerial inspections as an essential component of treaty monitoring and verification (BASIC April 1990).*

\subsubsection{Cancellations of Inspections}

Force

Majeure
An inspection shall be cancelled if, due to circumstances brought about by force majeure, it cannot be carried out. In the case of delay that prevents an inspection team, which is to perform an inspection pursuant to paragraphs [to be supplied] of Article [to be supplied] of the treaty, from arriving at the

\footnotetext{
* Details of the aerial inspection regime will be developed.
} 
inspection site within the time speolfled in paragraph lto be supplled] of Section [to be supplled] of this protocol, the Inspecting party may elther oancel or carry out the Inspection. If an inspection is cancelled due to circumstances brought about by force majaure or delay, the number of Inspection days to which the Inspecting party is entitled shall not be reduced (BASIC A.pril 1990).

\subsubsection{Inspection Reports (BASIC April 1990)}

Report

Stationing

Party

Copies of

Reports

Report

Authenti-

cation

a. Upon completion of Inspection at a declared or nondeclared site, the Inspection team chlef shall provide the inspected party with a written report within two hours. The report shall be written in any offleial Conference on Securlty and Cooperation in Europe (CSCE) language agreed upon between inspected and inspecting parties.

b. In the case of stationed forces, and in relation to 1 ts inspeoted TLE, a stationing party shall have the same rights and obligations of an inspected party as regards this section.

c. Each party shall retain one copy of the report. In the case of inspection of stationed forces, the stationing party shall also retain one copy. At the discretion of each party, the report shall be forwarded to other parties.

d. The report shall be signed by the inspection team chief and recelpt acknowledged in writing by the leader of the escort team. In the case of a stationing party's TLE being inspected, those parts of the report related to those TLE shall be acknowledged by a representative of the stationing party.

Declared Sites

e. Declared Sites. The report shall be factual and standardized (format to be developed). The report shall include the duration of the inspection, the inspection sites, and the type and number of TLEs counted/observed 
Nondeclared

Sites during the inspection. The parties shall, whenever possible, resolve ambigulties regarding factual information contalned in the report at the inspection site. Relevant clarifloation shall be recorded in the report. The inspeoted party has the right to include the written comments in the report. In the case of a stationing party's T'LE being Inspected, the sald stationing party shall have the right to include written comments related to the inspection of those TLE.

f. Nondeclared Sites. In the case of inspections at a nondeclared site, the inspection report shall be standardized (forrnat to be developed). It shall inolude the duration of the inspection, the inspection site, and the inspection team. The inspected party may comment in the report. In the case of statloned forces being inspected, the stationing party may include comments related to the inspection of those forces. The inspeating party may circulate to other parties an additional report within [to be supplied] days of the inspection being completed.

\subsubsection{Amendments To Protocol*}

\subsection{NATO PROTOCOL ON DESTRUCTION OF CONVENTIONAL ARMAMENTS}

Pursuant to and in implementation of the treaty on Conventional Armed Forces in Europe of. [to be supplied] 1990, hereinafter referred to as the treaty, the state parties hereby agree upon procedures governing the destruction of treatylimited armaments and equipment as set forth in Article XI of the treaty (BASIC April 1990).

\footnotetext{
*To be developed.
} 


\subsubsection{General Requirements for Destruction of Treaty-Limited Armaments and Equipment (BASIC April 1990)}

1. To ensure the rellable determination of the type and number of treaty-limited armaments and equipment being destroyed pursuant to the treaty, and to preclude the possibility of restoration of such items for purposes inconsistent with the provisions of the treaty, the state parties shall fulfill the requirements set forth in this protocol.

Declaration

of TLE

Types

Destruction

Destruction

Procedures
2. The speolflo types of treaty-limited armaments and equlpment subject to destruction in accordance with this protocol are llsted in the annex to the treaty on existing types of conventional armaments.

3. Upon entry into force to this treaty, each state party, as appropriate, shall provide to all other state partles in accordance with Article $\mathrm{XI}$ of this treaty the locations at which treatylimited armaments and equipment will be destroyed. Each state party shall have the right to designate as many destruction sites as it wishes and to revise without restriction its designation of such sites. The number of such sites at which each state party shall have the right to carry out destruction simultaneously shall be as follows:

- Each state party shall have the right to carry out destruction simultaneously at [to be supplied] sites; and

- For every [to be supplied] items of treatylimited armaments and equipment to be destroyed in each reduction phase, each state party also shall have the right to carry out destruction simultaneously during that reduction phase at an additional [to be supplied] sites.

4. Each state party shall use the destruction procedures as set forth in this protocol to carry out the destruction of treaty-limited armaments and equipment as required by the treaty. Each state party shall have the right 
Destruction

Monitoring

Procedures

Certifying

Destruction

Debris

Disposal to make use of the destruction procedures set forth in Sections II-VII of this protocol. In addition, each state party shall use whatever particular technological means it deems necessary to implement the procedures set forth in Sections II-VI.

5. Immediately prior to the initiation of destruction procedures carried out pursuant to Sections II-VII of this protocol, Inspectors shall confirm and record the type and number of items of treaty-limited armaments and equipment that are to be destroyed. At such time, the state party carrying out the destiuction shall ensure, subject to agreed upon salvage rules, that all treaty-limited armaments and equipment to be destroyed correspond in appearance and physical characteristies to photographs and technical descriptions specifying all necessary components of the equipment concerned (to be developed).

6. The destruction of treaty-limited armaments and equipment subject to this treaty shall be considered to have been completed upon completion of procedures set forth in this protocol and upon notifleation as required by Article [to be supplied] of the treaty. The destruction of items carried out pursuant to Sections II-VII of this protocol shall be certified in writing by the representative of the state party, be countersigned by inspectors of the inspecting state party who witnessed the destruction.

7. Conventional armaments destroyed in accordance with procedures set forth in this protocol shall no longer be considered to be subject to the treaty. Unless otherwise specifled in this protocol, state parties shall have the right to dispose of debris or other salvage items remaining after treaty-limited armaments and equipment have been destroyed in accordance with this protocol. 


\subsubsection{Procedures for Destruction of Battle Tanks at Destruction Sites (BASIC April 1990)}

MBT

Destruction

Promedure

Cutting
1. Each state party shall have the right to choose any of the following sets of procedures each time it carries out the destruction of battle tanks at destruction sites. Any one of the sets of procedures set forth in this section shall be considered sufficient, when conducted in accordance with this protocol, to carry out the destruction of any type of battle tank subject to the treaty.

2. Procedure for destruction by cutting (to be developed).

\subsubsection{Procedures for Destruction of Armored Combat Vehicles at Destruction Sites (BASIC April 1990)}

$\mathrm{ACV}$

Cutting

Other

Procedures

1. Each state party shall have the right to choose any of the following sets of procedures each time it carries out the destruction of armored combat vehicles at destruction sites. Any of the sets of procedures set forth in this Section shall be considered sufficient, when conducted in accordance with this protocol, to carry out the destruction of any type of armored combat vehicle subject to the treaty.

? Procedure for destruction by cutting (to be developed).

Other procedures for the cestruction of armored combat vehicles may be developed.

\subsubsection{Procedures fo: Destruction of Combat Aircraft at Destruction Sites (BASIC April 1990)}

\author{
Aircraft \\ Destruction
}

1. Each state party shall have the right to choose any of the following sets of procedures each time it carries out the destruction of combat aircraft at destruction sites. Any one of the sets of procedures set forth in this section shall be considered sufficient, when conducted in accordance with this protocol, to carry out the destruction of any type of combat aircraft subject to the treaty. 
Cutting

2. Procedure for destruction by cutting (to be developed).

\title{
3.13.5 Procedures for Destruction of Combat Helicopters at Destruction Sites (BASIC April 1990)
}

\section{Helicopter \\ Destruction}

Cutting

Other

Procedures
1. Each state party shall have the right of choose any of the following sets of procedures each time it carries out the destruction of combat helicopters at destruction sites. Any one of the sets of procedures set forth in this section shall be sufficient, when conducted in accordance with this protocol, to carry out the destruction of any type of combat helicopter subject to the treaty.

2. Procedure for destruction by cutting (to be developed).

Other procedures for the destruction of combat helicopters may be developed.

\subsubsection{Static Display (BASIC April 1990)}

Limits

\begin{abstract}
After treaty-limited armaments and equipment have been made usable for purposes inconsistent with the treaty through procedures that permanently render them militarily inoperative, the state parties may place them on static display. Each state party shall be limited to a total of and [to be supplied] battie tanks, [to be supplied] pieces, armored combat vehicles, [to be supplied] aircraft, and [to be supplied] combat helicopters on such static display.
\end{abstract}

\subsubsection{Procedures in the Event of Destruction by Loss or Accident (BASIC April 1990)}

If any treaty-limited armaments and equipment is lost or destroyed as a result of an accident, this loss or this destruction should be counted against the destructions the possessing state party has committed itself to do according to Article [to be supplied] of the treaty only if this loss or accident is notified within [to be supplied] days. Notification shall include the type of the destroyed item, its approximate or assumed location, and the circumstances related to the loss or aceidentál destruction. The states party's group shall be given the right to conduct a specific inspection of the point at which the accident occurred to provide confidence that the item has been destroyed. 


\section{IDENTIFICATION OF PROBLEM AREAS AND PROPOSED SOLUTIONS}

This section defines, in terms of the functional proposal areas listed in Sec. 3 , possible problem areas that need to be addressed in preparing programs for complying with or verifying the treaty articles. Proposed solution scenarios to address the problem areas are described, and recommendations are made for acting on the solutions.

\subsection{DATA DEFINITION}

\section{Problems.}

- Can a method be developed whereby the data contained in the definitions of each category of Treaty-Limited Equipment can be manipulated to rapidly determine which equipment is included in the definition, together with a description of the equipment?

- Can a dictionary of personnel uniforms and insignia be developed to assist inspectors in identifying personnel during inspections?

- Can a "wiring diagram" of organizational structure for each state party be prepared to show each military organization, its location (per baseline data exchange), and basic table of organization and equipment down to the regimental level?

Solutions. These problems involve three requirements: (1) developing a data base for equipment that falls within the TLE definitions, (2) providing a dictionary of uniforms and insignia for various personnel falling under the treaty, and (3) developing a wiring diagram of organizational structure that includes locations and tables of organization and equipment for each organization. The third requirement is a soft requirement, which means that if it were not met, the verification of the treaty would be unaffected. However, development of a data-base library, which could address these requirements and assist in the development of inspection-specific books for on-site inspection personnel, would benefit not only inspection personnel, but units hosting onsite inspection as well. Recommendation: The On-Site Inspection Agency (OSIA) should be designated to address these problems.

\subsection{AllianCe CeILINGS}

\subsubsection{Treuty-Limited Equipment Tracking}

Problem. How will the United States account for numbers of TLE in each category and ensure that this number does not exceed established NATO ceilings? 
Solution. Both the Army and the Air Force should establish executive managers for CFE affairs who would attend to all CFE matters for their services. Consolidation of TLE data should be the responsibility of the Office of the Joint Chiefs of Staff (OJCS). The OJCS would ensure that TLE held by U.S. forces are within the NATO ceiling apportioned for this nation. This is not as critical in Stage 1 as it is in the later stages, when various subceilings and TLE limits are in effect. The State Department would coordinate its efforts with other agencies involved with NATO and the Joint Consultative Group. Recommendation: Program management should oversee the development of solutions to this problem.

\subsubsection{NA'TO Treaty-Limited Equipment Tracking}

Problem. How will NATO track the number of TLE from each of its party states to ensure that the total does not breach the parity ceiling?

Solution. If data are exchanged among all participating states, and change notifications are provicied to all states, it will be possible to track the TLE status of each of the NATO member states. This should be the responsibility of the OJCS for NATO TLE and of the Defense Intelligence Agency (DIA) for Warsaw Pact TLE. The data on NATO state TLE holdings would be entered into the master data base by TLE category, location, and nation. This would allow the computer to continuously track aggregate numbers of TLE within the NATO subregions. Recommendation: Data-base management and communication should be used to address these problems.

\subsubsection{Harmonization and Cascading of Treaty-Limited Equipmnet}

\section{Problems.}

- How will NATO apportion and mandate TLE so that the parity ceiling for each state does not breach the aggregate ceiling? What is the "harmonization" scheme to ensure that equipment retained is based on a rationale of newest retained/oldest destroyed? What is the "cascading" plan to move TLE to other countries while destroying excess equipment?

- How will the U.S. track the TLE inventory for each of the NATO and WP states to ensure that each party's TLE data and change notifications do not exceed the aggregate alliance ceilings?

Solutions. These activities are best handled within the NATO council. When decisions for movement of TLE have been resolved by the NATO nations, services will be tasked to move their equipment. All data on these movements will be furnished by data exchange at the beginning of Stage 1 or through change notification messages after Stage 1. Kecommendation: NATO coordinator should be designated to deal with these problems. 


\subsubsection{Armored Infantry Fighting Vehicle and Heavy Armament Combat Vehicle Tracking}

Problem. How will the U.S. track individual subcategories of armored combat vehicles (e.g., AIFV and HACV) for each of the NATO and WP states?

Solution. The OJCS data base should have files on AIFV and HACV TLE that indicate type, location, organization, and nationality of owning uation. Routines will be established to ensure that these categories of TLE are maintained within NATO-assigned national limits. The data base could be configured to warn the program manager if U.S. stocks were in jeopardy of violating the ceiling or if the aggregate number for NATO was approaching the ceiling for either of these categories. Recommendation: Data-base management and communications should be used to deal with this problem.

\subsubsection{On-Site Inspcction Agency and Change}

Problem. Can on-site inspection reports and notification messages from the Army be used to automatically update the data base?

Solution. The OSIA should provide input to the data base by providing results of escort reports that would indicate findings and TLE counts of U.S. equipment. It is important to maintain a running count of what the Warsaw Pact has verified on U.S. TLE. Likewise, it is mandatory that change notifications automatically trigger the data base to show what changes are to occur and what changes have occurred at U.S. facilities in Europe. Results of these changes to the data base should be cross-checked with the services to ensure that the changes notified reflect the actual status of TLE. Recommendation: Data-base management and communications should be used to deal with this problem.

\subsubsection{Personnel Tracking}

Problem. How will personnel ceilings be tracked? Is it possible to use type organizations and OSI inspection reports to determine approximate numbers of personnel in the force? How will the U.S. track personnel from other NATO states if the decision is made to include these personnel in the overall personnel ceiling?

Solution. Personnel should be tracked by changes to the data-exchange message. Personnel could also be tracked by verifying personnel demobilization at demobilization points. This is not recommended as a way of verifying demobilization activity. It would be better to indicate personnel notification changes for units and make follow-up inspections of these units to determine if reductions have taken place. Personnel changes should be tracked by change notification message. Recommendation: Data-base management and communications should be used to deal with this problem. 


\subsubsection{Helicopter and Aircraft Tracking}

tags?

Problutha How are uircraft and helicopter strengths tracked? Is there a role for

Solution. Helicopters can be tracked in the same manner as other TLE because helicopters have a relatively short flight radius. More importantly, helicopters are normally employed in support of divisional units; therefore, tncy can be counted in the same manner as artillery. To deter shifting of helicopter assets and preclude double counting, tags are recommended as an inventory aid for helicopters.

Aircraft will be more difficult than helicopters to track. 'I'he flight radius for aircraft allows them to enter and leave the area of application easily and violate the regional TLE ceilings without being detected. It would be advantageous if a system were devised to enter the flight plan for all aircraft TLE into the notification net. Minor format changes in the flight plan would provide notification that a particular TLE is transiting, leaving, or returning to the area of application. Providing a surface tag to each aircraft TLE would provide evidence that the TLE ceiling is not being violated; however, this tracking method would be intrusive and expensive. Each aircraft would receive its own identifying tag, which would indicate nationality, subzone, and TLE identity. Change notifications for aircraft transfers would indicate tag number, which would facilitate consolidating total numbers of aircraft in subregions by nationality. Recommendation: Research, development, testing, and evaluation should be used to verify information.

\subsection{SUFFICIENCY CEILINGS}

Problem. How does the U.S. determine that the numbers of TLE reported in the data exchange for all states (after reductions have been achieved) do not exceed the single-country limits agreed upon? Can this be done daily using data received from notification messages, destruction messages, and results of on-site inspections?

Solution. The TLE data base should reflect the nationality of every TLE and its location. A data-base routine designed to compare national holdings with treaty sufficiency ceilings for each category would indicate if the treaty were being violated or in danger of being violated. Change notifications would update this data base and show on a daily basis if sufficiency ceilings were not in compliance. On-site inspections would verify that the number, location, and nationality of TLE were as shown on the running data base. Recommendaiion: Data-base management and communications should be used to address this proble:m. 


\subsection{STATIONING CEILINGS}

\subsubsection{Verifying Stationing Ceilings}

Problem. How can the U.S. determine from the data exchanged that the alliance is not exceeding the ceilings for TLI stationed outsicle of national territory in active units? Can this be tracked routinely using notification messages and the results of inspections?

Solution. The TLE data-base file for monitoring stationing ceilings should provide indications of noncompliance with NATO-prescribed active unit cellings for each country that has stationed forces outside of its national territory. Changes in totals of TLE in this category would be tracked using notification messages and periodic data exchanges. The United States should use its data base to track other NATO nations in this category. Services should be responsible for not exceeding prescribed limits and for providing accurate change messages during the reduction and parity stages. NATO will verify that national stationing ceilings are in compliance by on-site inspection and through use of N'T'M. Recommendation: Data-base management and communications should be used to address this problem.

\subsubsection{Verifying Storage Provisions}

Problem. How will the U.S. track TLE in storage and ensure that the difference between the overall limits on the TLE category and the sublimits stored does not violate the storage provision? Can the U.S. follow these data for other NATO states?

Solution. A separate data file to keep track of U.S. equipment in storage is required. Although the services will be resfonsible for maintaining TLE in storage within the required ceiling limits, the data base must be able to show graphically the numbers of $T L E$ in active units and in storage and compare these numbers with the overall country ceiling. The data base should also be able to track TLE in storage for other NATO nations. Change data on TLE in storage will be important to ensure overall treaty compliance. Recommendation: Data-base management and communications should be used to address this problem.

\subsubsection{Tracking Low-Strength Unit Treaty-Limited Equipment}

Problem. How will the U.S. follow Soviet TLE stationed outside of national territory? How will the U.S. track Soviet TLE stationed in low-strength units? Can a format be devised to pick off data on inspection of monitored and unmonitored lowstrength units? Would a tagging scheme be useful?

Solution. The NATO nations and the U.S. must rely on the Warsaw Pact data exchange to track equipment in low-strength units. The Office of the Joint Chicfs of Staff can determine if the Soviets are in compliance by using the same graphical layout 
used to track NATO stationed forces in storage. Low-strength monitoring reports and on-site inspection reports would serve to verify the data on file. Recommendation: Data-base management and communications should be used to address this problem.

\subsubsection{Tracking Personnel Demobilization}

Problem. How will the U.S. track demobilization of personnel?

Solution. Personnel demobilization could be tracked using the data-exchange documents and personnel and unit-strength change documents. This would be another data-base file that must be established at OJCS to monitor not only U.S. personnel reductions, but also those of our NATO allies and the Warsaw Pact. On-site inspection would verify that data-base files matched holdings reflected on inspected units' manning rosters. Recommendation: Data-base management and communications should be used to address this problem.

\subsection{REGIONAL CEILINGS}

\subsubsection{Tracking Treaty-Limited Equipment in Regional Subzones}

Problem. How will the U.S. track TLE located in each subzone, other than by using data from the data-exchange document? Can these data be made more timely by routine updating using notification messages, destruction messages, and the results of onsite inspection?

Solution. All state parties will exchange data on TLE at the beginning of Stage 3 (parity). These data will indicate location and unit to which the TLE belongs. Data on regional cellings should be tracked using a specific data-base file for these provisions. This file must be closely integrated with change notification messages to determine if subregion ceilings could be exceeded by transits and additions. Gecgraphic projections showing locations of units by subregion and totals by nation and TLE category should be designed. This provision is possibly the easiest to violate and should be monitored closely. Although the services are charged with monitoring numbers of their TLE in each zone, they will not be watching TLE of other nations and total NATO ceilings. A similar portrayal of Warsaw Pact holdings in the subregions would allow verification monitors to determine if WP locations and regions were at risk. This may assist in determining if an inspection is warranted. Recommendation: Data-base management and communications should be used to address this problem.

\subsubsection{Determining Data-Base Requirements}

\section{Problems.}

- Can a display be generated that would show summary data within each subzone of each category of TLI? Can these data be displayed 
by state and TLE category? Can this display react to out-oftolerance conditions in any of the zones? Can the display indicate which state is causing the out-of-tolerance condition?

- Can a regional subzone portrayal be produced to show amounts of TLE by nation/state in each subzone and indicate reduction requirements to meet subzone cellings prior to the end of the "reduction" phase?

Solutions. The CFE data base should have the capubility to use data files to determine status of subregions for all TLE for all nations. The system should be able to portray the region and the locations of major organizations. The system should also have the capability to call up locations of organizations having. TLE and show graphs of national holdings of TLE categories (aggregated to show total holding's versus the treaty celling for the region). Warning of possible noncompliance should be highlighted for both alliances. Recommendation: Data-base managernent and communications should be used to address these problems.

\subsection{COUNTING R.ULES}

\subsubsection{Counting Treaty-Limited Equipment}

Problem. How will TLE be counted -- by tag photograph, aerial inspection, or physical count?

Solution. The OSIA will probably visually count all TLE during the baseline inspection. If an aerial inspection regime can be instituted, TLE on display can be counted and a more accurate count of TLE can be made from photographs. During Stages 2 and 3, T.LE will not be displayed in formation, but use of photography would assist in verifying physical counts from on-site inspection. Counts of TLE in military educational establishments should be accomplished by on-site inspection. Storage site inspections $c$ in be accomplished by on-site inspection, and inventorying can be assisted by tagging different categories of TLE' stored in monitored storage. Tagging is especially useful for differentiating the types of armored combat vehicles. Tags could be used to identify attack helicorters and support helicopters, but the on-site inspector still must verify that helicopters are not capable of combat. Tags would be of use in inventorying TLE placed in temporary storage until it is eliminated or exchanged. Recommendation: OSIA should be designated to address this problem, and research, development, testing, and evaluation should be used to verify data.

\subsubsection{Conducting Mock Inspections}

Problem. Will a regime of mock inspections be needed to ensure that counting can be done in accordance with the treaty provisions? 
Solution. Services should conduct mock inspections of all aotive unlts, all temporary storage facilities (those facllities where TLE awaiting destruction are stored), all monitored storage sites, and U.S. training establishments in the area of application. These mock inspections should be conducted in coordination with OSIA and be soheduled In such a manner as will test communications notification procedures and data-base management systems. Communications with service headquarters, OJCS, State, and NATO must be tested. Recommendation: Data-base management and communications should be used to address this problem.

\subsection{DATA EXCHANGE}

\subsubsection{Formulating, Consolidating, and Transferring Data}

Problem. How will the U.S. consolidate, track, verify, and display the U.S. data to be exchanged?

Solution. Services (Army and Air Force) would formulate their holdings of TLE in formats required by NATO. These data will be transmitted to service executive agents. Services should forward their data to the OJCS for national consolidation. The OJCS would not be responsible for the accuracy of submitted TLE data. The submitted data would be consolidated and transmitted through State Department communications to all party states and NATO. TLE data recelved from other state parties and NATO would be sent by the State Department to OJCS for inclusion in the CFE data base. Recommendation: Data-base management and communications should be used to address this problem.

\subsubsection{Tracking and Updating Data}

\section{Problems.}

- How will the U.S. track data about other states in the NATO Alliance?

- How will the U.S. track data received from the Warsaw Pact?

- Will there be a need for a pictorial consolidation of the data exchanged? If so, can this be provided?

- Can subsequent data-exchange data be compared and differences displayed?

- How will the data to be exchanged be communicated from the services to each nation state? Which agency in the U.S. will be responsible for data transmission and data correctness? Will NATO have a communication responsibility? 
- How will the U.S. cheok its data base used for current holdings of national TLE against the reguirements for (1) entry-into-force data exchange, (2) achieving cellings data exchange, and (3) the annual data exchanges to verify that data recelved from services lor these speciflc data-exohange requirements are the same as the "running total," which represerits the last data-exchange document amended by notification messages?

Solutions. Services should provide change notification messages to the OJCS for entry into the CFE data base and for communication to other state parties and NATO. The Compliance Data Fusion Center for containing CFE data base should be at OJCS. This data base could be updated from messages transmitted and received by the State Communication Center. No data-base change would be made without backup by a message date/time group. Treaty-Limited Equipment for U.S, and all other state parties to include consolidation data for both NATO and the Warsaw Treaty Organization would be tracked by routines established in the OJCS CFE data-tracking system.

This OJCS Compliance Data Fusion Center would be responsible for maintaining the national CFE master data base, updating this data base, and developing required decision-making presentation applications as necessary. Redundant data bases maintained by the services and other agencles would be compared with this base to

ensure accuracy of the maintained data. Recommendation: Data-base management and communications should be used to address these problems.

\subsubsection{Performing Mock Data-Base Inspections}

Problem. Can the U.S. perform a mock data-exchange exercise to test the viability of both the data-consolidation process and the communication process? Are formats being produced for the initial data exchange? Are formats compatible with compliance checking equipment?

Solution. The OJCS should perform a mock inspection of the Compliance Data Fusion Center using the U.S. TLE holdings to ensure that the CFE data-tracking system and the system for receiving TLE data from the services is accurate. Recommendation: Data-base management and communications should be used to address this problem.

\subsubsection{Gathering Military Spending Data}

Problem. How will the data on military spending be gathered and integrated into the data to be exchanged?

Solution. Data on military spending would be censolidated by the Office of the Secretary of Defense (OSD) and provided to the OJCS to communicate to participating states. This proposal will probably disappear, as it is not verifiable and would not represent actual expenditures. Recommendation: none. 


\subsection{STABILITY MEASURES}

\subsubsection{Notification of Changes in Organizational Structure}

\section{Problems.}

- How can a notifleation of change lo organizational structure be best communicated to the decision maker? Can this change be compared with the data base to determine If the addition of the new element violates any of the treaty provisions?

- Can notifications of change in organizational structure be routinely added to the existing data base and highlighted for possible verifleation of on-site Inspection?

- Jow does the U.S. ensure that major changes to the organizational :tructure are reported 42 days in advance of the change?

Solutions. Services will be responsible for reporting appropriate organizational changes to the OJCS within the 42-clay limit for the notification. The OJCS would pass the information through State Department channels to NATO and other state parties. The OJCS master data base would be updated on the basis of the outgoing message from the State Department. Warsaw Treaty Organization change messages would be recelved by the Verification Data Fusion Center (probably located at the National Military Intelligence Center [NMICC]) and automatically entered Into the data base of the appropriate state party. The Arms Control Intelligence Staff (ACIS) will be the primary user of organizational change data for WTO state parties. OJCS must be able to use data from both the Compliance and Verification Data Fusion Centers to display and compare organizational change summary data on both U.S. elements and other state parties. Recommendation: Data-base management and communications should be used to address these problems.

\subsubsection{Notification of Changes in Force Strength Level}

\section{Problems.}

- Can changes to the force levels be compared with the previous data base to determine if changes of more than $10 \%$ in peacetime planned/authorized strength of personnel and of treaty-limited items have occurred? Can this be done for each state? Can the running data base be compared dally to determine if changes to force levels exceed the $10 \%$ limit?

- How will notification of change in force levels be applied to the data base? Can this change be displayed to determine its impact on the zone of appliogtion? 
- Can the flve-day notification rule be monitored using notifleation messages? Will there be a specific format for a strength change notlfication message, which must be renclered not later than live days af ter the change has occurred?

- Can data exchanges and other change notifications be compared with the last data-exchange document to determine if any $\mathrm{TLE}$ element down to regimental level has not changed more than $10 \%$ without recelpt of a strength change notification?

Solutions. Services will be responsible for providing strength changes in unlts down to the battalion/regimental levels that deviate by $10 \%$ from the authorized peacetime strength levels of these units. Notifications of these changes must be received and transmitted by the state Department no later than five days after the change has occurred. The OJCS data-base system should be able to take changes in unit strength from this type of notification message and automatically compare these strength data with a $10 \%$ change to determine if a violation has occurred. This should be accomplished for all state parties. Recommendation: Data-base management and communications should be used to address these problems.

\subsubsection{Notification of Reductions}

\section{Problems.}

- Can results of notification of destruction of TLE above agreed-upon cellings be displayed? Can these notifications be compared promptly with the results of destruction monitoring? Can the results of destruction messages be depicted showing time and area of destruction to determine current cumulative holdings of TLE?

- How will the schedule of reductions be handled? Will timetables of reductions be kept as part of the data base management system (DBMS)? Will these timetables be used to check notification messages on destructions? Will these timetables be used by decision makers to project changes in force strength?

- How will the notification of reduction of a TLE be handled? Does this reduction need to be checked against a "red" inspection report? Where should the final responsibility for tracking reductions in U.S. TLE be placed? Who tracks NATO allies' TLE reductions? Is there a need to track the TLE of our allies?

Solutions. Although reductions do not begin until Stage 2, services will be responsible for providing to the OJCS (1) a timetable for TLE reductions and (2) notification messages for TLE reduction. This information will be entered into a reductions data base in the OJCS CFE data-base system and used to track status and location of TLE in the reductions pipeline. Services must maintain a more complex 
reduotion traoking soheme for their TLE to include movement and transfor data on all Items and personnel to be reduced. Data on Warsaw Treaty Organization states' reductions would be tracked by a simllar routine in the Verffleation Data Fusion Center. Detalls on TLE in temporary storage, location of TLE in the reduction plpellne, and timetables for reduction of TLE should be avallable for comparison. Recommendation: Data-base management and communications should be used to address these problems.

\subsubsection{Notification of Changes in Maximum Levels}

Problem. Does the U.S. need to track the TLE levels of all NATO parties to always know each alliance's position about the treaty-mandated celling? How will the U.S. track the Warsaw Pact dally levels?

Solution. Although this provision will be the responsibllity of NATO, it is important that the OJCS CFE data-base system continuously compare TLE levels of both alliances to determine if there is a violation of cellings. If such a violation does occur, the data base must be able to identify which state party caused the vlolation. Recommendation: Data-base management ard communications should be used to address this problem.

\subsubsection{Notification of Temporarily Exceeding Levels}

Problem. How will the notification of temporarily exceeding cellings be handled when planned? How will this notification be handled when this condition is determined by the computer and is not intended? What will be the procedure if the computer reveals a condition that may result in an alliance overstrength caused by another NATO state?

Solution. Services will be responsible for immediately notifying the $\mathrm{CFE}$ program manager and OJCS of actions that will cause a temporary condition where TLE would exceed NATO limits. The State Department would notify NATO of the temporary overage so that NATO could prepare the necessary notification messages. The OJCS data-base system should be able to continually check data from all state parties to determine if conditions exist that indicate that an Alliance exceeded treaty levels. The system should be able to define which state party is in violation and the location of the overage condition in Europe. Recommendation: Data-base managemeri and communications should be used to address this problem.

\subsubsection{Notification of Reserve Mobilization}

\section{Problems.}

- Can a method be devised to check that reserve mobllization of U.S. forces exceeding call-up limits are reported to all states within the 42 days allowed? Can the results of surh a reserve mobllization notification from any participating stat: be displayed during its 
duration to show this activity, its designation, location, purpose, and duration of the call-up? Can a procedure be created to determine if the ceiling on the simultaneous call-up of reservists will be or is being violated?

- How can these ceilings be verified, or is there a need to verify the actual numbers of mobilized reservists?

Solutions. Services will be responsible for ensuring that mobilization of reserve forces in the area of application do not exceed treaty limits. If these limits are to be exceeded, NATO must be notified no later than 42 days before the mobilization. The OJCS data base should be able to reflect the mobilization activity, its designation, location, purpose, and the duration of the call-up. 'This system w suld also track notifications from other state parties and display these data during the duration of this call-up. Recommendation: Data-base management and communications should be used to address these problems.

\subsubsection{Notification of Equipment Movement}

\section{Problems.}

- Can the results of notification of equipment movements (all states) meeting the ceilings proposed be displayed to show the impact on a geographical area within the area of application by displaying normal peacetime location, route of movement to and from the new locations, and the purpose and intended duration of the presence of equipment in the new location?

- How will the U.S. ensure that any equipment movements that exceed the treaty ceilings are reported within the established 42day timeframe?

- Can the information about the movement of large numbers of TLE that exceed the established ceiling be established autorsitically from other notification documents?

- How will the U.S. verify that equipment movement does not exceed established ceilings? If equipment movements are noted by National Technical Means (NTM), how will this be compared to determine if a notification message on the movement has been received?

- How will states notify one another of transfers of TLE within the area of application, and how can these transfers be tracked to ensure that they do not exceed ceilings? 
Solutions. The Army will be responsible for providing notification of any ground movements of TLE that exceed treaty limits. Notification would be made by formatted message to NATO through the State Department. The OJCS CFE data-base system should display information on all movements of equipment that exceed the treaty limits. This display would include the geographical locatior, route, duration, purpose, and intended duration of movement in the new area. This $\mathrm{i}$...ormation should be displayed for all state parties, using information from their notification messages. Movements identified by NTM can be compared with notification data in the OJCS data-base display. Recommendation: Data-base management and communications should be used to address these problems.

\subsection{STABILITY REQUIREMENTS}

\subsubsection{Monitored Storage}

\section{Problems.}

- How does the J.S. ensure that its TLE in storage do not exceed treaty limits? Will this assessment be made at United States Army Europe (USAREUR) or at Army level for U.S. equipment? At what level will total amounts of TLE in monitored storage be tracked? Can the equation for monitored storage TLE -- "those equipment [sic] within the total authorized ceiling but in excess of the ceilings for active units" -- be monitored by computer? Would tags for this category of equipment be helpful?

- Will NATO establish ceilings on monitored storage for its member states?

- What does monitored storage mean? What equipment should or could be required to establish a monitored storage facility? How will monitoring be achieved? How is an effective separation of stored equipment from active equipment achieved? How carı storage boundaries be achieved, and how can exit and entrance points be enforced?

- Can the information declared on data exchange documents, which specify the qualities of Treaty-Limited Equipment located in the declared monitored storage sites and the location of these sites, be maintained by computer in such a manner that the difference between ceilings of TLE in active units and overall ceilings for TLE would not be more than the number of TLE kept in monitored storage?

Solutions. Services will be responsible for not exceeding limits for TLE they maintain in monitored storage. Information on location and amounts of TLE maintained 
in storage must be transmitted as part of the data-exchange documents. NATO mus,t provide ceilings for each state having TLE in monitored storage. NATO should also be responsible for ensuring that the total of all TLE in monitored storage does not violate treaty ceilings. The OJCS data-base dystem should have provisions for tracking TLE in monitored storage for all state parties and also have the capability for ensuring that numbers of TLE in monitored storage do not violate any of the treaty ceilings and rules. The data-base system should be able to indicate location of each monitored storage site and amounts of TLE stored in the site. Recommendation: Data-base management and communications should be used to address these problems.

\subsubsection{Monitored Storage Sites}

\section{Problems.}

- What will determine effective separation of stored equipment from active equipment? How will "ease of monitoring" be achieved? Could sensors be of use?

- Does the requirement to have clearly defined boundaries with limited entrance and exit points place restrictions on monitoring: procedures?

- What will be the "monitoring" regime for the monitored storage facilities?

Solytions. Monitored storage sites will probably not be monitored continuously; instead, they will be subject to more frequent on-site inspections than allowed by the current quota inspection process. To allow this inspection process to te done, tags could be placed on all TLE that indicate if the TLE has been moved since the last monitoring inventory. Sites will be monitored during periods of activity in which TLE are removed from the site in amounts that exceed maintenance requirements. Services will be responsible for preparing the monitored storage sites to conform to treaty requirements for separation of TLE, entrances and exits, and boundaries. If tags are not desired, a sensor system around the perimeter of each site would indicate if TLE leave the site through other than identified portals. Recommendation: Facilities should be prepared and research, development, testing, and evaluation should be used to verify information.

\subsubsection{Unmonitored Storage Sites}

Problem. How will unmonitored storage sites be verified? Can this type of site be entered into a data base and displayed as part of active units and active unit ceilings, but with different symbology?

Solution. Services will be resprinsible for including equipment at unmonitored storage sites (e.g., maintenance depots and replacement depots) in their data bases. TLE, in these installations will change frequently, and the data bases should be kept current 
because they affect active unit TLE ceilings. Although the OJCS data-base system would not reflect current holdings of equipment in unmonitored storage, it should have a capability to display locations of these sites and the latest known TLE holdings. Data on other state parties unmonitored storage sites and TLE at these sites should be available and should be updated when possible by inspection reports and data exchange. Recommendation: Data-base management and communications should be used to address this problem.

\subsubsection{Removal from Monitored Storage}

\section{Problems.}

- How will each alliance (and the U.S.) track equipment removed from monitored storage and verify that the equipment has not been removed for more than 42 days? Can this requirement to report TLE removed from monitored storage be computerized for possible quota inspection to determine if equipment is returned within the 42-day period?

- Will there be some method whereby reports of removal of TLE from monitored storage by monitoring personnel are entered into the data base to provide for checks on notification messages informing of this removal?

- Can the data base be used to compare data from notification messages on numbers of TLE removed from monitored sites with a running total of TLE removed from these sites? Will this ensure that TLE ceilings for this category of equipment in the alliance are not exceeded?

- How will the small amount of TLE that can be removed from monitored storage be tracked? Is there any need to track this TLE? Would a system of tags and sensors be of use?

- Will provisions be made to automatically update the data-exchange document with data on replacement of equiprnent in monitored storage? How will the TLE that has been replaced be tracked?

Solutions. Services will be responsible for notifying OJCS and subsequently NATO of removal of TLE from their monitored storage sites. The OJCS data-base system will track this TLE removal and display the amount, location of the TLE, and intended use during the period the TLE is removed from the monitored storage site. The service will ensure that the TLE removed will not violate the ceilings imposed by the treaty. The OJCS data-base system should be able to automatically calculate when TLE has been removed from the monitored storage site for more than 42 days. The data-base system should also indicate when replacement equipment is placed in the monitored storage site and the disposition of replaced equipment. On-site inspection would be the 
preferred method of verifying that the Warsaw Treaty Organization does not violate this treaty ceiling. Recommendation: Data-base management and communications should be used to address these problems.

\subsubsection{Equipment in Monitored Low-Strength Units}

\section{Problems.}

- How will each state monitor low-strength units? Should data processing account for these units and track their locations and TLE quantity in the same manner as monitored storage? Should this category of TLE be tagged?

- Can the data base show the location of all monitored low-strength units, with a capability to determine what kind of equipment is located in these units?

Solutions. The OJCS data-base system should be able to display locations and holdings of TLE in low-strength units for all state parties. The data system would treat these data in the same manner as monitored storage equipment. Recommendation: Data-base management and communications should be used to address these problems.

\subsubsection{Equipment in Unmonitored Storage}

Problem. Can data processing be used to identify unmonitored low-strength units and their equipment and carry these in the same category as active units for accountability? Should unmonitored storage items be tagged?

Solution. The OJCS data-base system should be able to track TLE in these units on the basis of data from periodic data exchange, charge messages, and inspection. The data-base system should treat these data in the same manner in which it treats unmonitored storage site data. Recommendation: Data-base management and communications should be used to address this problem.

\subsubsection{Mobile Bridging-Equipment Storage}

\section{Problems.}

- Can a data base identify total numbers of Armored Vehicle Launched Assault Bridges (AVLAB) in active units and in monitored storage, and can the data base send an alarm if the total in active units exceeds the ceiling of 700 ? Can this system be programmed to issue an alarm if more than 50 AVLAB are removed from monitored storage on the basis of information extracted from notification messages and inspection reports? Can the data base display AVLAB data as a separate category? 
- How would these provisions be verified by on-site inspection? By aerial inspection? By tags?

Solutions. The Army will be responsible for maintaining limits of AVLAB equipment in storage and for removal limits. Application of tags to this equipment would assist in inventory of the equipment and verification that all equipment is accuunted for. The OJCS data-base system should be able to track AVLAB by location and number in storage and active units. The system will indicate when and if more than 50 AVLAB are removed from storage and if more than 700 AVLAB are carried in active units. These data will be displayed in a submenu of the data-base system for state parties of both alliances. Recommendation: Data-base management and communications should be used to address inese problems.

\subsubsection{Exercise Size}

\section{Problems.}

- How are the provisions about exercise size to be verified? Can verification be made on the basis of notification message and monitoring the exercise? Can a data-processing routine be incorporated that would alert states to numbers of exercises that have been made by category and within the specified timeframes? Can an automated display be formulated from notification data that would show exercise locations and streng th?

- How will the different provisions of this article about the limits on numbers of exercises by size categories that can be held within time limits be tracked? Can a data-base routine be created that would track large-scale, medium-scale, and small-scale exercises and that would ensure that their notification and time-spacing requirements were not violated?

Solutions, Services are responsible for ensuring that their exercises do not violate treaty ceilings. Commander in Chiefs (CINCS) are responsible for ensuring that joint exercises do not violate these ceilings. The OJCS data-base system should have provisions for tracking and displaying exercises by size and location. This subsystem would also track the frequency oi exercises by size and would indicate if treaty provisions were violated. NATO would verify by on-site observation the size and the location of the exercises. Recommendation: Data-base management and communications should be used to address these problem.s.

\subsubsection{Military Activity Constraints}

\section{Problems.}

- How would these provisions be verified? Would notification of this military activity be sufficient to allow for on-site monitoring and 
N'TM of the activity, and would notification be required? Can the notification be entered into the data base and displayed in such a manner that the effect of the increased force in the geographical area can be shown? Can this type of activity be retained to determine if other equally extensive activity is conducted within the next two-year time-frame?

- Can the data on planned duration, projected start and end times, and envisaged number of troops be portrayed and highlighted during the timeframe of the activity? If this activity includes more than one state party, can this be highlighted?

- How can new production of TLE within the ATTU region be tracked to ensure that any increase will not violate treaty zonal ceilings?

Solutions. Services and CINCS will be responsible for ensuring that military activity does not exceed treaty ceilings. The OJCS should approve all military activity exceeding treaty ceilings at least one year prior to the activity and notify all state parties of the activity. The OJCS data-base System should be able to track and display all notifications of this type of activity and planned U.S. military activity. Recommenation: Data-base management and communications should be used to address these problems.

\subsubsection{Transfers of Treaty-Limited Equipment}

Problems.

- How do states verify that transfers do not violate zonal ceilings? Can notification data be compared with the updated data base to determine if transfers exceed ceilings? Can this be done for NATO notification messages prior to their being sent, to ensure that no violation would come from the transfer? Can the location of the transfer, including the exit and entry points, be displayed by date of anticipated transfer activity?

- Can reports of TLE transfers be compared with notification messages to determine if the 42-day advance notice requirement has not been violated?

- Can this activity be monitored at exit and entry points by equipment rather than by on-site monitoring personnel? Where will exit and entry points be located? What will these entry and exit points consist of?

- What equipment/manpower is needed to monitor exit and entry points where equipment movements cross borders of regions determined in the treaty? 
- How can the U.S. ensure that equipment movements that exceed TLE ceilings are using designated exit and entry points? Would a tagging and sensor scheme be helpf $u^{\prime}$ ?

Solutions. Services will be responsible for all transfers of TLE into, through, and out of the area of application. Prior to the transfer of any category of TLE, the service would coordinate the movement through NATO channels to ensure that treaty ceilings for that category of TLE are not exceeded. Additionally, the service would also coordinate with the OJCS to determine the impact of the transfer on NATO ceilings. The OJCS data-base system will be able to determine if the transfer action will violate treaty ceilings by applying the "NE transfer numbers to the existing numbers of TLE for all limits. Additionally, the data-base systern will indicate each transfer activity by location, duration, and category. The data-base system will also indicate transfers by other state parties to determine aggregate TLE activity in the regions and subregions. Transfer activity can be verified and monitored by NTM and on-site inspection. The use of exit and entry points will probably be' discouraged by NATO because of the intrusive nature of these monitoring points. It will be felt that NTM offers sufficient verification capability to eliminate the need for exit and entry points. Equipment can be tracked by the data base and verified by on-site inspection after the transfer has taken place. Recommendation: Data-base management and communications should be used to address these problems.

\subsubsection{Restructuring of Conventional Armed Forces}

Problem. Can this measure be verified? Should it be verified? Can measures designed to meet this provision be retained in file in the data base and provided during data-exchange opportunities?

Solution. The compliance manager will use the OJCS data-base systern to ensure that activities, transfers, exercises, and movements do not violate the spirit of this article. If the data-base display indicates changes that could violate the provisions of this article, NATO will be notified by separate message. The data base will indicate changes to data-exchange positions that may be in violation of this article. Recommendation: Data-base management and communications should be used to address this problem.

\subsection{VERIFICATION MEASURES}

\subsubsection{Inspection of Declared Sites}

\section{Problems.}

- Problem 1: How will states verify by on-site inspection the number of armaments and personnel at declared sites? Would tags be useful in this inspection? 
- What does "random basis" mean in reference to verification of data provided at signature and on coming into force (Warsaw Pact, paragraph II.2)? Can an appropriate statistical number of TLE be identified by computer?

Solutions. OSIA will have responsibility for U.S. inspection of declared sites. Reports of inspection and TLE nuinbers for each inspected location should be provided to the Verification Data Fusion Center data base. That data-base system would update the data exchanged and provide a running data base for the treaty. Likewise, the OSIA would provide reports of escort activity, which would provide a running data base of NATO activity as verified by WTO inspectors. The OJCS Data Fusion Center would provide a statistical approximation of TLE at each location on the basis of the inspection and escort reports. Recommendation: Data-base management and communications should be used to address thiese problems.

\subsubsection{Verification of Personnel}

Problem. How are personnel reductions verified? Can data exchange and riotification data be compared with the results of inspection to determine if personnel reductions are within established ceilings?

Solution. Verification of personnel strength would be done by comparing exchanged data with data on peacetime troop strength assigned to active and lowstrength units. The ACIS Verification Data Fusion Center data-base system would provide an approximation of strength for each state parties on the basis of the data-exchange information. Information about U.S. strength will be obtained from the services and displayed in the OJCS Compliance Data Fusion Center data base. Recommendation: Data-base management and communications should be used to address this problem.

\subsubsection{Verification of Residual Levels}

\section{Problems.}

- How are quotas to be controlled, monitored, and apportioned?

- How will inspection teams determine what residual levels remain at the time of the on-site inspection? Can the results of an inspection by the Eastern Bloc states of NATO alliance sites be used to maintain a parallel residual level count of NATO TLE?

Solutions. Services will maintain the current TLE residual level information that is on hand and available for inspection. OSIA inspection teams will not need residual information, and these teams should only verify what is on hand in the inspected locations. Inspection reports should be compared with the running data base to verify the residual levels. These residual levels should be compared with periodic data-exchange 
documents to establish if residual levels are within reasonable limits. Likewise, inspection results of NATO state parties should be compared with exchanged data to determine running residual levels. This, too, would be compared with new data to be exchanged to determine the extent of residual differences. Recommendation: Data-base management and communications should be used to address these problems.

\subsubsection{Verification of Compliance with Established Levels}

\section{Problems.}

- What will be the basis of inspection to confirm that a declared site is no longer in use?

- How will suspect site inspections be tracked and what special emphasis will be placed on this type of inspection? Can the data base provide highlighted information on any suspect site inspection in progress?

- What types of cooperative measures can be used to enhance National Technical Means (NTM)?

- What would be done if a state were thought: to be impeding the use of NTM?

Solutions. The verification manager would be responsible for coordinating suspect site inspections with NATO. OSIA would make an on-site inspection to verify that no TLE is located at $/$ the suspert site. NATO would inform the compliance manager/OJCS of requests to conduct suspect site inspections on a U.S. facility or at an installation in the area of application. After coordination with the CINC, services, and the State Department, OSIA would send ran escort team to the suspect site to coordinate preparations for the inspection. Respunsibility for determining refusal to inspect would rems.a.l with the service commander. Recommenaulivin: OSIA should be designated to ensure compliance.

\subsubsection{Verification of Remaining Forces after Parity}

\section{Problems.}

- How and when will exit and entry points be established?

- How will temporary excesses of ceilings for trocps and armaments related to routine replacement of troops or other reasons be verified?

- How will constraints on military activity be verified? 
- How will transfers of troops and conventional armaments into the area of application or transit transfers be verified? Can these provisions be verified or monitored by technology, such as sensors attached to the transfers?

Solutions. OSIA would conduct U.S. quota inspections to determine amounts of TLE available at inspected locations. NTM would provide information on sites not included in the on-site inspection regime. The OJCS Data Fusion Center data-base system would continue to track activity of all state parties and display this information to decision makers. An elaborate svstem of exit and entry points need not be established. Proper notification of transfers should suffice to inform all parties of the status of forces. Recommendation: OSIA should be designated to address these problems.

\subsubsection{Verification of Undeclared Sites}

\section{Problems.}

- How will the states define areas of inspection for suspect sites? What will be the method of inspection? How will quotas be differently weighted? How will quotas be tracked by the U.S. data base?

- Can the data base reflect any notification of declaration to inspect a NATO undeclared site? Should this be done on a priority basis, (automatically) notifying decision makers that a suspect site inspection has been requested and also providing information on the location requested?

Solutions. The OSIA would be responsible for U.S. inspection of urideclared sites during Stage 3. This activity would be handled in the same manner as for suspect sites during the preceding stages. Recommendation: OSIA should be designated to address these problems.

\subsubsection{Monitored Storage Sites and Low-Strength Units}

Problem. What measures are needed to verify armaments in permanent storage? Can this be done by on-site inspection (counting)? Would tagging TLE in the monitored storage sites facilitate tracking this category of TLE and ensure that rules for these items are not violated?

Solution. OSIA would make periodic U.S. insuections of low-strength units to determine invent, ipies of TLE in these units. Services will be responsible for assisting inventory inspection of monitored storage sites. OSIA would provide escorts for these inventory inspections. To assist the verification process, tags could be placed on each TLE in storage. These tags should also assist in verifying that changes to the stored 
inventory are correct. The threat of short-notice inventory inspection would be diminished if tags were placed on the TLE in the monitored storage site and in lowstrength units. Recommendation: Research, development, testing, and evaluation should be used to verify information.

\subsubsection{Monitoring Reductions}

\section{Problems.}

- How will inspection of destruction of TLE be accomplished?

- How will personnel reduction be verifled? Will demobilization of personnel take place at specific points? How will demobilization of personnel be verified over time? Can points of exit from the area of application be used to verify personnel demobilization? Can points of entry into the area of application be used to verify new accessions in the area? Does personnel need to be a separate category for monitoring in the data base?

- How, where, and by whom will destruction of TLE be done? What becomes of the end product?

- Is a legislative environmental assessment needed for the destruction of TLE in Europe?

Solutions. Services will be responsible for reducing their TLE within the area of application. If NATO decides to destroy TLE at joint destruction sites, the service responsible for the TLE will work with the host government to accomplish the destruction, which includes providing an environmental impact plan for the destruction process and outlining American responsibilities. Services will also develop a timetable for the reduction of 'TLE. This timetable would be provided to NATO through the CFE manager and OJCS for integration with the reduction schedules of other NATO state parties. The means of destruction, which may consist of cutting TLE, will be decided by NATO. Residual parts of TLE should be declared by inspectors as unserviceable and available for scrap. The NATO may accede to WTO desires to use conversion as a means of elimination. Recommendation: Program manager should be designated to address these problems.

Problem. Which agency has responsibility for planning the movement, storage, and destruction of TLE and the timetable for destruction? Can the data base contain a routine to track destruction accomplishment vs. a declared timetable for destruction over the three-year period?

Solution. The OSIA should provide inspectors to monitor the destruction process and to inspect temporary storage sites that are used to hold TLE awaiting destruction. These temporary storage sites should not be monitored sites; instead, the TLE in the sites should be treated as active-force TLE. If the TLE were tagged to indicate that the items 
were awaiting destruction, the TLE could be removed from the list of active TLE. All notifications of movements to the destruction site, TLE in temporary storage, and destruction would be made by the service responsible for the TLE. Communications would be established from the destruction site to facilitate these communications. Recommendation: OSIA/program marager should te designated to address this problem.

Problem. Can the data base have a destruction file that tracks Eastern Bloc TLE reductions and notifications and provides notification of U.S. reduction activity?

Solution. The OJCS data-base system should contain a data file on the destruction process. It would be used to track, through the use of notification messages and data exchange, all TLE in the elimination pipeline. This eliminations data base would indicate locations of all elimination sites, personnel demobilization sites, and temporary holding sites, and it would reflect numbers of TLE at these sites by type and nationality. Current status of destructions would be compared daily with state party destruction timetables to portray status and trends in the elimination process for all state parties and alliance holdings. Recommendation: Data-base mar.agement and communications should be used to address this problem.

\subsubsection{Replacement, Modernization, and New Technology}

Problems.

- HJw is TLE that is replaced counted in the data base? How is replacement TLE treated? Should the data base have a separate section for this category of TLE?

- What happens to TLE replaced by modernized equipment or new technology? Shall new-technology equipment be added to treaty definitions and have to conform to numerical ceilings?

Solutions. Replacements for TLE listed in the most recent data-exchange document would be repo:ted in transfer notification messages and also in subsequent data-exchange messages. If replacements are of a new, improved model of a TLE identified in the treaty definitions or of a new-technology weapon (such as a directed energy or laser weapon), this change will be reported in data-exchange documents and in transfer notification messages. On-site inspection would verify that the new TLE is in place and the old system has been removed or destroyed. The OJCS data base should highlight replacement TLE and TLE with new-technology weapons. The highlight would display location and type of weapon of this category. Recommendation: Data-base management and communications should be used to address these problems.

\subsubsection{Monitoring Call-Up of Reserves}

Problem. How will states monitor the call-up of reserve, the movernent of forces from one area to another, and the size of military detivity? 
Solution. Services would be responsible for reporting call-up of reserves. If inspection of U.S. reserve exercises in the ar ${ }^{2} \mathrm{a}$ of application is called for, the OSIA would provide escorts and services would be responsible for providing briefings and treispurtation. This provision would most likely be monitored in rear-mobilization areas and at entry points into the area of application. These mobilizations are normally part of other exercises, but they may be part of internal state problems requiring additional security forces. Monitoring internal security problems would be diplomatically sensitive and require special OSIA teams. Recommendation: OSIA/program manager should be designated to address this problem.

\subsubsection{Aerial Inspection}

\section{Problems.}

- What will be the purpose, methods of inspection, and application of quotas involved in aerial inspection?

- Which service will bear responsibility for aerial inspection? What part does the OSIA play in this regime? How are data from this activity shown in the overall CFE data bank?

Solutions. Treaty participants may incorporate requirements for aerial inspection into a more general "Open Skies" regime. Aerial inspection as part of the overall on-site inspection regime should be controlled by the OSIA and integrated into their overall program of inspection. Assets would be assigned to the OSIA and maintained by the Air Force. During inspection of U.S. TLE, OSIA personnel would accompany the aerial inspection. Recommendation: OSIA/program manager should be designated to address these problems.

\subsubsection{Verifying Helicopter and Aircraft Limits}

\section{P-oblems.}

- How will limits on combat aircraft and combat helicopters be verified? Can tags play a part in this verification scheme?

- How will NATO handle Warsaw Pact personnel stationed at its bases and airfields? What would be the NATO scheme for establishing inspection teams at these bases? Would having inspection teams at these bases on a random basis provide for proper verification of aircraft?

- What type of optical and electronic means of observation would be needed at air bases to assist inspection tearns? What is the risk of these items? 
- What would be the problems involved in allowing inspectors the right of examination, including the weapon system? How can these problems be eliminated?

Solutions. Helicopters should be verified in the same manner as other TLE. Onsite inspection of units would provide the accountability needed. Helicopter units are normally assigned in the same manner as artillery units. The assets are normally located withir range of the scheduled inspection. It would be an advantage if all helicopters were tagged to assist in the inventory and to determine nationality. The difference between attack and support helicopters could become a point of contention, but the OSIA would only be tasked to count helicopters and indicate type by model number. Again, tags would be of assistance in identifying which platforms have been declared in which category.

The parties will probably not agree to the WTO proposal to maintain inspectors at airfields. However, it would be important for inspectors to ensure that aircraft declared as one category actually conform to the definitions for that category. As a starting point for aircraft inventory, tagging of each declared aircraft to indicate its category and TLE number would assist the verification process. Inspectors can verify aircratt declared as training, interceptor, or heavy bomber by tag and ensure that the aircraft meet the definitions and are not combat aircraft. These aircraft would then be counted according to category. The OSIA would be responsible for devising a regime of simultaneous airfield inspection, if deemed necessary. The Verification Data Fusion Center data-base system should contain a specific data-tracking system for WTO aircraft. This system would track locations of all WTO aircraft and would be able to present types of aircraft declared to be at each airfield location. The Air Force would be responsible for maintaining the location and types of all U.S. aircraft, including naval shore-based aircraft. The OJCS aircraft compliance data base does not need to be updated by the Air Force to show U.S. aircraft TLE holdings by type and location. Recommendation: Data-base management and communications should be used to address these problems.

\subsubsection{Entry and Exit Points}

\section{Problems.}

- At which points (locations) should entry and exit points (EEPs) be established? What should entry and exit points consist of? Is equipment needed to count TLE? Can automated equipment be used to monitor the EEPs?

- Should there be a program for establishing entry and exit points at railheads, choke points, major highway junctions, seaports, and at air bases?

Solutions. Although the NATO state parties are most likely not to agree to having permanent exit and entry points on their territories in the later stages of treaty 
implementation, there may be a need to establish such points to verify reductions of personnel and replacement of declared TLE. Entry and exit points should be temporary and designed to do specific tasks. Mainly, these points should be defined points in the area of application where an inventory or monitoring process takes place. Definite rules for counting and monitoring should be agreed upon. Parties would be notified in advance when these entry and exit points are to be activated. Equipment will consist only of onsite inspection agreed-upon equipment. Recommendatic 7 : Program manager should be designated to address these problems. 


\section{ELEMENTS OF CONVENTIONAL ARMED FORCES \\ IN EUROPE PROGRAM}

\subsection{OVER VIEW}

\subsubsection{Purpose}

This section proposes a program for systematically implementing the provisions of CFE articles and protocols. This methodology was developed to assist the program manager in determining if any requirement of the treaty articles and protocols was overlooked.

\subsubsection{Scope}

This section is established to form a programmatic framework for work that should be done to implement the CFE treaty. It postulates major program areas, tasks to be accomplished within each of the program areas, and requirements that should be considered as part of each of the task areas. This section refers to all the major treaty articles and protocols. It has been designed to allow for new material to be introduced, if desired, as the treaty process continues.

\subsubsection{Approach}

This section defines six major program elements that could be established. Within these programs, "Key Tasks" are identified. Finally, to assist in developing each of the identified tasks, appropriate scenarios have been referenced from Sec. 4 of this report. Approaches to the tasks can be established by using these scenarios as "requirements."

\subsection{KEY PROGRAM ELEMENTS}

Key programs are grouped under the following headings:

1. Program Management,

2. Compliance Program,

3. Verification Program,

4. Verification RDT\&E Program,

5. Data Base and Communications Program, and

6. NATO Liaison Program. 
Major tasks for each of these programs are identified, and requirements are referenced to the scenario areas in Sec. 4 of this report. Although some of the tasks

have no requirements referenced, these tasks still need to be accomplished.

\subsection{PROGRAM TASKS AND REQUIREMENTS}

\section{PROGRAM 1. Program Management}

TASK 1.1 Develop a Compliance Strategy

- TLE Tracking (Sec. 4.2; subsection 4.2.1).

- Military Spending Data (Sec. 4.7; subsection 4.7.4).

- Destruction of TLE (Sec. 4.10; subsection 4.10.8).

- Entry and Exit Points (Sec. 4.10; subsection 4.10.13)

- Exceeding Ceilings (Sec. 4.8; subsection 4.8.5)

- Reserve Mobilization (Sec. 4.8; subsection 4.8.6)

- Equipment Movement (Sec.4.8; subsection 4.8.7)

- TLE Monitored Storage Tracking (Sec. 4.9; subsection 4.9.1)

- Monitored Storage Sites (Sec. 4.9; subsection 4.9.2)

- Unmonitored Storage Sites (Sec, 4.9; subsection 4.9.3)

- Removal of TLE from Monitored Storage (Sec. 4.9; subsection 4.9.4)

- Military Activity Constraints (Sec. 4.9; subsection 4.9.9)

- Transfers of TLE (Sec. 4.9; subsection 4.9.10)

- Personnel Strength Verification (Sec. 4.10; subsection 4.10.2)

- Verification of Residual Levels (Sec. 4.10; subsection 4.10.3)

- Suspect Site Inspection (Sec. 4.10; subsection 4.10.4)

- Replacement Items (Sec. 4.10; subsection 4.10.9)

- Monitoring Reserve Mobilization (Sec. 4.10; subsection 4.10.10) 
TASK 1.2 Develop an Acquisition Strategy

- Exceeding Ceilings (Sec. 4.8; subsection 4.8.5)

- Removal of TLE from Monitored Storage (Sec. 4.9; subsection 4.9.4)

- Personnel Strength Verification (Sec. 4.10; subsection 4.10.2)

- Verification of Undeclared Sites (Sec. 4.10; subsection 4.10.6)

- Tracking of TLE Undergoing Elimination (Sec. 4.10; subsection 4.10.8)

- Replacement Items (Sec. 4.10; subsection 4.10.9)

- Monitoring Reserve Mobilization (Sec. 4.10; subsection 4.10.10)

- Verifying Helicopter Limits (Sec. 4.10; subsection 4.10.12)

\section{TASK 1.3 Develop a CFE Master Schedule Program}

- Data-Base Mock Inspection (Sec. 4.7; subsection 4.7.3)

- Mock Inspection (Sec. 4.6; subsection 4.6.2)

- Destruction of TLE (Sec. 4.10; subsection 4.10.8)

TASK 1.4 Develop a CFE Funding Program

\section{PROGRAM 2. Compliance Program}

TASK 2.1 Prepare the Compliance Plan

- TLE Tracking (Sec. 4.2; subsection 4.2.2)

- Tracking of TLE Undergoing Elimination (Sec. 4.2)

- Tracking AIFV and HACV (Sec. 4.2; subsection 4.2.4)

- Tracking NATO TLE (Sec. 4.2; subsection 4.2.2)

- Tracking Personnel (Sec. 4.2; subsection 4.2.6)

- Tracking Helicopters (Sec. 4.2; subsection 4.2.7) 
- Tracking Aircraft (Sec. 4.2; subsection 4.2.7)

- Tracking Personnel Demobilization (Sec. 4.2; subsection 4.2.6)

- Tracking TLE in Regional Subzones (Sec. 4.5; subsection 4.5.1)

- Suspect Site Inspection (Sec. 4.10; subsection 4.10.4)

- Verification of Forces during Stage 3 (Sec. 4.10; subsection 4.10.5)

- Verifying Single-Country Limits (Sec. 4.3)

- Verifying Stationing Ceilings (Sec. 4.4; subsection 4.4.1)

- Methods for Counting TLE (Sec. 4.6; subsection 4.6.1)

- Storage Provisions (Sec. 4.4; subsection 4.4.1)

- Destruction of TLE (Sec. 4.10; subsection 4.10.8)

- Organizational Structure Changes (Sec. 4.8; subsection 4.8.1)

- Force Strength Changes (Sec. 4.8; subsection 4.8.2)

- Exceeding Cellings (Sec. 4.8; subsection 4.8.4)

- Reserve Mobilization (Sec. 4.8; subsection 4.8.6)

- Equipment Movement (Sec. 4.8; subsection 4.8.7)

- TLE Monitored Storage Tracking (Sec. 4.9; subsection 4.9.1)

- Monitored Storage Sites (Sec. 4.9; subsection 4.9.2)

- Mobile Bridging Equipment (Sec. 4.9; subsection 4.9.7)

- Exercise Size (Sec. 4.9; subsection 4.9.8)

- Military Activity Constraints (Sec. 4.9; subsection 4.9.9)

- Transfers of TLE (Sec. 4.9; subsection 4.9.10)

- Force Restructuring (Sec. 4.9; subsection 4.9.11)

- Personnel Strength Verification (Sec. 4.10; subsection 4.10.2)

- Verification of Residual Levels (Sec. 4.10; subsection 4.10.3) 
- Suspect Site Inspection (Sec. 4.10; subsection 4.10.4)

- Replasement Items (Sec. 4.10; subsection 4.10.9)

- Monitoring Reserve Mobilization (Sec. 4.10; subsection 4.10.10)

\section{TASK 2.2 Prepare Facilities}

- Prepare Installation Inspection Plan (no applicable scenario)

- Monitored Storage Sites (Sec. 4.9; subsection 4.9.2)

- Prepare Data Exchange Plan (no applicable scenario)

- Prepare Treaty Notification Plan (no applicable scenario)

- Notice of Reductions (Sec, 4.8; subsection 4.8.3)

- Changes in Maximum Levels (Sec. 4.8; subsection 4.8.4)

- Monitored Storage Sites (Sec. 4.9; subsection 4.9.2)

- Removal of TLE from Monitored Storage (Ser. 4.9; subsection 4.9.4)

- Mobile Bridging Equipment (Sec. 4.9; subsection 4.9.7)

- Inspection of Declared Sites (Sec. 4.10; subsection 4.10.1)

- Suspect Site Inspection (Sec. 4.10; subsection 4.10.4)

- Destruction of TLE (Sec. 4.10; subsection 4.10.8)

\section{TASK 2.3 Conduct Mock Inspections}

- Mock Inspection (Sec. 4,6; subsection 4.6.2)

- Monitored Storage Sites (Sec. 4.9; subsection 4.9.2)

- Removal of TLE from Monitored Storage (Sec. 4.9; subsection 4.9.4)

- Mobile Bridging Equipment (Sec. 4.9; subsection 4.9.7)

- Inspection of Declared Sites (Sec. 4.10; subsection 4.10.1)

- Verification of Residual Levels (Sec. 4.10; subsection 4.10.3) 
- Suspect Site Inspection (Sec. 4.10; subserstion 4.10.4)

- Destruction of TLE (Sec. 4.10; subsection 4.10.8)

- Tracking of TLE Undergoing Elimination (Sec. 4.10; subsection 4.10.8)

- Entry and Exit Points (Sec. 4.10; subsection 4.10.13)

TASK 2.4 Prepare the OSLA Compliance Program

- Equipment Data Base (Sec. 4.1)

a Inspection/Monitoring the Destruction Process (Sec. 4.10; subsection 4.10.8)

- Change Notification Messages (Sec. 4.2; subsection 4.2.5)

- Methods for Counting TLE (Sec. 4.6; subsection 4.6.1)

- Mobile Bridging Equipment (Sec. 4.9; subsection 4.9.7)

- Inspection of Declared Sites (Sec. 4.10; subsection 4.10.1)

- Verification of Residual Levels (Sec. 4.10; subsection 4.10.3)

- Suspect Site Inspection (Sec. 4.10; subsection 4.10.4)

- Destruction of TLE (Sec. 4.10; subsection 4.10.8)

- Replacement Items (Sec. 4.10; subsection 4.10.9)

- Entry and Exit Points (Sec. 4.10; subsection 4.10.13)

PROGRAM 3. Verification Prograin

TASK 3.1 Prepare OSIA Program

- Equipment Data Base (Sec. 4)

- Inspection (Sec. 4.10; subsection 4.10.1)

- Undeclared Sites (Sec. 4.10; subsection 4.10.6)

- Verification of Monitored Storage Sites (Sec. 4.10; subsection 4.10.7)

- Monitoring Reserve Mobilization (Sec. 4.10; subsection 4.10.10) 
- Aerial Inspection (Sec. 4.10; subsection 4.10.11)

- Verifying Aircraft Limits (Seo. 4.10; subsection 4.10.12)

- Notice of Reductions (Sec. 4.8; subsection 4.8.3)

- Equipment Movement. (Sec. 4.8; subsection 4.8.7)

- Equipment in Unmonitored Storage (Sec. 4.9; subsection 4.9,6)

- Mcbile Bridging Equipment (Sec. 4.9; subsection 4.9.7)

- Inspection of Declared Sites (Sec. 4.10; subsection 4.10.1)

- Verification of Residual Levels (Sec. 4.1.0; subsection 4.10.3)

- Suspect Site Inspection (Sec. 4.10; subsection 4.10.4)

- Verification of Forces during Stage 3 (Sec. 4.10; subsection 4.10.5)

- Verification of Undeclared Sites (Sec. 4.10; subsection 4.10.6)

- Destruction of TLE (Sec. 4.10; subsection 4.10.8)

- Inspection/Monitoring of the Destruction Process (Sec. 4.10; subsection 4.10.8)

- Replacement Items (Sec. 4.10; subsection 4.10.9)

- Monitoring Reserve Mobilization (Sec.4.10; subsection 4.10.10)

- Verifying Helicopter Limits (Sec. 4.10; subsection 4.10.12)

- Entry and Exit Points (Sec. 4.10; subsection 4.10.13)

TASK 3.2 Prepare Verification Plan

- Methods for Counting TLE (Sec. 4.6; subsection 4.6.1)

- Tracking Helicopters (Sec. 4.2; subsection 4.2.7)

- Verifying Helicopter Limits (Sec. 4.10; subsection 4.10.12)

- Tracking Aircraft (Sec. 4.2; subsection 4.10.12)

- Tracking TLE in Regional Subzones (Sec. 4.5; subsection 4.5.1) 
- Verifying Single-Country Limits (Sec. 4.2)

- Verifying Staticning Ceilings (Sec. 4.4; subsection 4.4.1)

- Storage Provisions (Sec. 4.4; subsection 4.4.2)

- Low-Strength Unit TLE Tracking (Sec. 4.4; subsection 4.4.1)

- Tracking Personnel Demobilization (Sec. 4.4; subsection 4.4.1)

- Urganizational Structure Changes (Sec. 4.8; subsection 4.8.1)

- Force Strength Changes (Sec. 4.8; subsection 4.8.2)

- Notice of Reductions (Sec. 4.8; subsection 4.8.3)

- Changes in Maximum Levels (Sec. 4.8; subsection 4.8.4)

- Exceeding Ceilings (Sec. 4.8; subsection 4.8.5)

- Reserve Mobilization (Sec. 4.8; subsection 4.8.6)

- Equipment Movement (Sec. 4.8; subsection 4.8.7)

- Removal of TLE from Monitored Storage (Sec. 4.9; subsection 4.9.4)

- Equipment in Monitored Low-Strength Units (Sec. 4.9; subsection 4.9.5)

- Equipment in Unmonitored Storage (Sec. 4.9; subsection 4.9.6)

- Mobile Bridging Equipment (Sec. 4.9; subsection 4.9.7)

- Exercise Size (Sec. 4.9; subsection 4.9.8)

- Military Activity Constraints (Sec. 4.9; subsection 4.9.9)

- Force Restructuring (Sec. 4.9; subsection 4.9.11)

- Personnel Strength Verification (Sec. 4.L0; subsection 4.10.2)

- Verification of Residual Levels (Sec. 4.10; subsection 4.10.3)

- Verification of Forces during Stage 3 (Sec. 4.10; subsection 4.10.5)

- Verification of Undeclared Sites (Sec. 4.10; subsection 4.10.6)

- Verific ztion of Monitored Storage Sites (Sec. 4.10; subsection 4.10.7) 
- Destruction of TLE (Sec. 4.10; subsection 4.10.8)

- Inspection/Monitoring of the Destruction Process (Sea. 4.10; subsection 4.10.8)

- Tracking of TLE Undergoing Elimination (Sec. 4.10; subsection 4.10.8)

- Replacernent Items (Sec. 4.10; subsection 4.10.9)

- Monitoring Reserve Mobilization (Sec. 4.10; subsection 4.10.10)

- Verifying Aircraft Limits (Sec. 4.10; subsection 4.10.12)

\section{TASK 3.3 Prepare Acquisition Strategy}

- Tracking TLE (Sec. 4.2; subsection 4.2.1)

- Tracking AIFV and HACV (Sec. 4.2; subsection 4.2.4)

- Tracking TLE in Regional Subzones (Sec. 4.5; subsection 4.5.1)

- Change Notification Messages (Sec. 4.2)

- Tracking Personnel (Sec. 4.2; subsection 4.2.6)

- Personnel Strength Verification (Sec. 4.10; subsection 4.10.2)

- Methods for Counting TLE (Sec. 4.6; subsection 4.6.1)

- Equipment Movement (Sec. 4.8; subsection 4.8.7)

- Equipment in Monitored Low-Strength Units (Sec. 4.9; subsection 4.9.5)

- Equipment in Unmonitored Storage (Sec. 4.9; subsection 4.9.6)

- Transfers of TLE (Sec. 4.9; subsection 4.9.10)

- Suspect Site Inspection (Sec. 4.10; subsection 4.10.4)

- Verification of Forces during Stage 3 (Sec. 4.10; subsection 4.10.5)

- Verification of Undeclared Sites (Sec.4.10; subsection 4.10.6)

- Tracking of TLE Undergoing Elimination (Sec. 4.10; subsection 4.10.8)

- Replacement Items (Sec. 4.10; subsection 4.10.9) 
- Verifying Helicopter Limits (Sec. 4.10; subseotion 4.10.12)

- Verifying Aircraft Limits (Sec. 4.10; subsection 4.10.12)

- Entry and Exit Points (Sec. 4.10; subsection 4.010.13)

\section{PROGRAM 4: RDT\&E Program}

TASK 4.1 Develop a Perimeter Portal Monitoring Program

- Entry and Exit Points (Sec. 4.10; subsection 4.10.13)

- Removal of TLE from Monitored Storage (Sec. 4.9; subsection 4.9.4)

- Equipment in Monitored Low-Strength Units (Sec. 4.9; subsection 4.9.5)

- Mobile Bridging Equipment (Sec. 4.9; subsection 4.9.7)

- Destruction of TLE (Sec. 4.10; subsection 4.10.8)

- Inspection/Monitoring of the Destruction Process (Sec. 4.10; subsection 4.10 .8 )

- Entry and Exit Points (Sec. 4.10; subsection 4.10.13)

\section{TASK 4.2 Prepare Tagging Alternatives}

- Tracking Aircraft (Sec. 4.2; subsection 4.2.7)

- Tracking AIFV and HACV (Sec. 4.2; subsection 4.2.4)

- Monitored Storage Sites (Sec. 4.9; subsection 4.9.2)

- Verification of Monitored Storage Sites (Sec. 4.10; supsection 4.10.7)

- Verifying Helicopter Limits (Sea. 4.10; subsection 4.10.12)

- Verifying Aircraft Limits (Sec. 4.10; subsection 4.10.12)

- Methods for Counting TLE (Sec. 4.6; subsection 4.6.1)

- Removal of TLE from Monitored Storage (Sec. 4.9; subsection 4.9.4)

- Equipment in Monitored Low-Strength Units (Sec. 4.9; subsection 4.9.5) 
- Mobile Bridging Equipment (Sec. 4.9; subsection 4.9.7)

- Destruction of TLE (Sec. 4.10; subsection 4.10.8)

- Inspection/Monitoring of the Destruction Process (Sec. 4.10; subsection 4.10 .8 )

- Tracking of TLE Undergoing Elimination (Sec. 4.10; subsection 4.10.8)

- Replacement Items (Sec. 4.10; subsection 4.10.9)

\section{TASK 4.3 Develop an Aerial Sensors Study Program}

\section{TASK 4.3.1 Develop an Open Skies Framework Program}

- Methods for Counting TLE (Sec. 4.6; subscction 4.6.1)

- Exercise Size (Sec. 4.9; subsection 4.9.8)

- Military Activity Constraints (Sec. 4.9; subsection 4.9.9)

- Verification of Forces during Stage 3 (Sec. 4.10; subsection 4.10.5)

- Verification of Undeclared Sites (Sec. 4.10; subsection 4.10.6)

- Verification of Monitored Storage Sites (Sec. 4.10; subsection 4.10.7)

- Destruction of TLE (Sec. 4.10; subsection 4.10.8)

- Inspection/Monitoring of the Destruction Process (Sec. 4.10; subsection 4.10 .8 )

- Tracking of TLE Undergoing Elimination (Sec. 4.10; subsection 4.10.8)

- Replacement Items (Sec. 4.10; subsection 4.10.9)

- Monitoring Reserve Mobilization (Sec. 4.10; subsection 4.10.10)

- Aerial Inspection (Sec. 4.10; subsection 4.10.11)

- Verifying Helicopter Limits (Sec. 4.10; subsection 4.10.12)

- Verifying Aircraft Limits (Sec. 4.10; subsection 4.10.12)

- Entry and Exit Points (Sec. 4.10; subsection 4.10.13) 
TASK 4.3.2 Develop a Video/Photography Framework Program

- Methods for Counting TLE (Sec. 4.6; subsection 4.1)

- Equipment in Unmonitored Storage (Sec. 4.9; subsection 4.9.6)

- Mobile Bridging Equipment (Sec، 4.9; subsection 4.9.7)

- Replacement Items (Sec. 4.10; subsection 4.10.9)

TASK 4.4 Develop a Framework for Utilization of Movement Sensors

- Equipment Movement (Sec. 4.8; subsection 4.8.7)

- Mobile Bridging Equipment (Sec. 4.9; subsection 4.9.7)

- Transfers of TLE (Sec. 4.9; subsection 4.9.10)

- Entry and Exit Points (Sec. 4.10; subsection 4.10.13)

PROGRAM 5: Data-Base and Communications Program

TASK 5.1 Develop an OJCS Data-Base System Program

- Define Requirements for the OASIS System

- Data Exchange Formulation, Consolidation, and Transfer (Sec. 4.7; subsection 4.7.1)

- Data Tracking and Update (Sec. 4.7; subsection 4.7.2)

- Change Notification Messages (Sec. 4.2)

- Tracking NATO TLE (Sec. 4.2; subsection 4.2.2)

- Tracking AIFV AND HACV (Sec. 4.2; subsection 4.2.4)

- Tracking Personnel (Sec. 4.2; subsection 4.2.6)

- Tracking Helicopters (Sec. 4.2; subsection 4.2.7)

- Verifying Helicopter Limits (Sec. 4.10; subsection 4.10.12)

- Tracking Aircraft (Sec. 4.2; subsection 4.2.7) 
- Verifying Single-Country Limits (Sec. 4.3)

- Verifying Stationing Ceilings (Sec. 4.4; subsection 4.4.1)

- Storage Provisions (Sec. 4.4; subsection 4.4.2)

- Low-Strength Unit TLE Tracking (Sec.4.4; subsection 4.4.3)

- Trackirg Personnel Demobilization (Sec. 4.4; subsection 4.4.4)

- Tracking TLE in Regional Subzones (Sec. 4.4; subsection 4.5.1)

- CFE Data-Base Tracking System (Sec. 4.7)

- Organizational Structure Changes (Sec. 4.8; subsection 4.8.1)

- TLE Monitored Storage Tracking (Sec. 4.9; subsection 4.9.1)

- Tracking of TLE Undergoing Elimination (Sec. 4.9; subsection 4.10.8)

- Replacement Items (Sec. 4.10; subsection 4.10.9)

- Equipment Data Base (Sec. 4.1)

- Mock Inspection (Sec. 4.6; subsention 4.6.2)

- Data-Base Mock Inspection (Sec. 4.7; subsection 4.7.1)

- Force Strength Changes (Sec. 4.8; subsection 4.8.2)

- Notice of Reductions (Sec. 4.8; subsection 4.8.3)

- Changes in Maximum Levels (Sec. 4.8; subsection 4.8.4)

- Exceeding, Ceilings (Sec. 4.8; subsection 4.8.5)

- Reserve Mobilization (Sec. 4.8; subsection 4.8.6)

- Equipment Movement (Sec. 4.8; subsection 4.8.7)

- TLE Monitored Storage Tracking (Sec. 4.9; subsection 4.9.1)

- Monitored Storage Sites (Sec. 4.9; subsection 4.9.2)

- Unmonitored Storage Sites (Sec. 4.9; subsection 4.9.3)

- Removal of TLE from Monitored Storage (Sec. 4.9; subsection 4.9.4) 
- Equipment in Monitored Low-Strength Units (Sec. 4.9; subsection 4.9.5)

- Equipment in Unmonitored Storage (Sec. 4.9; subsection 4.9.6)

- Mobile Bridging Equipment (Sec. 4.9; subsection 4.9.7)

- Exercise Size (Sec. 4.9; subsection 4.9.8)

- Military Activity Constraints (Sec. 4.9; subsection 4.9.9)

- Transfers of TLE (Sec. 4.9; subsection 4.9.10)

- Force Restructuring (Sec. 4.9; subsection 4.9.11)

- Inspection of Declared Sites (Sec. 4.10; subsection 4.10.1)

- Personnel Strength Verification (SEc. 4.10; subsection 4.10.2)

- Verification of Residual Levels (Sec. 4.10; subsection 4.10.3)

- Suspect Site Inspection (Sec. 4.10; subsection 4.10.4)

- Veritication of Forces during Stage 3 (Sec. 4.10; subsection 4.10.5)

- Destruction of TLE (Sec. 4.10; subsection 4.10.8)

- Inspection/Monitoring of the Destruction Process (Sec. 4.10; subsection 4.10 .8 )

- Tracking of TLE Undergoing Elimination (Sec. 4.10; subsection 4.10.8)

- Replacement Items (Sec. 4.10; subsection 4.10.9)

- Monitoring Reserve Mobilization (Sec. 4.10; subsection 4.10.10)

- Verifying Aircraft Limits (Sec. 4.10; subsection 4.10.12)

\section{TASK 5.2. Develop a CFE Communications Program}

- Tracking and Updating Data (Sec. 4.7; subsection 4.7.2)

- CFF Data-Base Tracking System (Sec. 4.7)

- Inspections (Sec. 4.10; subsection 4.10.1)

- Mock Inspection (Sec. 4.6; subsection 4.6.1) 
- Data-Base Mock Inspection (Sec. 4.7; subsection 4.7.3)

- Force Strength Changes (Sec. 4.8; subsection 4.8.2)

- Notice of Reductions (Sec. 4.8; subsection 4.8.3)

- Changes in Maximum Levels (Sec. 4.8; subsection 4.8.4)

- Transfers of TLE (Sec. 4.9; subsection 4.9.10)

- Personnel Strength Verification (Sec. 4.10; subsection 4.10.2)

- Verification of Residual Levels (Sec. 4.10; subsection 4.10.3)

- Suspect Site Inspection (Sec. 4.10; subsection 4.10.4)

- Tracking of TLE Undergoing Elimination (Sec. 4.10; subsection 4.10.8)

- Verifying Aircraft Limits (Sec. 4.10; subsection 4.10.12)

- Entry and Exit Points (Sec. 4.10; subsection 4.10.13)

\section{TASK 5.3 Prepare a Service Data-Base Program}

\section{TASK 5.3.1 Prepare an Army Data-Base Program}

- Change Notification Messages (Sec. 4.2)

- Tracking A.IFV and HACV (Sec. 4.2; subsection 4.2.4)

- Tracking Helicopters (Sec. 4.2; subsection 4.2.7)

- Tracking Aircraft (Sec. 4.2; subsection 4.2.7)

- Verifying Single-Country Limits (Sec. 4.3)

- Verifying Stationing Ceilings (Sec. 4.4; subsection 4.4.1)

- Storage Provisions (Sec. 4.4; subsection 4.4.2)

- Trauking Personnel Demobilization (Sec. 4.4; subsection 4.4.1.)

- Tracking TLE in Regional Subzones (Sec. 4.5; subsection 4.5.1)

- Data Exchange Formulation, Consultation, and Transfer (Sec. 4.7; subsection $4,7,1$ ) 
- Data Tracking and Update (Sec. 4.7; subsection 4.7.2)

- Data-Base Mock Inspection (Sec. 4.7; subsection 4.7.3)

- Organizational Structure Changes (Sec. 4.3; subsection 4.8.1)

- Force Strength Changes (Sec. 4.8; subsection 4.8.2)

- Notice of Reductions (Sec. 4.8; subsection 4.8.3)

- Exceeding Ceilings (Sec. 4.8; subsection 4.8.5)

- Reserve Mobilization (Sec. 4.8; subsection 4.8.6)

- Equipment Movement (Sec. 4.8; subsection 4.8.7)

- TLE Moritored Storage Tracking (Sec. 4.9; subsection 4.9.1)

- Monitored Storage Sites (Sec. 4.9; subsection 4.9.2)

- Unmonitored Storage Sites (Sec. 4.9; subsection 4.9.3)

- Removal of TLE from Monitored Storage (Sec. 4.9; subsection 4.9.4)

- Mobile Bridging Equipment (Sec. 4.9; subsection 4.9.7)

- Exercise Size (Sec. 4.9; subsection 4.9.8)

- Military Activity Constraints (Sec. 4.9; subsection 4.9.9)

- Transfers of TLE (Sec. 4.9; subsection 4.9.10)

- Force Restructuring (Sec. 4.9; subsection 4.9.1.1)

- Personnel Strength Verification (Sec. 4.10; subsection 4.10.2)

- Verification of Residual Levels (Sec. 4.10; subsection 4.10.3)

- Suspect Site Inspection (Sec. 4.10; subsection 4.10.4)

- Destruction of TLE (Sec. 4.10; subsection 4.10.8)

- Tracking of TLE Undergoing Elimination (Sec. 4.10; subsection 4.10.8)

- Replacement Items (Sec، 4.10; subsection 4.10.9)

- Monitoring Reserve Mobilization (Sec. 4.10; subsection 4.10.10) 
TASK 5.3.2 Prepare an Air Force Data-Base Program

- Change Notification Messages (Sec. 4.2)

- Tracking Helicopters (Sec. 4.2; subsection 4.2.7)

- Tracking Aircraft (Sec. 4.2; subsection 4.2.7)

- Verifying Single-Country Limits (Sec. 4.3)

- Verifying Stationing Ceilings (Sec. 4.4; subsection 4.4.1)

- Storage Provisions (Sec. 4.4; subsection 4.4.1)

- Tracking Personnel Demobilization (Sec. 4.4; subsection 4.4.4)

- Tracking TLE in Regional Subzones (Sec. 4.5; subsection 4.5.1)

- Data Exchange Formulation, Consolidation, and Transfer (Sec. 4.7; subsection 4.7.1)

- Data Tracking and Update (Sec. 4.7; subsection 4.7.2)

- Data-Base Mock Inspection (Sec. 4.7; subsection 4.7.3)

- Organizational Structure Changes (Sec. 4.8; subsection 4.8.1)

- Force Strength Changes (Sec. 4.8; subsection 4.8.2)

- Notice of Reductions (Sec.4.8; subsection 4.8.3)

- Exceeding Ceilings (Sec. 4.8; subsection 4.8.5)

- Reserve Mobilization (Sec. 4.8; subsection 4.8.6)

- Equipment Movement (Sec. 4.8; subsection 4.8.7)

- TLE Monitored Storage Tracking (Sec. 4.9; subsection 4.9.1)

- Monitored Storage Sites (Sec. 4.9; subsection 4.9.2)

- Unmonitored Storage Sites (Sec. 4.9; subsection 4.9.3)

- Rumoval of TLE from Monitored Storage (Sec. 4.9; subsection 4.9.4)

- Exercise Size (Sec. 4.9; subsection 4.9.8)

- Military Activity Constraints (Sec. 4.9; subsection 4.9.9) 
- Transfers of TLE (Sec. 4.9; subsection 4.9.10)

- Force Restructuring (Sec. 4.9; subsection 4.9.11)

- Personnel Strength Verification (Sec. 4.10 ; subsection 4.10.2)

- Verification of Residual Levels (Sec. 4.10; subsection 4.10.3)

- Suspect Site Inspection (Sec. 4.10; subsection 4.10.4)

- Destruction of TLE (Sec. 4.10; subsection 4.10.8)

- Tracking of TLE Undergoing Elimination (Sec. 4.10; subsection 4.10.8)

- Replacement Items (Sec. 4.10; subsection 4.10.9)

- Monitoring Reserve Mobilization (Sec. 4.10; subsection 4.10.10)

- Verifying Aircraft Limits (Sec. 4.10; subsection 4.10.12)

TASK 5.3.3 Prepare a Navy Data-Base Program

- Change Notification Mezsages (Sec. 4.2)

- Tracking Aircraft (Sec. 4.2; subsection 4.2.7)

- Verifying Single-Country Limits (Sec. 4.3)

- Verifying Stationing Ceilings (Sec. 4.4; subsection 4.4.1)

- Storage Provisions (Sec. 4.4; subsection 4.4.2)

- Tracking Personnel Demobilization (Sec. 4.4; subsection 4.4.4)

- Data Exchange Formulation, Consolidation, and Transfer (Sec. 4.7; subsection 4.7.1)

- Data Tracking and Update (Sec. 4.7; subsection 4.7.2)

- Data-Base Mock Inspection (Sec. 4.7; subsection 4.7.3)

- Organizational Structure Changes (Sec. 4.8; subsection 4.8.1)

- Force Strength Changes (Sec. 4.8; subsection 4.8.2)

- Notice of Reductions (Sec. 4.8; subsection 4.8.3) 
- Exceeding Cellings (Sec. 4.8; subsection 4.8.5)

- Reserve Mobilization (Sec. 4.8; subsection 4.8.6)

- Unmonitored Storage Sïtes (Sec. 4.9; subsection 4.9.3)

- Transfers of TLE (Sec. 4.9; subsection 4.9.10)

- Force Restructuring (Sec. 4.9; subsection 4.9.1.1)

- Personnel Strength Verification (Sec. 4.10; subsection 4.10.2)

- Verification of Residual Levels (Sec. 4.10; subsection 4.10.3)

- Suspect Site Inspection (Sec. 4.10; subsection 4.10.4)

- Replacement Items (Sec, 4.10; subsection 4.10.9)

- Monitoring Reserve Mobilization (Sec. 4.10; subsection 4.10.10)

- Verifying Aircraft Limits (Sec. 4.10; subsection 4.10.12)

TASK 5.4 Prepare a Defense Intelligence Agency Data-Base Program

- Tracking TLE (Sec. 4.2; subsection 4.2.1)

- Tracking TLE in Regional Subzones (Sec. 4.5; subsection 4.5.1)

- CFE Data-Base Tracking System (Sec. 4.7; subsection 4.5.1)

- Organizational Structure Changes (Sec. 4.8; subsection 4.8.1)

- Force Strength Changes (Sec. 4.8; subsection 4.8.2)

- Notice of Reductions (Sec. 4.8; subsection 4.8.3)

- Changes in Maximurn Levels (Sec. 4.8; subsection 4.8.4)

- Exceeding Ceilings (Sec. 4.8.5)

- Equipment Movement (Sec. 4.8; subsection 4.8.7)

- Removal of TLE from Monitored Storage (Sec. 4.9; subsection 4.9.4)

- Equipment in Monitored Low-Strength Units (Sec. 4.9; subsection 4.9.5)

- Equipment in Unmonitored Storage (Sec. 4.9; subsection 4.9.6) 
- Mobile Bridging Equipment (Sec. 4.9; subsection 4.9.7)

- Transfers of TLE (Sec. 4.9; subsection 4.9.10)

- Force Restructuring (Sec. 4.9; subsection 4.9.11)

- Inspection of Declared Sites (Sec. 4.10; subsection 4.10.1)

- Verification of Personnel Strength (Sec. 4.10; subsection 4.10.2)

- Verification of Residual Levels (Sec. 4.10; subsection 4.10.3)

- Suspect Site Inspection (Sec. 4.10; subsection 4.10.4)

- Verification of Forces during Stage 3 (Sec. 4.10; subsection 4.10.5)

- Verification of Undeclared Sites (Sec. 4.10; subsection 4.10.6)

- Destruction of 'T'LE (Sec. 4.10; subsection 4.10.8)

- Replacement Item/s (Sec. 4.10; subsection 4.10.9)

- Monitoring Reserve Mobilization (Sec. 4.10; subsection 4.10.10)

- Verifying Aircraft Limits (Sec. 4.10; subsection 4.10.12)

TASK 5.5 Prepare a Notifications Requirements Program

- OSIA and Change Notification Messages (Sec. 4.2)

- Organizational Struature Change (Sec. 4.8; subsection 4.8.1)

- Force Strength Changes (Sec. 4.8; subsection 4.8.2)

- Notlce of Reductions (Sec. 4.8; subsection 4.8.3)

- Changes to Maximum Levels (Sec. 4.8; subsection 4.8.4)

- Exceeding Ceilings (Sec. 4.8; subsection 4.8.5)

- Reserve Mobilization (Sec. 4.8; subsection 4.8.6)

- Equipment Movement (Sec. 4.8; subsection 4.8.7)

- Data Exchange Formulation, Consolidation, and Transfer (Sec. 4.7; subsection 4.7.1) 
- Data Tracking and Ujpdate (Sec. 4.7; subsection 4.7.2)

- CFE Data-Base Tracking System (Sec. 4.7)

- Removal of TLE from Monitored Storage (Sec. 4.9; subsection 4.9.4)

- Equipment in Unmonitored Storage (Sec. 4.9; subsection 4.9.6)

- Exercise Size (Sec. 4.9; subsection 4.9.8)

- Military Activity Constraints (Sec. 4.9; subsection 4.9.9)

- Transfers of TLE (Sec. 4.9; subsection 4.9.10)

- Irispention of Declared Sites (Sec. 4.10; subsection 4.10.1)

- Personnel Strength Verification (Sec. 4.10; subsection 4.10.2)

- Suspect Site Inspection (Sec. 4.10; subsection 4.10.4)

- Destruction of TLE (Sec. 4.10; subsection 4.10.8)

- Traoking of TLE Undergoing Elimination (Sec. 4.10; subsection 4.10.8)

- Replacement Items (Sec. 4.10; subsection 4.10.9)

- Monitoring Reserve Mobilization (Sec. 4.10; subsection 4.10.10)

- Verifying Aircraft Limits (Sec. 4.10; subseciton 4.10.12)

\section{TASK 5.6 Prepare a Data-Exchange Program}

- Data Exchange Formulation, Consolidation, and Transfer (Sec. 4.7; subsection, 4.7.1)

- CFE Data-Base Tracking System (Sec. 4.7)

- Unmonitored Storage Sites (Sec. 4.9; subsection 4.9.3)

- Equipment in Unmonitored Storage (Sec. 4.9; subsection 4.9.6)

- Mobile Bridging Equipment (Sec. 4.9; subsection 4.9.7)

- Exercise Size (Sec. 4.9; subsection 4.9.8)

- Replacement Items (Sec. 4.10; subsection 4.10.9) 
TASK 5.7 Prepare a NATO Communications Program

- Mock Inspection (Sec. 4.6; subsection 4.6.2)

- Notice of Reductions (Sec, 4.8; subsection 4.8.3)

- Changes in Maximum Levels (Sec. 4.8; subsection 4.8.4)

- Military Activity Constraints (Sec. 4.9; subqection 4.9.9)

- Transfers of TLE (Sec. 4.9; subsection 4.9.10)

- Force Restructuring (Sec. 4.9; subsection 4.9.11)

- Inspection of Declared Sites (Sec. 4.10; subsection 4.10.1)

- Verification of Residual Levels (Sec. 4.10; subsection 4.10.3)

- Suspect Site Inspection (Sec. 4.10; subsection 4.10.4)

- Verification of Forces during Stage 3 (Sec. 4.10; subsection 4.10.5)

- Tracking of TLE Undergoing Elimination (Sec. 4.10; subsection 4.10.8)

TASK 5.8 Prepare a Treaty Analy:sis and Presentation Program

- Equipment Data-Base (Sec. 4.1)

- Data-Base Requirements (Sec. 4.5; subsection 4.5.2)

- Organizational Structure Changes (Sec. 4.8; subsection 4.8.1)

- Force Strength Changes (Sec. 4.8; subsection 4.8.2)

- Unmonitored Storage Sites (Sec. 4.9; subsection 4.9.3)

- Removal from Monitored Storage (Sec. 4.9; subsection 4.9.4)

- Monitored Low-Strength Units (Sec. 4.9; subsection 4.9.5)

- Unmonitored Storage at: Low-Strength Units (Sec. 4.9; subsection 4.9.6)

- Mobile Bridging Equipment (Sec. 4.9; subsection 4.9.7)

- Exercises (Sec. 4.9; subsection 4.9.8)

- Transfers of TLE (Sec. 4.9; subsection 4.9.10) 
- Force Restructuring (Sec. 4.9; subsection 4.9.11)

- Personnel Strength Verification (Sec. 4.10; subsection 4.10.2)

- Residual Levels (Sec. 4.10; subsection 4.10.3)

- Verifying Alroraft Limits (Sec. 4.10; subsection 4.10.12)

- Tracking TLE in Regional Subzones (Sec. 4.5; subsection 4.5.1)

- Data Exchange Formulation, Consolidation, and Transfer (Sec. 4.7; subsection 4.7.1)

- Data Tracking and Update (Sec. 4.7; subsection 4.7.2)

- CFE Data-Base Tracking System (Sec. 4.7)

- Organizational Structure Changes (Sec.4.8; subsection 4.8.1)

- Force Strength Changes (Sec. 4.8; subsection 4.8.2)

- Notice of Reductions (Sec. 4.8; subsection 4.8.3)

- Changes in Maximum Levels (Sec. 4.8; subsection 4.8.4)

- Exceeding Cellings (Sec. 4.8; subsection 4.8.5)

- Reserve Mobilization (Sec. 4.8; subsection 4.8.6)

- TLE Monitored Storage Tracking (Sec. 4.9; subsection 4.9.1)

- Monitored Storage Sites (Sec. 4.9; subsection 4.9.2)

- Unmonitored Storage Sites (Sec. 4.9; subsection 4.9.3)

- Removal of TLE from Monitored Storage (Sec. 4.9; subsection 4.9.4)

- Equipment in Monitored Low-Strength Units (Sec. 4.9; subsection 4.9.5)

- Equipment in Unmonitored Storage (Sec. 4.9; subsection 4.9.6)

- Mobile Bridging Equipment (Sec. 4.9; stbsection 4.9.7)

- Ersercise Size (Sec. 4.9; subsection 4.9.8)

- Military Activity Constraints (Sec. 4.9; subsection 4.9.9)

- Force Restructuring (Sec. 4.9; subsection 4.9.11) 
- Inspection of Declared Sites (Sec. 4.10; subsection 4.10.1)

- Verification of Residual Levels (Sec. 4.10; subsection 4.10.3)

- Suspect Site Inspection (Sec. 4.10; subsection 4.10.4)

- Verification of Forces during Stage 3 (Sec. 4.10; subsection 4.10.5)

- Destruction of TLE (Sec. 4.10; subsection 4.10.8)

- Tracking of TLE Undergoing Elimination (Sec. 4.10; subseotion 4.10.8)

- Replacement Items (Sec. 4.10; subsection 4.10.9)

- Monitoring Reserve Mobilization (Sec. 4.10; subsection 4.10.10)

- Verifying Aircraft Limits (Sec. 4.10; subsection 4.10.12)

\section{PROGRAM 6: NATO Liaison Program}

\section{TASK 6.1 Develop a NATO CFE Program}

- Force Restructuring (Sec. 4.9; subsection 4.9.11)

- Inspection of Declared Sites (Sec. 4.10; subsection 4.10.1)

TASK 6.2 Develop a NATO CFE Implementation Program

- Harmonization and Cascading of TLE (Sec. 4.2; subsection 4.2.3)

- Inspection of Declared Sites (Sec. 4.10; subsection 4.10.1)

- Verification of Residual Levels (Sec. 4.10; subsection 4.10.3)

- Suspect Site Inspection (Sec. 4.10; subsection 4.10.4)

- Verification of Forces during Stage 3 (Sec. 4.10; subsection 4.10.5)

- Destruction of TLE (Sec. 4.10; subsection 4.10.8)

- Tracking of TLE Undergoing Elimination (Sec. 4.10; subsection 4.10.8)

- Monitoring Reserve Mobilization (Sec. 4.10; subsection 4.10.10)

- Verifying Aircraft Limits (Sec. 4.10; subsection 4.10.12) 


\section{RECOMMENDATIONS}

This work identifies possible verification technologies applicable to the CFE treaty. Recommended follow-on actions are described in this section. These actions fall in to the following categories:

1. Analysis of negotiating positions,

2. Identification of technology requirements, and

3. Treaty implementation planning.

The recommenced next step is to continue the systematic analysis of the CFE treaty negotiation process begun in this study.

Substantial progress has already been achieved in round seven of the negotiations. As a result of the dramatic changes within the Warsaw Pact and in Europe in general, it is imperative to track treaty progress on a timely basis.

The threat of a Warsaw Pact with strong forward-based Soviet forces capable of attacking on short notice is diminishing. Although a conventional threat continues, a Soviet attack would now have to start from within the western USSR, move through a comparatively hostile eastern Europe, and use forces preoccupied with an expanding internal security problem. Reduction of Soviet forces has resulted in increased Western warning time and in reduced Soviet numerical superiority. As CFE treaty negotiations orogress, work should also continue in analyzing how the newly agreed-upon provisions will be implemented, what problems are envisioned, and what technological aids might be required to assist in the treaty verification process.

\subsection{ANALYSIS OF NEGOTIATING POSITIONS}

Continuation of the systematic method of comparing proposals from both alliances in specific functional areas would reveal which proposals have been completed and the major differences between the proposals. It is important to determine which proposals remain to be agreed upon and what was agreed upon, as well as to define verification problem areas that could benefit from a technological solution. To systematically analyze the results of the negotiation process, each functional area presented in this study should be analyzed and questions should be asked about how the provision would be verified and verification provisions implemented. Answers to these questions would result in scenarios that could be used to determine the need for additional verification technologies or implementation tasks.

\subsection{IDENTIFICATION OF TECHNOLOGY REQUIREMENTS}

New requirements for sensors, tags, data processing, and other technology could suríace as negotiâtioúns cuntinue and the finai treaty framework takes shape. 
Data-management systems should change as the desires of the parties are negotiated and agreed upon. Without a systematic and continuous analysis of the results of the negotiation process, research and development of needed technologies could be started too late to be properly implemented, and important areas of verification interest could be overlooked. Therefore, a systematic approach to defining technology requirements should be used concurrently with ongoing negotiations.

\subsection{TREATY IMPLEMENTATION PLANNING}

Results of systematic analysis of the CFE treaty negotiation process should also continue to be used to refine tasks assigned for implementation planning and to provide new tasks for development and implementation. It is imperative that the final rounds of the CFE treaty negotiation process be reanalyzed to ensure that all requirements and tasks are included in the implementation planning process. Continued use of a systematic methodology for identifying major program areas, key implementation requirements, and subordinate tasks within functional areas would help to ensure development of a complete and succinct implementation plan. 


\section{REFERENCES}

BASIC, 1989, Basic Reports from Vienna, British American Security Information Council, Washington, L.C., pp. 3-7, 21 Sept.

BASIC, 1989, Basic Reports from Viennr, British American Security Information Council, Washington, D.C., pp. 3-7, 6 Nov.

BASIC, 1990, Basic Reports from Vienna, British American Security Information Council, Washington, D.C., pp. 3-15, 15 Jan.

BASIC, 1990, Basic Reports from Vienna, British American Security Information Council, Washington, D.C., pp. 4-6, 22 Feb.

BASIC, 1990, Basic Reports from Vienna, British American Security Information Council, Washington, D.C., pp. 3-15, 11 April.

Houser, G.M., 1989, Future Treaties: A Proposed Framework for Verifying the Reduction of Conventional Forces in Europe, Argonne National Laboratory Report ANL/ACTV-89/4, Sept.

IDS, 1990, The Arms Control Reporter, Institute for Defense Studies, Brookline, Mass., March.

IDS, 1.990, The Arms Control Reporter, Institute for Defense Studies, Brookline, Mass., Jan. 

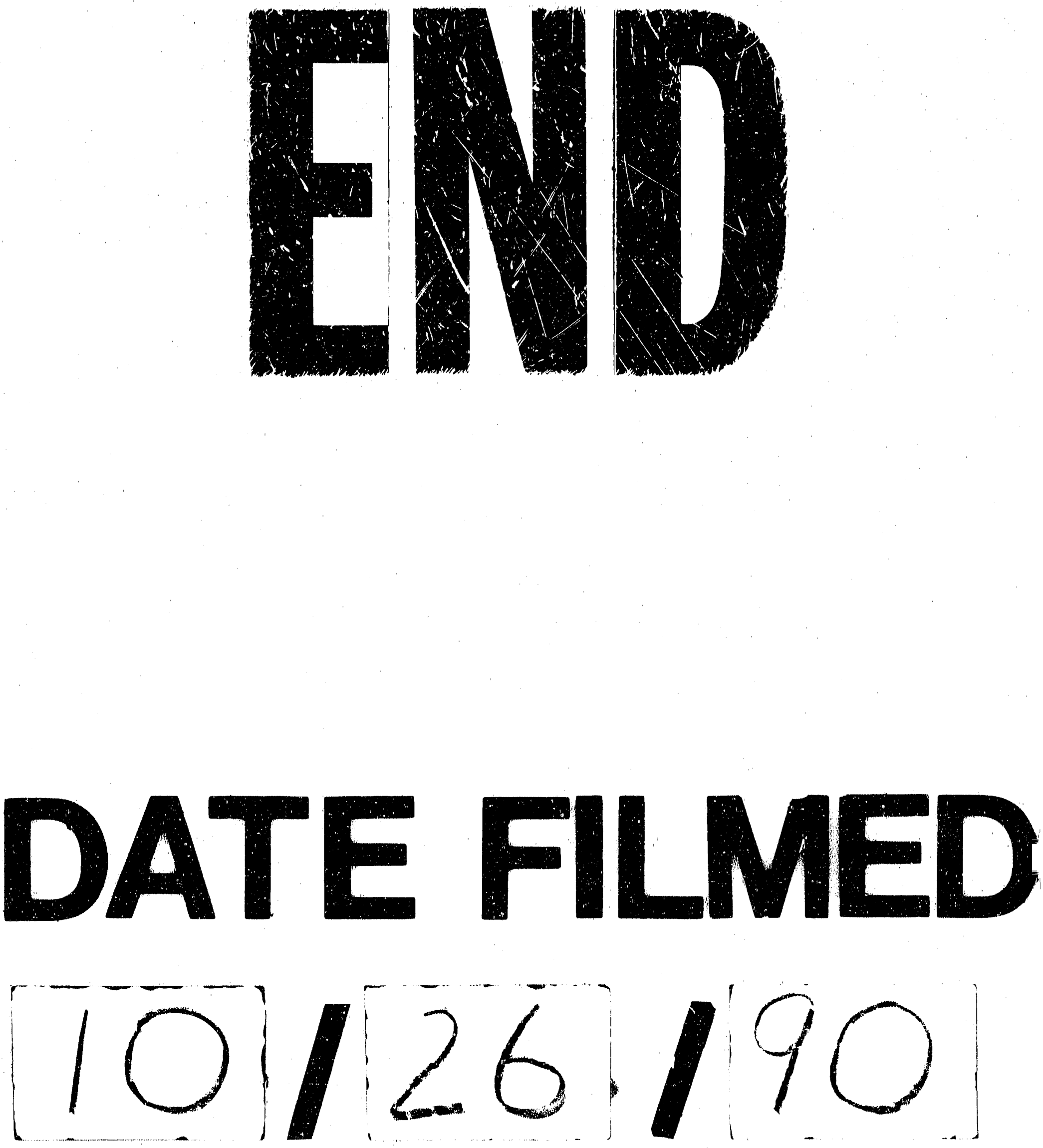
